\title{
Global Ocean Storage of Anthropogenic Carbon (GOSAC)
}

\author{
J. C. Orr
}

April 2, 2002

U.S. Department of Energy

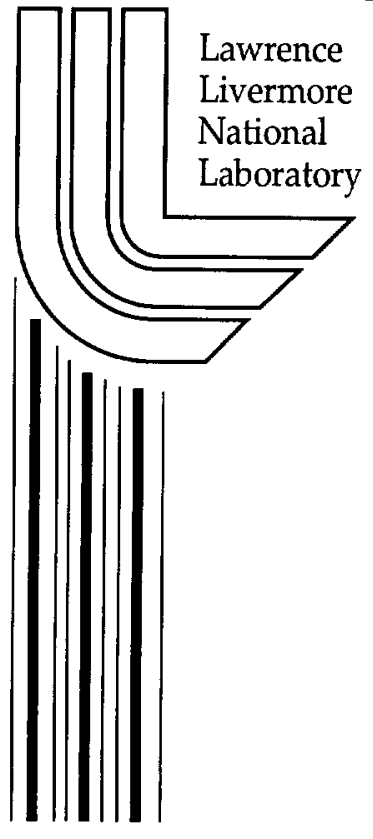

Approved for public release; further dissemination unlimited 


\section{DISCLAIMER}

This document was prepared as an account of work sponsored by an agency of the United States Government. Neither the United States Government nor the University of California nor any of their employees, makes any warranty, express or implied, or assumes any legal liability or responsibility for the accuracy, completeness, or usefulness of any information, apparatus, product, or process disclosed, or represents that its use would not infringe privately owned rights. Reference herein to any specific commercial product, process, or service by trade name, trademark, manufacturer, or otherwise, does not necessarily constitute or imply its endorsement, recommendation, or favoring by the United States Government or the University of California. The views and opinions of authors expressed herein do not necessarily state or reflect those of the United States Government or the University of California, and shall not be used for advertising or product endorsement purposes.

This work was performed under the auspices of the U. S. Department of Energy by the University of California, Lawrence Livermore National Laboratory under Contract No. W-7405-Eng-48.

This report has been reproduced directly from the best available copy.

Available electronically at http://www.doc.gov/bridge

Available for a processing fee to U.S. Department of Energy

And its contractors in paper from

U.S. Department of Energy

Office of Scientific and Technical Information

P.O. Box 62

Oak Ridge, TN 37831-0062

Telephone: (865) 576-8401

Facsimile: (865) 576-5728

E-mail: reports@adonis.osti.gov

Available for the sale to the public from

U.S. Department of Commerce

National Technical Information Service

5285 Port Royal Road

Springfield, VA 22161

Telephone: (800) 553-6847

Facsimile: (703) 605-6900

E-mail: orders@ntis.fedworld.gov

Online ordering: http://www.ntis.gov /ordering.htm

OR

Lawrence Livermore National Laboratory

Technical Information Department's Digital Library

http://www.llnl.gov/tid/Library.html 
Global Ocean Storage of Anthropogenic Carbon (GOSAC)

\author{
EC Environment and Climate Programme \\ (Contract ENV4-CT97-0495)
}

Final Report

(December 1, 1997 to March 31, 2001)

\author{
Project Coordinator: \\ James C. Orr \\ (IPSL/CNRS) \\ France
}

April 2, 2002 


\section{Contact Information:}

James Orr

LSCE/CEA Saclay

Bat. 709, L'Orme

F-91191 Gif-sur-Yvette, Cedex

France

Telephone: (33) 169087723

Fax: (33) 169087716

e-mail: orr@cea.fr 


\section{Executive Summary}

GOSAC was an EC-funded project (1998-2001) focused on improving the predictive capacity and accelerating development of global-scale, three-dimensional, ocean carbon-cycle models by means of standardized model evaluation and model intercomparison. Through the EC Environment and Climate Programme, GOSAC supported the participation of seven European modeling groups in the second phase of the larger international effort OCMIP (the Ocean Carbon-Cycle Model Intercomparison Project). OCMIP included model comparison and validation for both $\mathrm{CO}_{2}$ and other ocean circulation and biogeochemical tracers. Beyond the international OCMIP effort, GOSAC also supported the same EC ocean carbon cycle modeling groups to make simulations to evaluate the efficiency of purposeful sequestration of $\mathrm{CO}_{2}$ in the ocean. Such sequestration, below the thermocline has been proposed as a strategy to help mitigate the increase of $\mathrm{CO}_{2}$ in the atmosphere. Some technical and scientific highlights of GOSAC are given below:

1. CFC-11 and CFC-12: All 13 OCMIP-2 model groups submitted CFC output, in standard format, to validate the models by comparing simulated distributions to the database of of these inert ocean circulation tracers that have been measured with great precision throughout the world ocean. Standard output from these simulations was quality controlled, archived, and made available electronically. The OCMIP-2 simulated range of global CFC-11 uptake varied by $\pm 30 \%$ around the mean, pointing out the need for an estimate of the observed global inventory. Differences in the modeled global inventory were found to be largely due to differences in uptake in the Southern Ocean. Much uptake occurs in the Southern Ocean due to ventilation of intermediate waters. Ventilation via a major component of Southern intermediate waters, Sub-Antarctic Mode Water (SAMW), was realistic only in models with lateral diffusion oriented along surfaces of constant density (isopycnals). Furthermore, ventilation of the deep Southern Ocean by Antarctic Bottom Water (AABW) was inadequate except in circulation models that were coupled to a sea-ice component model. In the north, models systematically under-predicted CFC-11 inventories in the subtropics; and due to their coarse-resolution, models fared poorly in resolving the CFC-11 distribution in the Deep Western Boundary Current in the the Western Atlantic. Modeldata comparison along sections reveals that some models generally underpredict the CFC-11 observations whereas others generally over-predict. The OCMIP-2 models probably also bracket the real ocean's global inventory. The CFC analysis and publication were led by a GOSAC project scientist [Dutay et al., 2002] .

2. Radiocarbon: All 13 OCMIP-2 groups made standard simulations for natural and anthropogenic ${ }^{14} \mathrm{C}$. Responsibilities for analyzing ${ }^{14} \mathrm{C}$ were split according to the nature of each component: GOSAC adopted the responsibility of analyzing simulated vs. observed natural ${ }^{14} \mathrm{C}$ (an excellent tracer of deep- 
ocean circulation); efforts within U.S. OCMIP focused on the anthropogenic "bomb" component (a tracer of near surface circulation). Here we focus only on results from analysis of the natural component. The range of results from the OCMIP-2 models for deep ${ }^{14} \mathrm{C}(<1000 \mathrm{~m})$ were found to bracket the observed global mean for deep ${ }^{14} \mathrm{C}(-150 \%)$; we use this constraint for setting limits on modern ocean uptake of anthropogenic $\mathrm{CO}_{2}$ (see below). Distribution patterns of natural ${ }^{14} \mathrm{Cwere}$ compared, after first removing the mean natural ${ }^{14} \mathrm{C}$ bias from each model. All models simulated the major meridional features of the ${ }^{14} \mathrm{C}$ distribution pattern in the deep Pacific Ocean; conversely, few models properly simulated the more complicated, meridional ${ }^{14} \mathrm{C}$ distribution in the deep Atlantic. In the Pacific Ocean, the new WOCE ${ }^{14} \mathrm{C}$ data set also allowed us to evaluate the zonal structure of natural ${ }^{14} \mathrm{C}$. The near bottom zonal structure in the South Pacific appears largely controlled by east-west differences in bottom bathymetry: young dense waters from the south fill bathymetric lows in the west; older waters are returned, eventually, in the east (shallower bathymetry). OCMIP exploited a new observational constraint for ${ }^{14} \mathrm{C}$ along the $\sigma_{2}=36.925$ density surface. On that surface is found the entire range of ${ }^{14} \mathrm{C}$ in the deep ocean: in the real ocean, one end-member lies at the core of the youngest deep water (North Atlantic Deep Water-NADW) and another end member lies at the heart of the oldest deep water (North Pacific Deep Water-NPDW). A fair number of models have difficulty simulating the proper depth of this surface, which itself is a useful diagnostic of model performance. It would be useful for model evaluation if these new observed diagnostics for observed ${ }^{14} \mathrm{C}$ (i.e., the bottom map and $\sigma_{2}=36.925$ surface map) could be extended beyond the Pacific into the Atlantic.

3. Natural $\mathrm{CO}_{2}$ : all OCMIP-2 groups made the Abiotic simulation for the natural component of $\mathrm{CO}_{2}$, and all but one of the groups made the optional Biotic simulation (proposed by U.S. OCMIP after the start of GOSAC). For the latter, all models used a common biogeochemical model that carried five tracers: alkalinity (Alk), oxygen $\left(\mathrm{O}_{2}\right)$, dissolved inorganic carbon (DIC), dissolved organic carbon (DOC), and the nutrient phosphate $\left(\mathrm{PO}_{4}^{3-}\right)$. New production in each model was determined by restoring simulated surface $\mathrm{PO}_{4}^{3-}$ to the observed surface distribution. GOSAC adopted the task of analyzing the $\mathrm{CO}_{2}$ fluxes from these runs, whereas U.S. OCMIP took on related analysis for $\mathrm{PO}_{4}^{3-}$, new production, and $\mathrm{O}_{2}$. The OCMIP-2 models show consistent patterns for thermal driven $\mathrm{CO}_{2}$ fluxes, with uptake due to cooling in the high latitudes and out-gassing due to warming in the tropics. Air-sea fluxes due to the biological component are in sharp contrast, with out-gassing in the Southern Ocean and uptake in the low latitudes. The Southern Ocean is the site for the largest uptake for the thermal-driven component and the largest out-gassing for the the biological component. When combined, the magnitude of the air-sea flux in the Southern Ocean is much 
smaller. Models disagree about whether that region was a net sink or a net source during preindustrial time. The OCMIP-2 preindustrial air-sea fluxes were also used to evaluate global meridional transport in the preindustrial ocean. This "initial condition" of the ocean must be quantified to properly predict the magnitude of the terrestrial carbon sink in the northern hemisphere. The global southward transport in the OCMIP-2 models ranged from 0.1 to $0.7 \mathrm{PgC} \mathrm{yr}^{-1}$, the high end of which is much larger than the prediction

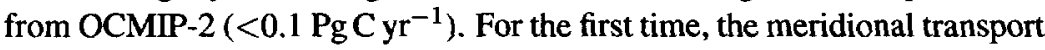
simulated by ocean carbon cycle models is as large as that estimated from measurements in the Atlantic Ocean (0.3 to $0.5 \mathrm{PgC} \mathrm{yr}^{-1}$ ). Additionally, preindustrial fluxes from OCMIP-2 were used as boundary conditions to two atmospheric tracer transport models (TM2 and TM3) in order to estimate the the marine preindustrial component of $\mathrm{CO}_{2}$ in the lower troposphere. The models explain up to about half to the $0.8 \mathrm{ppm}$ north-south preindustrial difference, based on time extrapolation of measurements at Mauna Loa (Hawaii) and South Pole stations to zero emissions. The models show a high correlation between meridional transport and the preindustrial MLO-SPO difference in marine atmospheric $\mathrm{CO}_{2}$.

4. Anthropogenic $\mathrm{CO}_{2}$ : all groups made simulations for the anthropogenic $\mathrm{CO}_{2}$, forced by observed $\mathrm{CO}_{2}$ during the historical period. The anthropogenic component is the change from the preindustrial state to present. For the 1980's the 13 OCMIP-2 models and 3 additional sensitivity runs simulated a range of $1.99 \pm 0.43 \mathrm{Pg} \mathrm{Cyr}^{-1}$ (half the range over the mean). For the 1990's the OCMIP-2 models predict a $24 \%$ uptake increase ( $2.38 \pm 0.53$ $\mathrm{PgC}_{\mathrm{yr}}{ }^{-1}$ ), in contrast with the 1980 s-to-1990s decrease predicted by the most recent IPCC TAR report [Houghton et al., 2001, Chapter 3]. The IPCC results were based on a budget determined largely from atmospheric $\mathrm{O}_{2}$ measurements. However, it has been shown by two separate studies that errors in that budget compromise IPCC evaluation of the 1980's to 1990's increase [Plattner et al., 2001b; Bopp et al., 2001]. The GOSAC/OCMIP-2 range for the modern uptake of anthropogenic $\mathrm{CO}_{2}$ probably brackets real ocean uptake because

(a) the OCMIP-2 model range for the CFC-11 inventory brackets the real ocean inventory (see above),

(b) the OCMIP-2 models bracket the observed deep-ocean $\Delta^{14} \mathrm{C}$ (see above),

(c) the modern global uptake of anthropogenic $\mathrm{CO}_{2}$ is correlated with both of these global criteria.

5. Total $\mathrm{CO}_{2}$ : During OCMIP-2, we also compared simulated results to databased estimates of the air-sea $\mathrm{CO}_{2}$ flux, obtained by multiplying the "observed" estimates of the difference between surface ocean and atmospheric $\mathrm{pCO}_{2}$ (i.e., $\Delta \mathrm{pCO}_{2}$ ), [Takahashi et al., 1999; Takahashi et al., 2002] ) times 
the OCMIP-2 fields of gas exchange). To compare the full space-time distribution, we used the recently developed Taylor diagram to assess model performance in regards to the zonal annual mean, zonal anomalies, and seasonal anomalies. The models all performed well in regard to their ability to simulate the zonal annual mean. However, none of the models showed any skill in simulating the zonal or seasonal anomalies. The seasonality problem may be linked to the common Biotic model used in OCMIP-2 which has no explicit plankton dynamics. Sensitivity tests with one model will be necessary to further investigate the causes of this problem.

6. Future $\mathrm{CO}_{2}$ : Most modeling groups made simulations for two future scenarios from the IPCC (IS92a and S650) Models agree for the modern era within $\pm 22 \%$, but diverge in the future in both scenarios. In year 2100 , agreement about the mean was $\pm 30 \%$ for the less severe $\$ 650$ scenario (where atmospheric $\mathrm{CO}_{2}$ was stabilized at $650 \mathrm{ppm}$ ) and $\pm 33 \%$ for scenario CIS92a (where atmospheric $\mathrm{CO}_{2}$ reached $800 \mathrm{ppm}$ in 2100). For the S650 run, which was continued until year 2300 , model agreement remained near $\pm 30 \%$, reaching at most $\pm 33 \%$ in year 2200 . Neglecting the high and low models, which appears justified based on $\mathrm{CFC}-11$ and natural ${ }^{14} \mathrm{C}$ tracer constraints, the agreement between models improves considerably. It remains at $\pm 18 \%$ through year 2100 , under both future scenarios. In the longer $\mathbf{S 6 5 0}$ run, agreement after year 2100 worsens, but only slightly to $\pm 22 \%$.

7. Purposeful $\mathrm{CO}_{2}$ Sequestration: To mitigate rising levels of atmospheric $\mathrm{CO}_{2}$, it has been proposed to purposefully sequester $\mathrm{CO}_{2}$ generated by power plants in the deep ocean. Five of the GOSAC groups made simulations, as specified in the Injection HOWTO, to evaluate the efficiency of the ocean in retaining this sequestered $\mathrm{CO}_{2}$; motivated by the GOSAC effort, three nonEuropean OCMIP modeling groups also contributed. Injection was carried out at seven separate sites, at three different depths. At $3000 \mathrm{~m}$ all models reveal at least a $85 \%$ global efficiency in year 2200 , i.e., 100 years after the end of the 100-year injection period); at the same time, 1500-m injection is $60-80 \%$ efficient and $800-\mathrm{m}$ injection is only $42-61 \%$ efficient. A sensitivity test in the SOC model reveals that continuing injection after year 2100 increases global efficiency from $66 \%$ to $77 \%$ in 2200 and from $38 \%$ to $58 \%$ in 2500 . Most of the models simulate that for the $1500-\mathrm{m}$ injection, the Pacific sites are more efficient than those in the Atlantic, and that injection in the Indian Ocean yields intermediate efficiencies. Such would be expected based upon our understanding of the age of deep waters in each of these three basins. The models generally predicted that Injection at New York was amongst the least efficient sites and that injection offshore of San Francisco was most efficient. Most of the $\mathrm{CO}_{2}$ injected at $3000 \mathrm{~m}$ was lost from the Southern Ocean (the principal region by which the deep ocean is ventilated); at shallower depths, relatively more was lost sooner, from the 
northern hemisphere and the tropics. It appears that the modeled efficiencies for the $3000-\mathrm{m}$ injection brackets what would be real ocean behavior (under an identical injection scenario), based on correlations of the global injection efficiency at that depth with the global mean CFC-11 inventory as well as with the global mean, deep-ocean natural $\Delta^{14} \mathrm{C}$; such would also be expected based on the large diversity of models that participated in this exercise. For shallower injections, the correlation is less clear $(1500-\mathrm{m})$ or nonexistent $(800-\mathrm{m})$.

8. HOWTO's: GOSAC-OCMIP protocols for the CFC, Abiotic, Biotic, Injection, and Helium simulations were developed and made available as detailed HOWTO documents through the OCMIP Web page; these documents also provide the boundary conditions and code to make these simulations and store output in standard OCMIP format. They will remain available, as an important legacy of this project.

9. Model Output Database (MOD): all standard output from GOSAC-OCMIP model simulations were archived and organized hierarchically; the current database contains about 50 Gbytes of GOSAC-OCMIP model output. Some of it is already publicly available, and the rest will be made available soon. The OCMIP-2 model output database now provides as a solid benchmark for community, a legacy of OCMIP.

10. GAP: two stable versions of the analysis software developed for this project were made available to GOSAC and OCMIP participants; GAP now provides an excellent tool for model-model and model-data comparison. It easily visualizes maps on the original model or grids, which may be irregular or unstructured. Thus GAP is unlike any other existing model comparison software. Furthermore, GAP also facilitates model-data comparison along sections, multi-variable analysis, and zonal mean analysis, all of which were crucial for the GOSAC/OCMIP-2 comparison.

11. OCMIP Web page: the OCMIP web page at regards to developments during GOSAC. It too will remain available as OCMIP moves into its third phase, with European modeling groups supported by the new EC project NOCES (Northern Ocean Carbon Exchange Study) that will focus on interannual to decadal variability of the air-sea $\mathrm{CO}_{2}$ flux. 


\section{Contents}

Project Synthesis 1

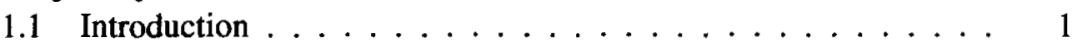

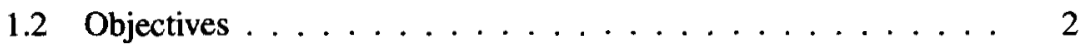

1.3 Models ....................... . . 4

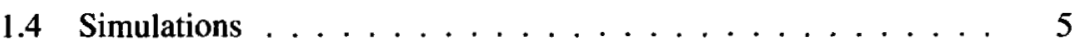

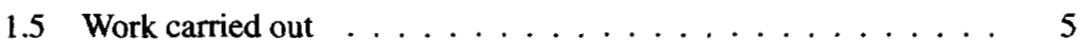

1.6 Results . . . . . . . . . . . . . . . . . . . . . 7

CFC-11 and $\mathrm{CFC}-12 \ldots \ldots \ldots 7$

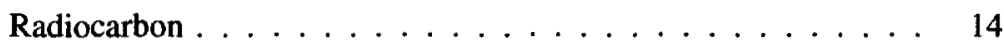

Natural $\mathrm{CO}_{2} \ldots \ldots \ldots \ldots . \ldots \ldots 25$

Total $\mathrm{CO}_{2} \ldots \ldots \ldots \ldots . \ldots \ldots$

Anthropogenic $\mathrm{CO}_{2} \ldots \ldots \ldots 36$

Injected $\mathrm{CO}_{2} \ldots \ldots \ldots \ldots 43$

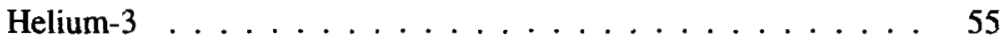

References ........................ 59

Individual Reports $\quad 62$

2.1 Partner 1: IPSL (LSCE and LODyC) . . . . . . . . . . . . . 63

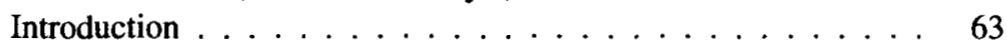

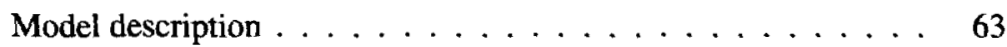

Work completed . . . . . . . . . . . . . . 64

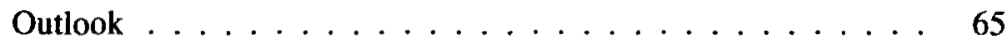

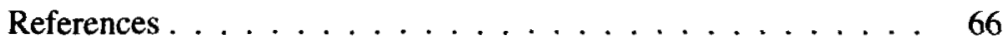

2.2 Partner $2:$ SOC . . . . . . . . . . . . . . 72

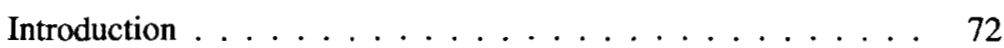

Model Description .................. 72

Work completed . . . . . . . . . . . . . . . . 74

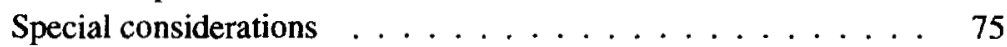

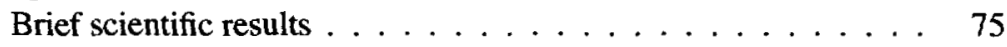

References .................... 82

2.3 Partner 3: AWI . . . . . . . . . . . . . . . 83

Model Description . . . . . . . . . . . . . . . 83

Work completed . . . . . . . . . . . . . . . 84 
AWI Model Simulations: Special Considerations . . . . . . . . 85

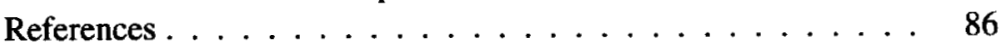

2.4 Partner 4: UL (LPAP and2 ASTR) . . . . . . . . . . . . . . . . . 88

Introduction . . . . . . . . . . . . . . . 88

Model Description ................. 88

Assessment of OCMIP-2 results for UL group . . . . . . . . . . 91

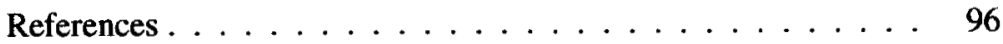

2.5 Partner 5: MPIM Hamburg, Germany . . . . . . . . . . . . 100

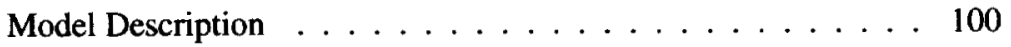

Work completed . . . . . . . . . . . . . . . 101

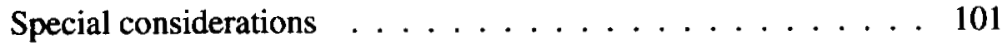

References ...................... 101

2.6 Partner 6: NERSC . . . . . . . . . . . . . . . 103

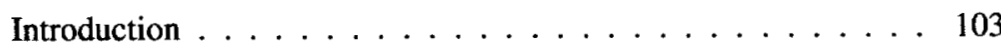

Model description . . . . . . . . . . . . . . . . . . . 103

Work completed . . . . . . . . . . . . . . . . 104

Special considerations . . . . . . . . . . . . . . . . 105

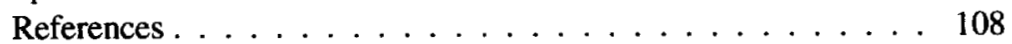

2.7 Partner 7 : PIUB . . . . . . . . . . . . . . . . . . 110

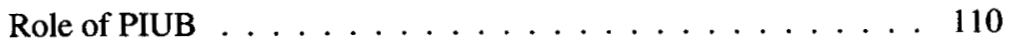

Model Description . . . . . . . . . . . . . . 110

Work Performed . . . . . . . . . . . . . . . . . 111

Selected Results . . . . . . . . . . . . . . . 111

References .................... 116 


\section{List of Figures}

1.1 Temporal evolution of CFC-11 in the atmosphere and ocean . . 10

1.2 CFC-11 along the AJAX section .............. 11

1.3 CFC-11 and PCFC-11 inventories along WOCE P13 . . . . . 12

1.4 CFC-11 section along WOCE A24N . . . . . . . . . . 13

1.5 Taylor Diagram for Deep Natural ${ }^{14} \mathrm{C} \ldots \ldots . . \ldots 14$

1.6 Natural ${ }^{14} \mathrm{C}$ section in the West Atlantic . . . . . . . . . . 17

1.7 Bottom ${ }^{14} \mathrm{C}$ in the Pacific ................ . . 18

$1.8{ }^{14} \mathrm{C}$ on the $\sigma_{2}=36.925$ surface ............. 19

1.9 Depth of the $\sigma_{2}=36.925$ surface ............. 20

$1.10{ }^{14} \mathrm{C}$ along WOCE P6 (South Pacific ... . . . . . . . . . 24

1.11 Air-sea $\mathrm{CO}_{2}$ flux components (as zonal integrals) . . . . . . . 28

1.12 Preindustiral northward transport of $\mathrm{CO}_{2} \ldots \ldots . . . . . . .29$

1.13 Preindustrial marine component of atmospheric $\mathrm{CO}_{2} \ldots \ldots$

1.14 Preindustrial cross-equatorial transport vs. atmospheric $\mathrm{CO}_{2} \ldots . \quad 31$

1.15 Maps of the total air-sea $\mathrm{CO}_{2}$ flux ... . . . . . . . . . 34

1.16 Taylor diagram of the total air-sea $\mathrm{CO}_{2}$ flux $\ldots \ldots . \ldots 35$

1.17 Global anthropogenic $\mathrm{CO}_{2}$ uptake vs. other tracers . . . . . . 38

1.18 Uptake, storage, and transport of anthropogenic $\mathrm{CO}_{2} \ldots \ldots$

1.19 Changes in anthropogenic $\mathrm{CO}_{2}$ in the atmosphere and ocean . . . 41

1.20 Global Injection efficiency . . . . . . . . . . . . . . . . . . . 44

1.21 Injection efficiency by site $(800-\mathrm{m}$ injection $) \ldots \ldots 45$

1.22 Injection efficiency by site $(1500-\mathrm{m}$ injection $) \ldots . \ldots 46$

1.23 Injection efficiency by site $(3000-\mathrm{m}$ injection) $\ldots . . . . . . .47$

1.24 Zonal integral sea-to-air loss of injected $\mathrm{CO}_{2} \ldots \ldots$. . . . . . . 48

1.25 Zonal integral ocean storage of injected $\mathrm{CO}_{2}(2100)$. . . . . . . . 49

1.26 Zonal integral ocean storage of injected $\mathrm{CO}_{2}(2200) \ldots . . . . .50$

1.27 Zonal integral ocean storage of injected $\mathrm{CO}_{2}(2500) \ldots \ldots 51$

1.28 Injection efficiency vs. other tracers . . . . . . . . . . . 53

$1.29 \delta^{3} \mathrm{He}$ section in the Western Atlantic . . . . . . . . . . . 55

$1.30 \delta^{3} \mathrm{He}$ section in the South Pacific (WOCE P6) . . . . . . . . . 57

2.1 SOC natural, abiotic air-sea $\mathrm{CO}_{2}$ flux ........... 76

2.2 SOC changes in abiotic air-sea $\mathrm{CO}_{2}$ flux ........... 76

2.3 SOC surface $\mathrm{pCO}_{2}$ from Pulse run . . . . . . . . . . . . . . 77

2.4 SOC Anthropogenic $\mathrm{CO}_{2}$ maps . . . . . . . . . . . 78 
2.5 SOC Anthropogenic $\mathrm{CO}_{2}$ sections . . . . . . . . . 79

2.6 SOC downward POP flux (Biotic run) . . . . . . . . . . 80

2.7 SOC zonal mean $\mathrm{O}_{2}$ (Biotic run) ............. 80

2.8 SOC Gain from $\mathrm{CO}_{2}$ injection . . . . . . . . . . . . 81

2.9 UL zonal basin averages of $\Delta^{14} \mathrm{C}$ in LOCH . . . . . . . . . . 92

2.10 UL zonal basin averages of $\Delta^{14} \mathrm{C}$ in LOCH-CLIO . . . . . . . 93

$2.11 \mathrm{UL}$ differences in $\mathrm{O}_{2}$ with difference advection schemes . . . . 95

2.12 NERSC CFC-11 fluxes vs. inventories . . . . . . . . . . 106

2.13 NERSC cumulative CFC-11 fluxes and inventories . . . . . . 107

2.14 PIUB future carbon uptake . . . . . . . . . . . . . 113

2.15 PIUB reduction in the air-sea $\mathrm{CO}_{2}$ flux due to global warming . . 113

2.16 Atmospheric $\mathrm{O}_{2}$ and $\mathrm{CO}_{2}$ budget (IPCC) . . . . . . . . . 114

2.17 Changes of Atmospheric $\mathrm{CO}_{2}$ (Pulse run) . . . . . . . 115 


\section{List of Tables}

1.1 Output submitted by the OCMIP-2 modeling groups. . . . . . . . . . 6

1.2 Mean ocean uptake of anthropogenic $\mathrm{CO}_{2} \ldots \ldots . \ldots 36$

2.1 UL model annual global averages for selected tracers . . . . . . . 91

2.2 NERSC tests for tracer conservation ............. 105 


\section{Project Synthesis}

\subsection{Introduction}

Ocean carbon-cycle models are tools which help synthesize our understanding of the fundamental processes which control the ocean's redistribution of carbon, the resulting impact on air-sea $\mathrm{CO}_{2}$ fluxes, and on the global carbon cycle. Such models describe the transport and the redistribution of carbon in the ocean by combining fundamental notions of ocean circulation and biogeochemistry. The more complex variety of these models describe the ocean in three dimensions at the global scale, and they allow extrapolation both in space and time. Yet despite their complexity, such models may yield predictions which are substantially biased.

Essential improvements to such models have come only slowly. Partly to blame are the intense computer time and memory requirements of these models. Also much time and effort are needed to diagnose model misbehavior, reformulate the perceived difficulty, and then make new simulations. Improvements have also been slowed because of unnecessary redundancy between modeling groups, further complicated by inconsistent practices for modeling and analysis. Thus it has been difficult to explore global and regional differences between models and to determine if model predictions are robust. With these difficulties in mind, ocean carbon-cycle modeling groups have taken steps to work more closely together, pooling resources and developing standards as a means (1) to identify the principal differences between models, (2) to accelerate their development, and (3) to improve their predictive capacity. A cornerstone of this effort has been the GOSAC project. 


\subsection{Objectives}

GOSAC was a research project funded from 1 December 1997 to 31 March 2001 by the EC Environment and Climate Programme. GOSAC's focus was to improve understanding of the ocean's role in the global carbon cycle through model comparison. Previous efforts focused on other components of the climate system have shown that models improve more rapidly when resources are pooled, when understanding is shared among modeling groups, and when models are systematically evaluated against observations. GOSAC undertook this task for the European ocean carbon-cycle model community. Specifically, GOSAC had three primary goals:

- to better quantify past, present, and future $\mathrm{CO}_{2}$ uptake by the ocean, which is limited by relatively slow natural processes;

- to assess global aspects of the proposal which offers to artificially accelerate ocean storage of $\mathrm{CO}_{2}$ by diverting $\mathrm{CO}_{2}$ emissions from fossil-fuel fired power plants directly into the deep ocean, thereby short-circuiting the slow natural process; and

- to guarantee that predictions stemming from the first two objectives are reasonable by paying close attention to model evaluation.

GOSAC goals (1) and (3) pertain directly to a larger international programme: the Ocean Carbon-Cycle Model Intercomparison Project (OCMIP). Through GOSAC, the Environment and Climate Programme funded seven European modeling groups to participate in OCMIP. At the international program level, OCMIP unites efforts between two core projects from IGBP (International Geosphere-Biosphere Programme): GAIM (Global Analysis Interpretation and Modeling Task Team) and JGOFS (Joint Global Ocean Flux Study). A previous phase of this project (OCMIP-1) was carried out during 1995 to 1997 and focused on $\mathrm{CO}_{2}$ and ${ }^{14} \mathrm{C}$. OCMIP-1 identified large, regional model differences, particularly in the Southern Ocean. Such differences motivated plans for the second phase of OCMIP (19982000), which involved more simulations and 13 models, seven of chich were European. The focus of OCMIP is on $\mathrm{CO}_{2}$. However, during the second phase we also used new circulation tracers (e.g., CFC's) to better diagnose model differences. Furthermore, the OCMIP-2 groups implemented a common biogeochemical model, which allowed diagnosis based on biogeochemical fields such as $\mathrm{O} 2$ and new production. An original and critical component of the OCMIP-2 effort were the data experts who led synthesis of new data sets, from JGOFS and the WOCE (World Ocean Circulation Experiment). These new data were used for the first time in OCMIP-2 expressly for global model validation. Here we report on GOSAC/OCMIP- 2 results.

The second goal of GOSAC was of a more applied nature, going beyond the original objectives of the international OCMIP effort. Nonetheless, the GOSAC 
effort here prompted three non-European modeling groups to also make these simulations contribute output. The purposeful $\mathrm{CO}_{2}$ sequestration simulations made by the European modeling groups were funded by the Environment and Climate Programme. Analysis of that model output (for objective 2) was funded by the International Energy Agency Greenhouse Gas Research and Development Programme (IEA GHG). 


\subsection{Models}

The GOSAC modeling groups include

1. IPSL, (Institute Pierre Simon Laplace), Paris, France;

2. SOC (Southampton Oceanography Centre) / SUDO / Hadley Center (UK Met. Office), England;

3. AWI (Alfred Wegener Institute for Polar and Marine Research), Bremerhaven, Germany;

4. UL (University of Liege) /UCL (University Catholique de Louvain), Belgium;

5. MPI, (Max Planck Institut fr Meteorologie - Hamburg) Germany;

6. NERSC, (Nansen Environmental and Remote Sensing Center), Bergen, Norway; and

7. PIUB (Physics Institute, University of Bern) Switzerland.

In addition to the 7 GOSAC partners, 6 non-European modeling groups also participated in OCMIP-2. These non-European groups include

1. LLNL (Lawrence Livermore National Laboratory), Livermore, California, USA;

2. PRINCEton (Princeton University [AOS, OTL]/GFDL), Princeton NJ, USA;

3. NCAR (National Center for Atmospheric Research), Boulder, Colorado, USA;

4. MIT, Boston, MA, USA;

5. IGCR/CCSR (Institute for Global Change Research, Frontier Research), Tokyo, Japan; and

6. CSIRO, Hobart, Australia.

As will become clear from the model descriptions later in this report that the GOSAC/OCMIP-2 models are a diverse group. This diversity results in large differences in model predictions, which in turn provides a measure of uncertainty that is not possible to obtain with only one model. Validation of all these models with ocean circulation tracers measured extensively throughout the world ocean further suggests that to a large extent the range of predictions from the GOSAC/OCMIP-2 group of models brackets real ocean behavior. 


\subsection{Simulations}

Numerous simulations were carried out during GOSAC. These included simulations for passive tracers of ocean circulation $\left(\mathrm{CFC}-11,{ }^{14} \mathrm{C}\right.$, and ${ }^{3} \mathrm{He}$ ), natural and anthropogenic $\mathrm{CO}_{2}$, and purposeful $\mathrm{CO}_{2}$ sequestration. To insure rigorous comparison, GOSAC/OCMIP-2 provided detailed protocols, including boundary conditions, model code, and output routines. We call these protocols the GOSACOCMIP "HOWTO" documents. As an important legacy of this project, they remain available on the OCMIP Web page (http://www.ipsl.jussieu.fr/OCMIP/).

\subsection{Work carried out}

Achievements in GOSAC were in part technical. We constructed and maintained the OCMIP Web page, and through it made available final versions of the detailed protocol documents: the CFC HOWTO, the Abiotic HOWTO, the Biotic HOWTO, the Injection HOWTO, and the Helium HOWTO. Additionally, we provided our analysis software (GAP), results from ongoing analysis, and an archive of mail messages to our electronic discussion forum (ocmip-all mailing list).

Model output from each of the OCMIP groups was provided in a standard predefined format based on netCDF and GDT. That standard output from all simulations from all groups was consolidated into one standard hierarchical OCMIP-2 model output archive at IPSL. That archive, at IPSL, now occupies about $50 \mathrm{~Gb}$. This archive has been made available to other OCMIP participants. Part of this archive is currently accessible via the WWW (DODS protocol). Soon the entire archive will be released, i.e., after final quality control has been assured.

Two stable versions of the GOSAC Analysis Package (GAP) were made available to GOSAC-OCMIP members. The GAP set of tools was expressly developed by the coordinating group IPSL for use during analysis of GOSAC model output. GAP can compare data, along any ship track or section, to output from all OCMIP models. GAP can likewise compare maps (e.g., observed vs. modeled air-sea fluxes). Other analysis modules were created to make comparisons in multi-variable space (e.g., comparing ${ }^{14} \mathrm{C}, \mathrm{CO}_{2}$, and $\mathrm{CFC}-11$, simultaneously). We used the visualization component of GAP (based on Tecplot) in conjunction with the data analysis capabilities of the oceanographic software Ferret.

All 3-D modeling groups from GOSAC and OCMIP contributed output for simulations for CFC-11 and CFC-12. That output has gone through quality control, to verify consistency, by the central analysis group at IPSL (Table 1.1). Some groups were required to resubmit CFC output, with corrections. The OCMIP-2 CFC model output is now considered in final form. Carbon simulations have been submitted by most of the GOSAC groups. Five GOSAC groups have submitted the Abiotic Equilibrium, Historical and Future simulations for $\mathrm{CO}_{2}$ and ${ }^{14} \mathrm{C}$. The other two groups should contribute their output for those runs soon (see reports from Individual groups). Other simulations (Abiotic Pulse, Biotic, Injection) are required 


\begin{tabular}{|c|c|c|c|c|c|c|c|c|c|c|c|c|c|c|}
\hline \multirow[t]{3}{*}{ Vit: 131} & \multirow[t]{3}{*}{$\mathrm{CFC}$} & \multicolumn{8}{|c|}{ ABIOTIC } & \multicolumn{4}{|c|}{ INJECTION } & \multirow[t]{3}{*}{ BIOTIC } \\
\hline & & \multirow[t]{2}{*}{ Equil } & \multirow[t]{2}{*}{ His } & \multirow[t]{2}{*}{ Pulse } & \multicolumn{2}{|c|}{ Furure } & \multicolumn{3}{|c|}{ Control } & \multirow[b]{2}{*}{ C1500 } & \multirow[b]{2}{*}{ C3000 } & \multirow[b]{2}{*}{$c 800$} & \multirow[b]{2}{*}{$E 1500$} & \\
\hline & & & & & CIS92A & \begin{tabular}{|l|}
$\mathbf{5 6 5 0}$ \\
\end{tabular} & dtrlH & etriff & ctrlP & & & & & \\
\hline 14: & OK & OK & OK & ox & OK & $\mathrm{OK}$ & OK & OK & NO & OK & OK & OK & OK & OK \\
\hline (STRA) & OK & OK & OK & NO & OK & OK & No & NO & NO & OK & OK. & OK & No & OK \\
\hline ais $\mathrm{K}$ & OK & OK & OK & oK & OK & OK & oK & OK & OK & No & wo & No & No & OK \\
\hline $\mathrm{PM}$ & $\mathrm{OK}$ & OK & OK & no & OK & $O K$ & oK & OK & No & No & no & NO & Nor & OK \\
\hline 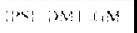 & OK & $\mathrm{OK}$ & OK & No & OK & OK & OK & OK & NO & OK & OK & OK & OK & OK \\
\hline 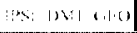 & OK & $\mathrm{OK}$ & OK & vo & OK & OK & $\mathrm{OK}$ & OK & $\mathrm{NO}$ & OK & $\mathrm{OK}$ & OK & OK & OK \\
\hline$\because n N$ & OK & OK & OK & No & OK & NO & lox & OK & No) & oK & OK & $\mathrm{OK}$ & ox & OK \\
\hline$v$ & OK & OK & OK & $\mathrm{NO}$ & No & NO & $\mathrm{NO}$ & No & NO & No & No & No & No) & OK \\
\hline$\because 18$ & OK & OK & OK & oK & ox & ok & ok & OK & $\mathrm{NO}$ & OK & OK & OK & OK & OK \\
\hline $46 . x$ & OK & OK & OK & No & OK & NO & No & No & No) & vol & vo & NO & NO & OK \\
\hline पह KX & $\mathrm{OK}$ & OK & OK & NO & $\mathrm{NO}$ & No & OK & 10 & NO & vo & $\mathrm{No}$ & No & No & No \\
\hline int lis & OK & OK & OK & OK & OK & OK & OK & OK & OK & OK & OK & OK & OK & OK \\
\hline 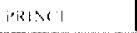 & OK & OK & OK & 10 & oK & OK & OK & no & No & OK & OK & OK & No & OK \\
\hline$\therefore x$ & OK & OK & OK & OK & oK & OK & ok & OK & OK & OK & OK & $\mathrm{OK}$ & $\mathrm{OK}$ & $\mathrm{OK}$ \\
\hline : & OK & OK & OK & OK & oK & OK & OK & OK & OK & No & No) & No & No & OK \\
\hline
\end{tabular}

Table 1.1: Output submitted by the OCMIP-2 modeling groups.

in the third year of GOSAC; some groups have nonetheless submitted those results in advance. As for the CFC's, submitted model output undergoes verification. That process is ongoing for output from the OCMIP carbon simulations.

The seven GOSAC groups were well represented at each of three OCMIP-2 International Workshops: (i) Gif-sur-Yvette, France (May 27-28, 1999), (ii) Princeton, New Jersey (June, 2000), and (iii) Amsterdam (June 2001). At these workshops, participants discussed developments concerning (1) groundwork for comparison, (2) observational data sets to be used as references, (3) results, and (4) future plans. 


\subsection{Results}

\section{CFC-11 and CFC-12}

Oceanographers use CFC-11 and CFC-12 to track waters that have been ventilated through air-sea gas exchange within recent decades. These man-made, inert tracers (CFCs) were first produced in the 1930's and their inadvertent release to the atmosphere gradually increased until about the 1970's. The campaign to make precise measurements of these tracers throughout the ocean began in the 1980's. Largely due to efforts during the recently completed World Ocean Circulation Experiment (WOCE), we now have an extensive, global database. We exploit that database here for the purpose of ocean model validation. To do so, we made standard CFC11 and CFC-12 simulations in the 13 OCMIP-2 models. Here we highlight this model-data comparison, focusing on CFC- 11 ; the CFC-12 results lead to the same conclusions. Greater detail is provided in our recent OCMIP-2 publication on this subject [Dutay et al., 2002].

\section{Global CFC-11 Uptake:}

The range of global CFC-11 uptake predicted by the OCMIP- 2 models varied by $\pm 30 \%$ around the mean, pointing out the need for an estimate of the observed global inventory. Such does not exist but would be a valuable contribution of the data synthesis community. Our analysis also revealed a linear relationship between models for the increasing trend in the global CFC-11 inventory (Fig. 1.1). This relationship exists because global CFC uptake is limited by the magnitude of the global subduction rate. That is, surface ocean CFC-11 concentrations equilibrate rapidly with the atmosphere and all models were forced to follow the same temporal CFC-11 increase in the atmosphere. Furthermore, we examined if model-model and model-data differences were simply due to differences in temperature. We used the $\mathrm{CFC}-11$ solubility to remove the temperature bias, thereby analyzing the partial pressure of CFC-11 (PCFC-11) as well as the CFC-11 inventory along data sections. Our conclusions were unchanged whether we used CFC-11 or PCFC-11. Thus differences are due to different model circulation fields.

Differences in the simulated global CFC-11 oceanic inventory derive mainly from the Southern Ocean, where CFC's are concentrated in the Subantarctic Mode Water (SAMW). As detailed below, the observed sections reveal excessive CFC11 concentrations in the NERSC and UL models, indicating that their Southern Ocean ventilation is too strong. Conversely, the PRINCE model exhibits weak ventilation (low CFC-11 concentrations) in the Southern Ocean, particularly in the SAMW. Thus the OCMIP-2 predictions for the global CFC-11 inventory bracket the observations. 


\section{Southern Ocean CFC-11:}

The AJAX section provides an in-depth view of model performance in the Southern Ocean (Fig. 1.2. The observed CFC-11 distribution along this section reveals the signature of the principal water masses of the Southern Ocean. The sharp subsurface tracer penetration down to approximately $1000 \mathrm{~m}$, between $55^{\circ} \mathrm{S}$ and $40^{\circ} \mathrm{S}$ reflects the formation of Subantarctic Mode Water (SAMW). At greater depths, low CFC concentrations south of the ACC reveal weakly ventilated Circumpolar Deep Water (CDW). Nearer the bottom, higher CFC-11 concentrations indicate recently ventilated Antarctic Bottom Water (AABW). Some models (AWI, CSIRO, IPSL, LLNL, MIT, NCAR, SOC, PRINCE and NERSC) succeed in reproducing the sharp subsurface penetration of the CFCs at the subantarctic front associated with the SAMW ventilation. In other models (MPIM, IGCR and UL), CFC-11 penetration is less realistic, extending vertically into the Circumpolar Current, but not diagonally (along isopycnals) towards the subtropics. The general CFC-11 distribution in the SAMW subduction region along the AJAX section in the Atlantic Ocean $\left(55^{\circ} \mathrm{S}-40^{\circ} \mathrm{S}\right)$ is captured by several of the models, with simulated penetration depths and inventories that are close to those observed $(800 \mathrm{~m})$. However, there is a tendency in several models (MPIM, LLNL, CSIRO, PIUB, and PRINCE) for these quantities to be too low. The OCMIP-2 CFC comparison suggests that the subgrid-scale mixing scheme (for lateral diffusion) is important for subsurface ventilation, particularly in the Southern Ocean. Models with only horizontal mixing (IGCR, MPIM, UL, PIUB) show particularly unrealistic subsurface ventilation, i.e., they provide inadequate ventilation of Sub-Antarctic Mode Waters (SAMW). Conversely, the other OCMIP models, all of which include explicit formulations for mixing on surfaces of constant density (isopycnals) produce more realistic ventilation of SAMW.

Another clear difference between models is the degree to which they are able to produce realistic ventilation of young Antarctic Bottom Waters (Fig. 1.2). The inverse model (AWI), the isopycnic model (NERSC), and the four ocean models that were coupled with a sea-ice component model (LLNL, MPIM, PIUB, and UL) all show significant $\mathrm{CFC}$ concentrations at the bottom due to $\mathrm{AABW}$ ventilation. However, their skill varies: the AABW CFC-11 concentrations are realistic in the LLNL model, but over-predicted by more than a factor of 10 in the five other models mentioned above. LLNL appears to succeed due to its specific parameterization for vertical redistribution of brine rejection during sea-ice formation. Generally, ocean models that were not coupled to a sea ice model had weaker ventilation of AABW.

\section{CFC-11 in the Northern Oceans:}

In the subtropics of both the North Atlantic and the North Pacific, all models underpredict the CFC-11 inventory, the PCFC-11 inventory and the penetration depth. For example see the meridional WOCE P13 section located near the Subtropical 
Mode Water (STMW) formation region in the Pacific (Fig. 1.3. Such systematic under-prediction suggests a consistent shortcoming in the model circulation fields. Perhaps, meso-scale eddies, which are not resolved by any of the OCMIP-2 models, may play an important role in ventilating the subtropical gyre. Such systematic bias does not exist further north, i.e., the models bracket the observations. However, the shallow penetration depth simulated by some of the models may be due to the poor representation of the marginal seas (Sea of Okhotsk) and inadequate exchange through straits.

Of particular interest is the WOCE longitudinal section that cuts across the path of young NADW as it flows southward (Fig. 1.4). This section proves a most difficult test for the coarse resolution models used in OCMIP-2. Some of the models have well-defined DWBC (e.g., AWI, IPSL, MPIM, NCAR and NERSC) whereas others (e.g., CSIRO, LLNL and MIT) produce excessive ventilation into the ocean interior. All models, except for the NERSC isopycnal model, produce CFC-11 concentrations in the DWBC that are too low. Section A24N reveals two maxima of recently ventilated water along the western continental slope, which make up the Deep Western Boundary Current (DWBC). The deep maximum centered at $3500 \mathrm{~m}$ is the Lower North Atlantic Deep Water (LNADW); the shallower maximum at $1500 \mathrm{~m}$ is the Upper North Atlantic Deep Water (UNADW). Recirculation features transport some of the CFC from the DWBC as far westward as $50^{\circ} \mathrm{W}$. Only the AWI model succeeds in producing two maxima along the western boundary, as found in the observations. The other models produce, at best, only the maximum due to the UNADW. Yet even for the UNADW, the model structure and position of that $\mathrm{CFC}$ maximum is inaccurate and varies considerably between models.

Further details about the OCMIP-2 CFC comparison can be found in [Dutay et al., 2002]. 
CFC-11 Atmospheric Mole Fractions
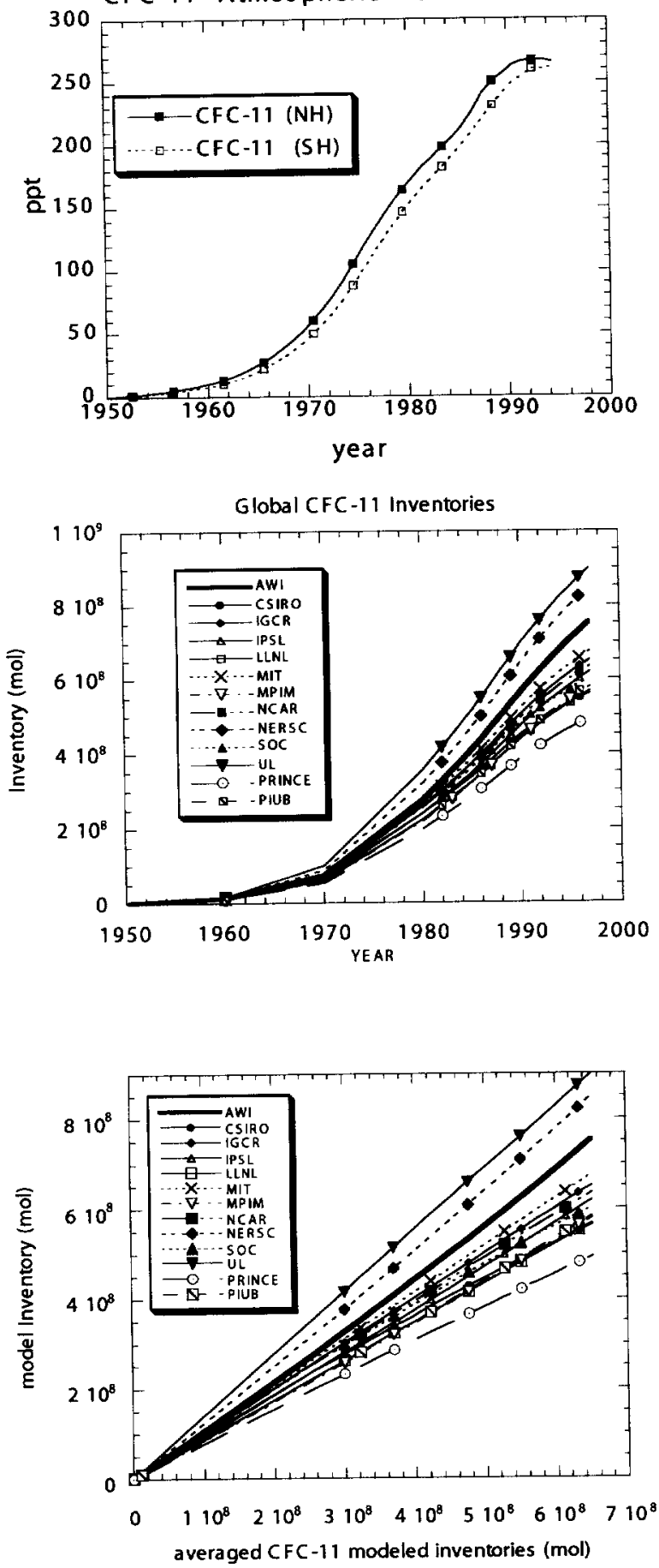

Figure 1.1: Temporal evolution of CFC-11 in the atmosphere and ocean: the atmospheric CFC-11 mixing ratio in both hemispheres (top panel); the simulated global CFC-11 inventories (middle panel). Also shown are the simulated global CFC-11 inventories vs. the mean global CFC-11 inventory from the 13 OCMIP-2 models (bottom panel). 

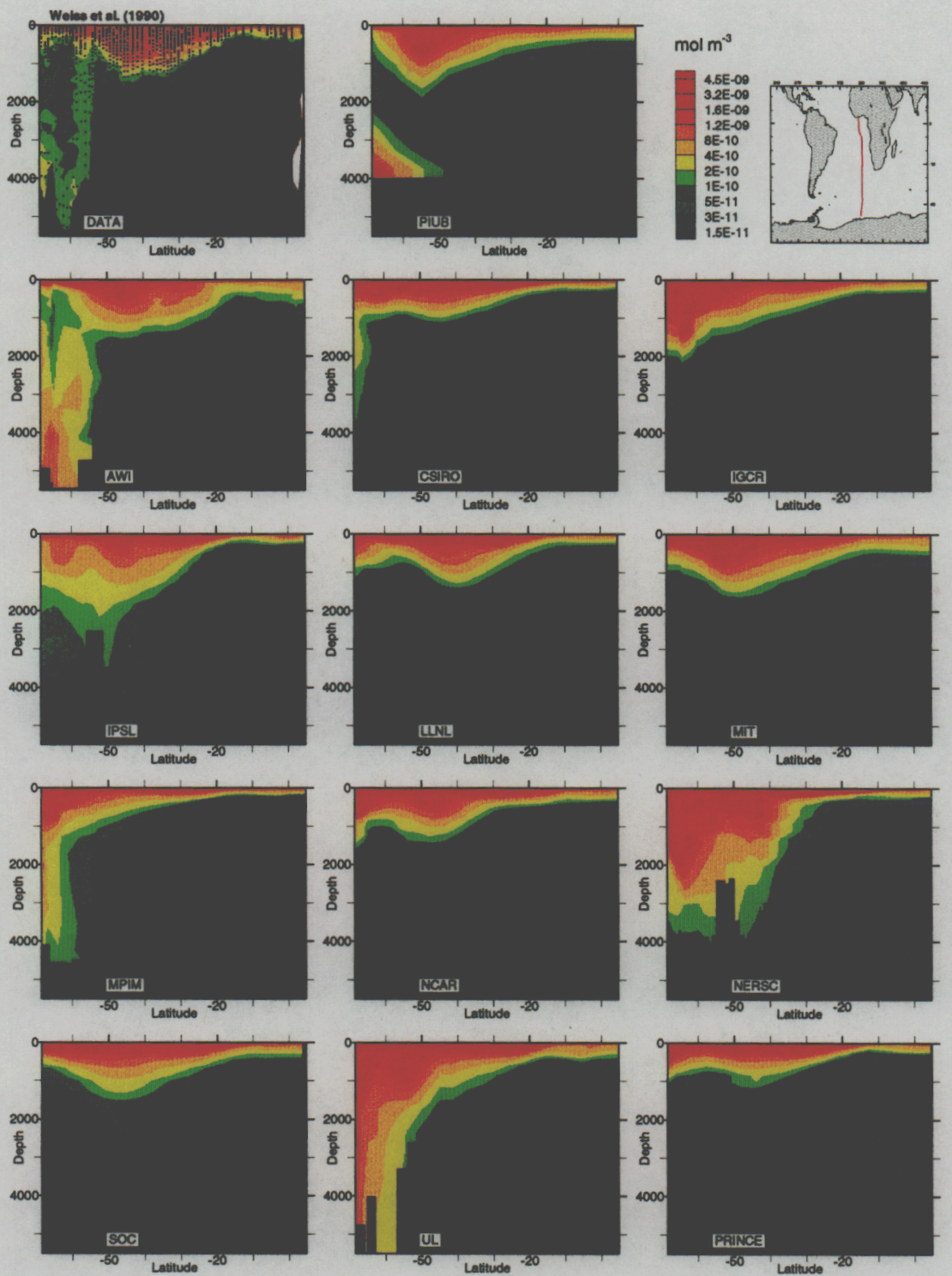

Figure 1.2: Observed and simulated CFC-11 along the AJAX section taken in 1983. Concentrations are in $\mathrm{mol} \mathrm{m}^{-3}$. 


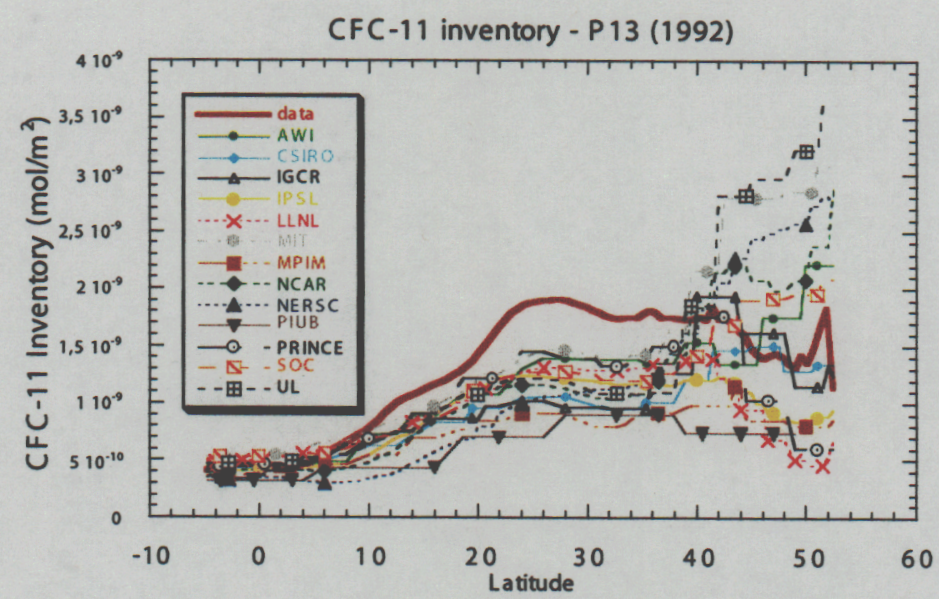

Pcfe-11 inventory - P 13 (1992)
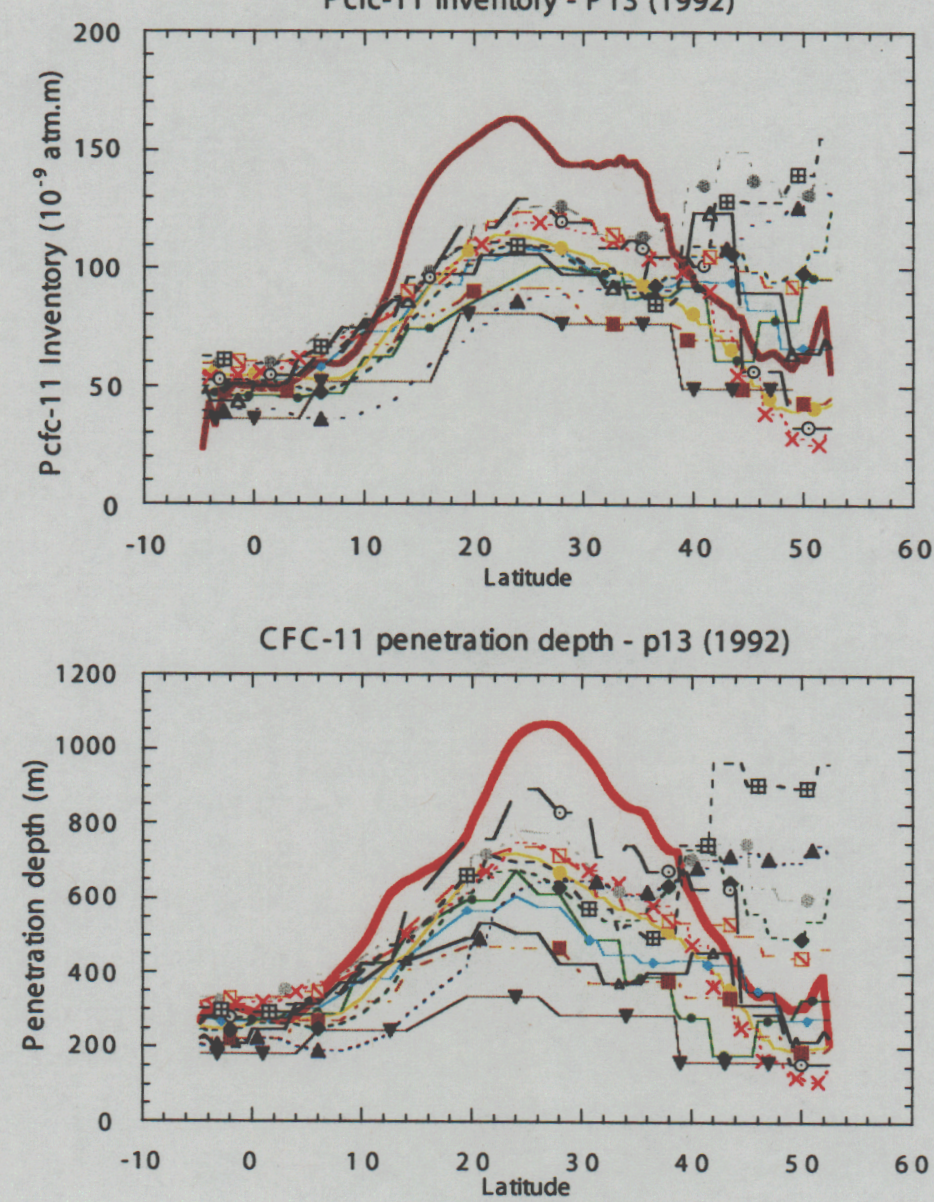

Figure 1.3: CFC-11 and PCFC-11 vertical inventories and penetration depths along WOCE section P13, a meridional section in the N.W. Pacific. 

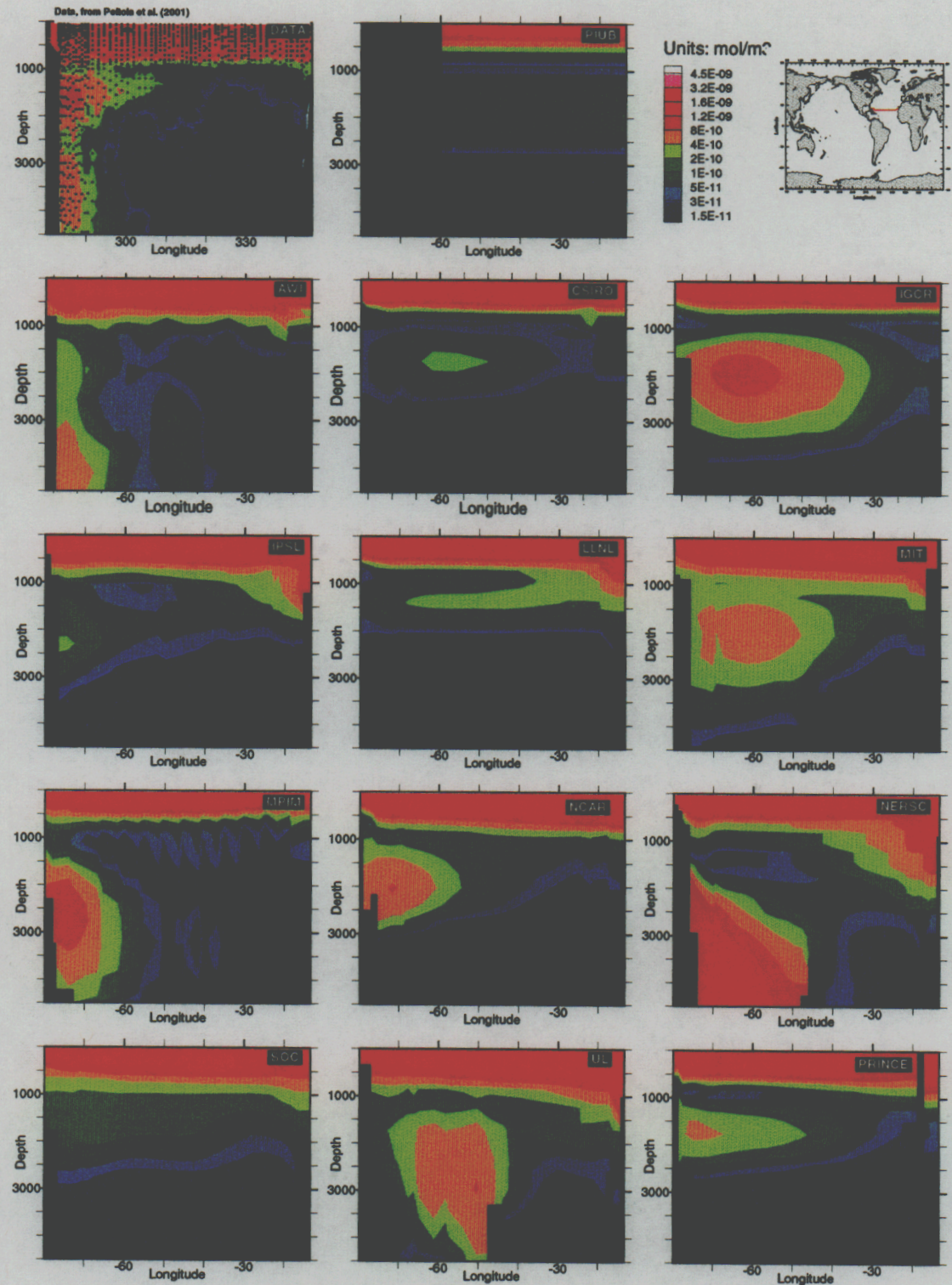

Figure 1.4: Observed and simulated CFC-11 along a WOCE section A24N, i.e., along $24^{\circ} \mathrm{N}$ in the North Atlantic. Concentrations are given in $\mathrm{mol} \mathrm{m}^{-3}$. 


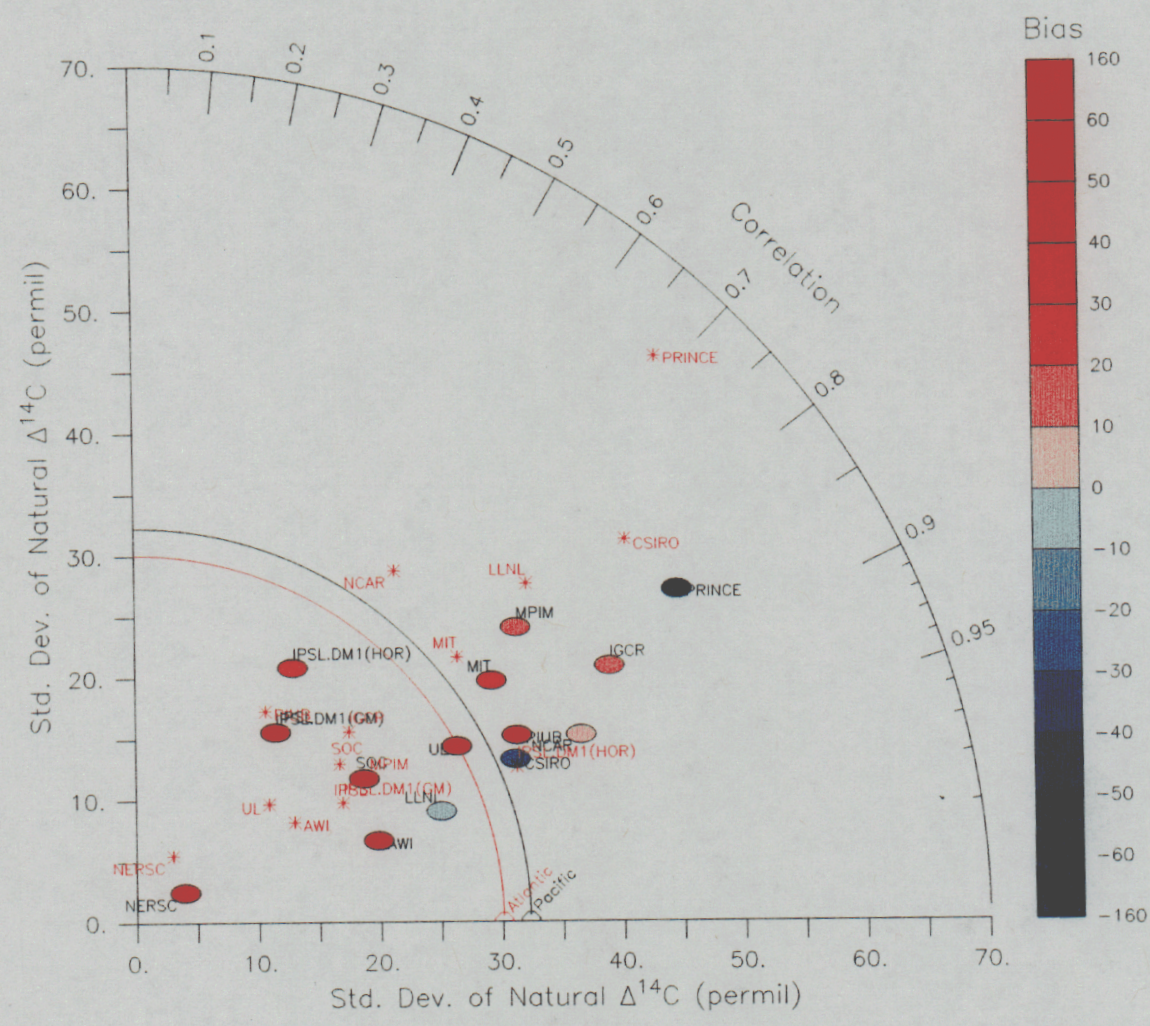

Figure 1.5: Taylor Diagram for deep natural $\Delta^{14} \mathrm{C}$ (below $1000 \mathrm{~m}$ ) showing summary statistics for the OCMIP-2 models and the GEOSECS data. Separate analysis is shown for the Atlantic (red) and Pacific basins (black reference, colored ovals). The color within each oval indicates overall bias (model mean - observed mean) for the Pacific basin analysis. The bias shows that the models bracket the observations.

\section{Radiocarbon}

Within the near future, substantial concentrations of anthropogenic $\mathrm{CO}_{2}$ will have invaded the entire deep North Atlantic. We know this from measurements of radiocarbon $\left({ }^{14} \mathrm{C}\right)$ which tell us that deep waters in the North Atlantic were last ventilated less than 200 years ago. In the future, more anthropogenic $\mathrm{CO}_{2}$ will reach the deep ocean, where it will be necessary to establish greater skill in modeling deepocean circulation. To evaluate model skill on a longer time scale than for CFC-11, the 13 OCMIP-2 models made standard simulations for natural radiocarbon. Natural $\Delta^{14} \mathrm{C}$ is particularly useful because it exhibits horizontal and vertical gradients in the deep ocean due to a combination of its decay rate $\left(t_{1 / 2}=5730\right.$ years $)$ and the slow ventilation of deep ocean waters (100 to 1000 years). Thus natural $\Delta^{14} \mathrm{C}$ 
offers time-dependent information, unlike tracers such as temperature and salinity. During GOSAC, we compared simulated natural $\Delta^{14} \mathrm{C}$ with observations from two global ocean sampling campaigns: GEOSECS (Geochemical Ocean Sections Survey) and the World Ocean Circulation Experiment (WOCE).

Oceanic measurements of ${ }^{14} \mathrm{C}$ include both a natural component and an anthropogenic component. In OCMIP, simulations were made for both. Our focus in GOSAC has been on natural ${ }^{14} \mathrm{C}$; members of OCMIP in the USA have taken on the responsibility of analyzing the anthropogenic component, and thus we do not discuss it further here. Because of its radioactive decay, the natural ${ }^{14} \mathrm{C}$ component is useful to evaluate circulation and ventilation of the deep ocean. Fortunately for this purpose, there is little contamination by anthropogenic ${ }^{14} \mathrm{C}$ below $1000 \mathrm{~m}$, except near deep-water formation areas (notably, in the North Atlantic). The GEOSECS program in the 1970's provided sufficient data for a twodimensional view of ocean $\Delta^{14} \mathrm{C}$. Two north-south $\Delta^{14} \mathrm{C}$ sections in each of the Atlantic, Pacific, and Indian Oceans provided an indication of the age structure of deep waters. During OCMIP-2, we first compared simulated natural $\Delta^{14} \mathrm{C}$ with that estimated during GEOSECS by Broecker et al. [1995].

\section{GEOSECS $\Delta^{14} \mathrm{C}$ Comparison:}

To quantitatively evaluate overall model performance, we relied on a innovative diagram that was first developed to compare atmospheric models [Taylor, 2001]. This "Taylor" diagram simultaneously presents several statistics that are useful in model-data comparison. To construct this diagram for the comparison to the nongridded ${ }^{14} \mathrm{C}$ data, we first sampled each of the OCMIP-2 models at the station locations and depths where we have data-based estimates for natural ${ }^{14} \mathrm{C}$ during GEOSECS [Broecker et al., 1995]. Second, we computed the five corresponding summary statistics: the standard deviation of the model $\sigma_{f}$ and that of the data $\sigma_{r}$, the correlation coefficient $R$, the centered pattern RMS error $E^{\prime}$, and the overall bias $E$. Finally, we plotted the results (Fig. 1.5). More details about the make-up of a Taylor diagram can be found in the caption to Fig. 1.16).

Figure 1.5 shows a Taylor diagram, with separate analysis for each of the Atlantic and Pacific basins. The Pacific basin, makes up about half the volume of the global ocean and is thus our main focus here. The colored ovals indicate the Pacific basin's overall bias (i.e., the basin-wide mean for the model minus that for the data). In many of the models, the magnitude of overall bias term is unusually large, larger than either the variance of the model (radius from the origin) or the r.m.s. pattern error (distance between the model point and the reference point along the $x$ axis). The overall bias term further indicates that most of the models overestimate the observed deep ${ }^{14} \mathrm{C}$ mean in the Pacific (red colors). Therefore their deep ${ }^{14} \mathrm{C}$ is too young and their global deep ventilation is too strong. Conversely, two of the models (CSIRO and PRINCE) simulate deep ${ }^{14} \mathrm{C}$ that is too old, revealing inadequate ventilation (blue colors). The best models in terms of the overall bias are the LLNL and NCAR models (white ovals), i.e., their mean deep Pacific ${ }^{14} \mathrm{C}$ is within 
$\pm 10 \%$ of that for the observations.

This.bias term is also useful to quickly identify extremes. One extreme is PRINCE model with the oldest $\Delta^{14} \mathrm{C}$; it is valuable because the ${ }^{14} \mathrm{C}$ data tell us that PRINCE ventilation is much too sluggish. On the other extreme are the AWI, SOC, and IPSL.DM1 (GM) models, with deep-ocean ventilation that is too strong (deep ${ }^{14} \mathrm{C}$ that is much too young). Later we will use these extremes as well as correlations with natural ${ }^{14} \mathrm{C}$ to help place limits on ocean uptake of anthropogenic $\mathrm{CO}_{2}$ as well as the efficiency of purposeful ocean sequestration.

Figure 1.5 also tells us how the modeled pattern of deep ${ }^{14} \mathrm{C}$ correlates with that of the observations. In the Pacific, many of the models (AWI, CSIRO, LLNL, NCAR, and PIUB) have a correlation coefficient $R$ of 0.9 or better, which means they explain $81 \%$ or more of the variance. It is noteworthy that PIUB is a zonal model and correlates about as well with the data as do any of the others; this appears to reflect the dominance of latitudinal variability and perhaps the sampling design of GEOSECS (two meridional sections in the Pacific). Most of the other models have $R$ 's of at least 0.8 . Most of the models also perform better in the Pacific than in the Atlantic. This is not surprising given the more complex deep-ocean circulation in the Atlantic (see Fig. 1.6). However, the two versions of the IPSL model exhibit the worst correlations in the Pacific, but the best correlations in the Atlantic. Both exceptions may be explained by IPSL's restoring of temperature and salinity throughout the water column over much of the ocean [Aumont et al., 1998]. The other OCMIP-2 models perform only surface restoring.

In Figure 1.5, we include the NERSC model to investigate what might be learned even before a ${ }^{14} \mathrm{C}$ simulation reaches steady state. Unfortunately, the NERSC model's intensive computing requirements did not allow it to be integrated for more than a few hundred years; the other models were all integrated for at least several thousand years to attain the OCMIP-2 criterion for quasi steady state. Thus, the NERSC overall bias term is unusable and its variance is too low. On the other hand, the NERSC model exhibits a relatively high correlation $R$, suggesting that the deep-ocean patterns of the $\Delta^{14} \mathrm{C}$ distribution may be set well before a model reaches steady state. If so, the Taylor Diagram could serve as an early indicator of model performance for these long integrations of at least 4000 years. Nonetheless, a high "early" correlation for NERSC does not imply that its overall bias would be reasonable when the model did finally attain the OCMIP-2 equilibrium criterion. In fact, based on the NERSC model's excess ventilation in the Southern Ocean, as diagnosed with CFC-11, we would expect that its equilibrium natural $\Delta^{14} \mathrm{C}$ would be much too young.

Overall, the ${ }^{14} \mathrm{C}$ Taylor diagram quantifies the performance of the models in terms of their general patterns of deep-ocean ${ }^{14} \mathrm{C}$. Generally, The OCMIP-2 models do well in the Pacific, and not so well in Atlantic. They bracket the observed mean deep-ocean ${ }^{14} \mathrm{C}$ in the Pacific and in the global ocean.

Figure 1.6 shows the model-data natural $\Delta^{14} \mathrm{C}$ comparison along the Western Atlantic GEOSECS section. Clearly it remains a challenge for models to reproduce the data along this section. To do so, a model must properly estimate the formation 

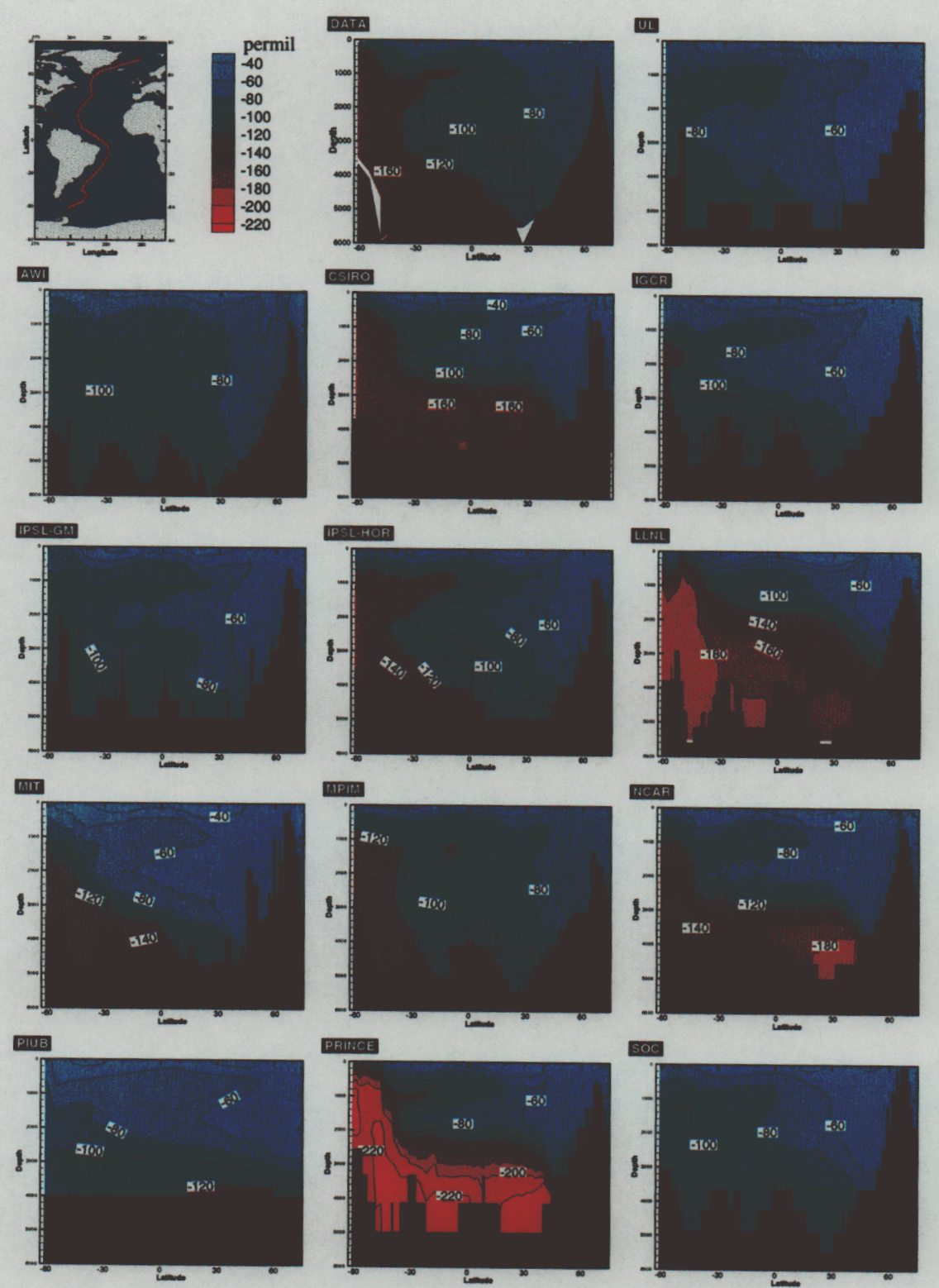

Figure 1.6: Comparison of observed vs. modeled natural $\Delta^{14} \mathrm{C}$ along the Western Atlantic GEOSECS track, sampled in 1972 and 1973.

rate and approximate density of young waters entering from the north (North Atlantic Deep Water) and the relatively older waters entering from the south (Antarc- 


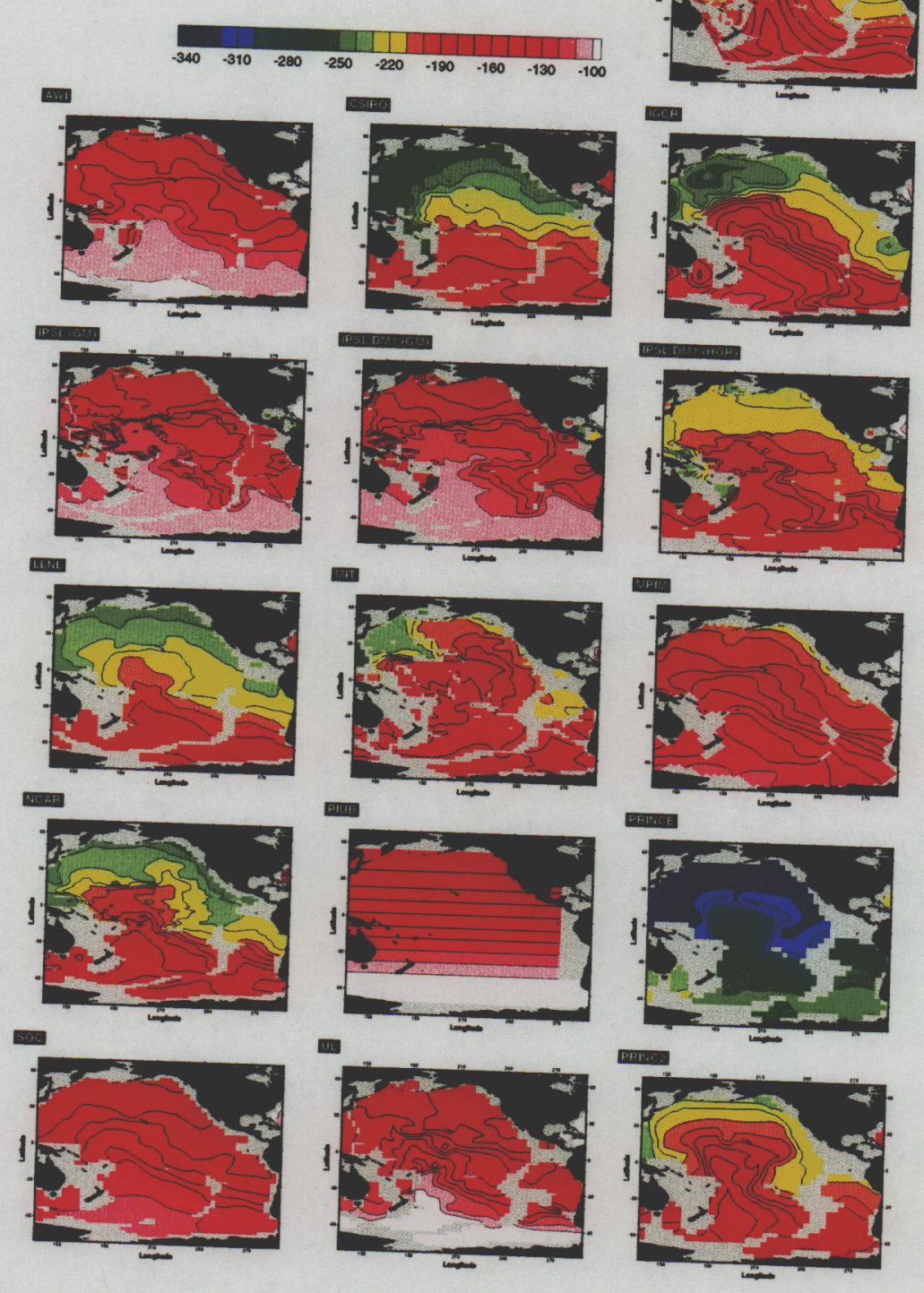

Figure 1.7: Near-bottom radiocarbon in the OCMIP models. Results are taken from the deepest ocean layer which varies spatially in each model. Typically the deepest model layer is about $500 \mathrm{~m}$ thick. Depths above $3500 \mathrm{~m}$ are shaded light gray. 


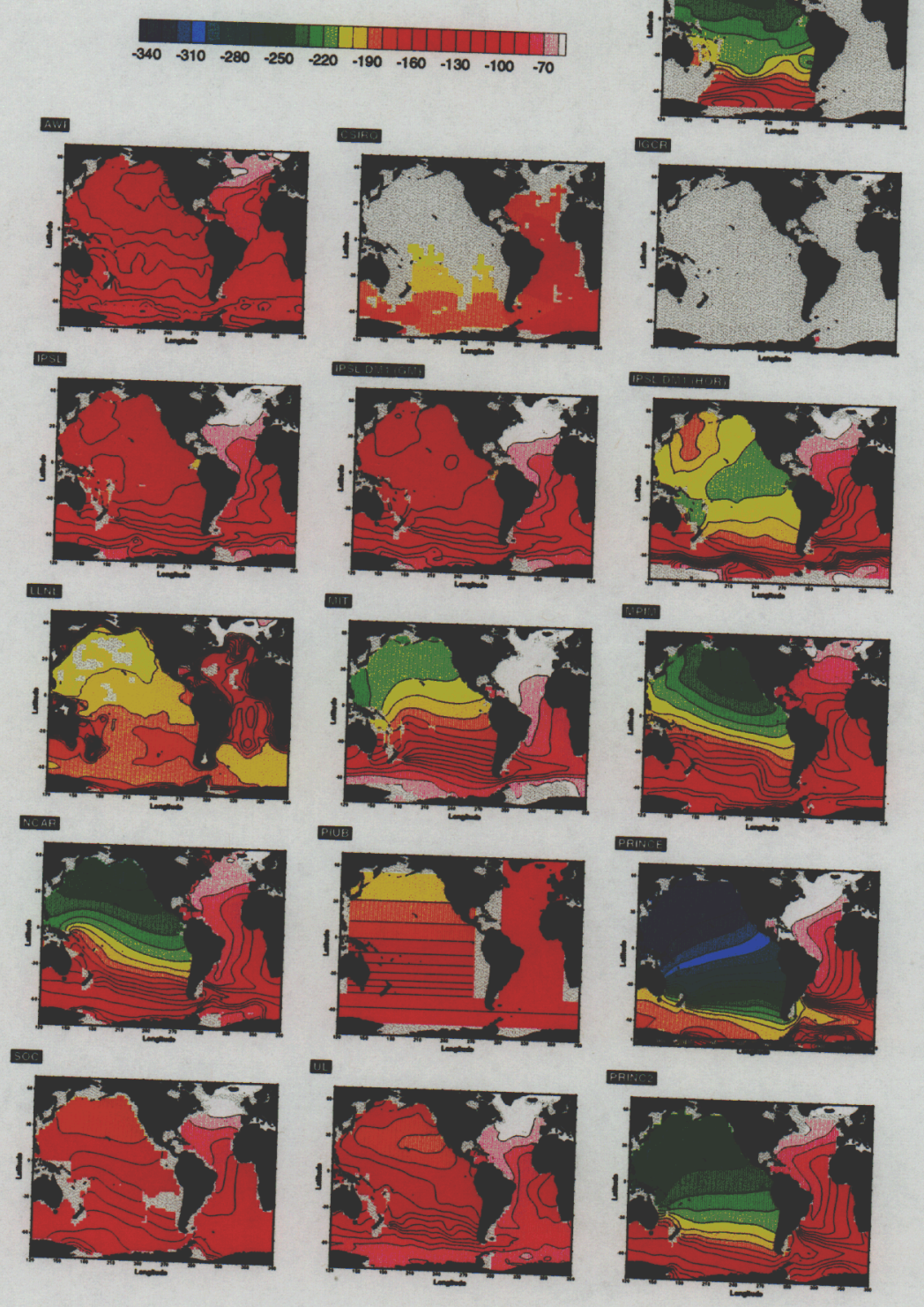
Figure 1.8: Simulated natural radiocarbon on the isopycnal surface where $\sigma_{2}=36.925$.
Gray areas indicate grid points where this surface does not exist. 


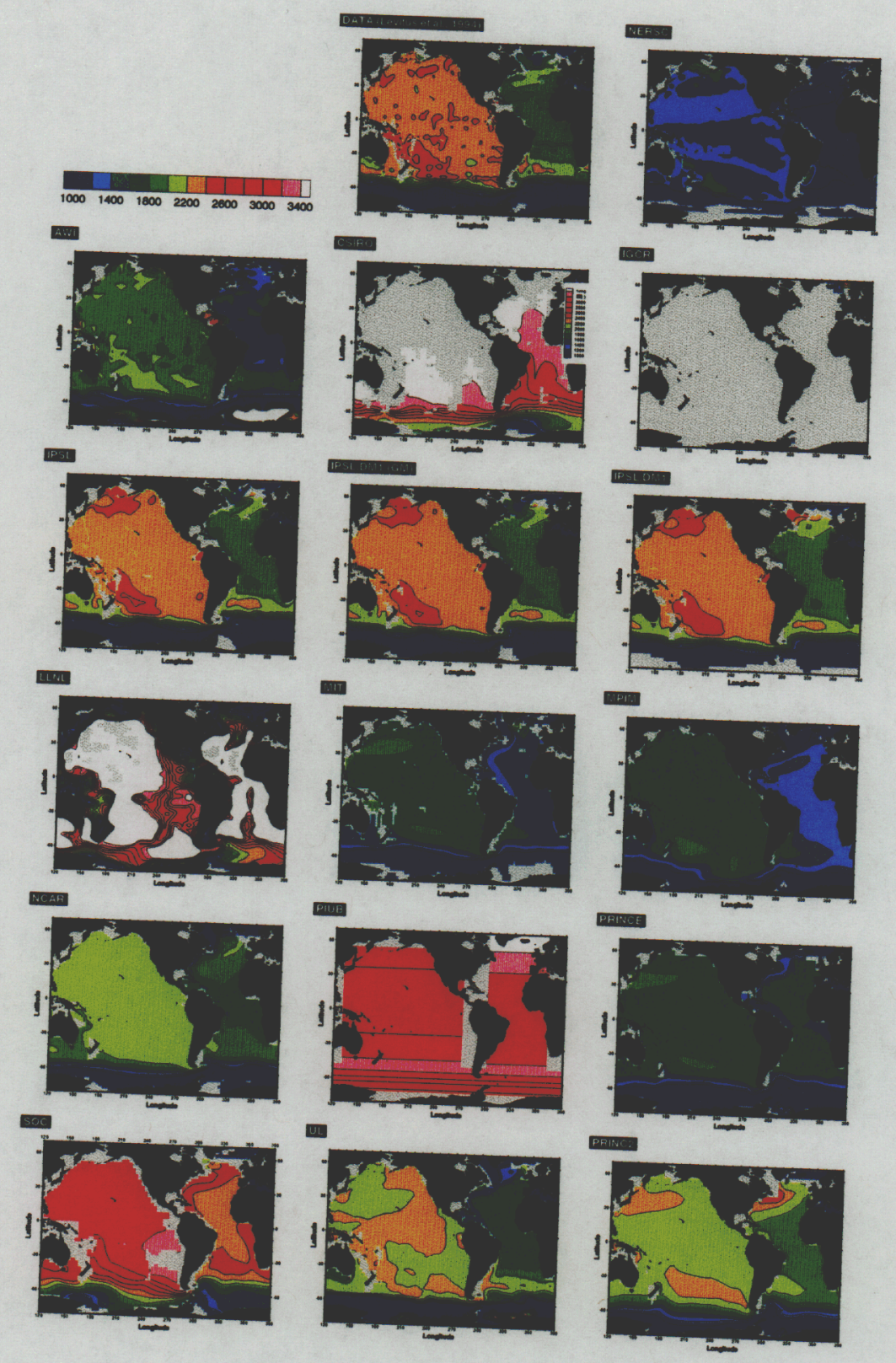
Figure 1.9: Depth (m) of the isopycnal surface where $\sigma_{2}=36.925$. Gray areas indicate
grid points where this surface does not exist. 
tic Bottom Water and Intermediate Water). Four of the OCMIP-2 models (Princeton, LLNL, NCAR, CSIRO) reveal a classic problem [Toggweiler et al., 1989]: their young northern deep waters penetrate no deeper than $3000 \mathrm{~m}$, leaving room for very old southern bottom waters to move northward up to about $50^{\circ} \mathrm{N}$. The other nine models simulate younger deep Northern Atlantic bottom waters. However in seven cases (AWI, IGCR, IPSL-GM, MIT, PIUB, SOC, UL) their natural $\mathrm{C}-14$ is too young (excess ventilation) throughout the section. The two remaining models (IPSL-HOR, and MPIM) simulate roughly the right level of D14C along this section. In particular, both models simulate the southward moving tongue of younger North Atlantic Deep Water (NADW) confined by older waters moving in from the Southern Ocean, both above (AAIW) and below (AABW). Yet both the IPSL-HOR and MPIM models still have trouble matching observed gradients in natural $\triangle^{14} \mathrm{C}$, particularly along the bottom, which could indicate inadequate northward penetration of AABW. The MIT model performs better in this regard.

\section{WOCE Pacific Ocean $\Delta^{14} \mathrm{C}$ Comparison:}

During the 1990's the World Ocean Circulation Experiment (WOCE) increased the total number of ocean $\Delta^{14} \mathrm{C}$ measurements by more than an order of magnitude. Although the WOCE $\Delta^{14} \mathrm{C}$ measurements are not yet complete, the Pacific data is available and was used to evaluate the OCMIP-2 models. The increased spatial coverage of the WOCE data set allowed us to compare models and data in the Pacific on longitudinal as well as latitudinal sections and on depth and density surfaces. Figures 1.7, 1.9, and 1.10 illustrate some of the OCMIP-2 data-model comparison using the WOCE $\Delta^{14} \mathrm{C}$ Pacific data set. Again, we are concerned here with the deep ocean (below $1000 \mathrm{~m}$ ), where bomb contamination in the Pacific is negligible.

An intriguing finding in the data is the dramatic difference between near bottom waters in the eastern vs. the western tropical Pacific [Key, 1998], as illustrated in Figure 1.7. Based on ${ }^{14} \mathrm{C}$, bottom waters in the west are several hundred years younger than those in the east. Relatively young Circumpolar Deep Water (CDW) from the south is generally thought to move northward as a deep current through the relatively deep Tonga-Kermadec trench in the west, then to upwell slowly. However, exactly where that upwelling occurs is not clear, nor are the general flow patterns of bottom water in the North Pacific. One can draw insight from the datamodel comparison.

Figure 1.7 also shows the near bottom $\Delta^{14} \mathrm{C}$ in ten OCMIP models. Although the magnitude of near-bottom $\Delta^{14} \mathrm{C}$ varies tremendously between models, the trend of the large observed east-west difference is roughly reproduced in most cases. The trend suggests that younger waters are moving northward in the west and older waters are moving southward in the east. The only model not exhibiting this trend is the zonal-mean PIUB model, as would be expected since by definition this model has no longitudinal discretization in the Pacific, Atlantic, and Indian basins. 
Spatial variation in ocean bathymetry, which is well represented within the resolution constraints of each of the models, appears to be one reason for the good structural agreement between models and data. As the young, dense CDW moves northward, it fills bathymetric lows. As this water ages, it is displaced into higher levels due to the continual supply of young, dense waters from the south. Thus east-west differences in bathymetry seem to partially explain why the deep bottom waters in the west are younger than shallower bottom waters in the east. Yet the route waters take into the North Pacific, their residence time there, and their return path also play a role.

Based on observed ${ }^{14} \mathrm{C}$, the North Pacific Deep Water (NPDW) is the oldest water in the global ocean. The remarkable contrast between the NPDW and the young North Atlantic Deep Water (NADW) covers almost the entire observed ocean range in $\Delta^{14} \mathrm{C}$. Deep-water formation in the North Atlantic provides a source of ${ }^{14} \mathrm{C}$, whereas the long residence time of waters in the North Pacific provides a sink, due to radioactive decay. That dramatic contrast in nicely illustrated by ${ }^{14} \mathrm{C}$ on the $\sigma_{2}=36.925$ surface of constant density (Fig. 1.8). In the real ocean, that density surface lies at the core of both the NPDW and the NADW.

Unfortunately, there are strikingly large differences between models concerning the depth of this $\sigma_{2}$ surface (Fig. 1.9). Differences were expected, but such a comparison exercise points out how large they can be. For instance, the IGCR model does not even have this surface. In the CSIRO model, this surface exists, but it is limited to parts of the Southern Ocean (south of $30^{\circ} \mathrm{S}$ ), and it is much too deep. In the other models, this surface extends all the way to the North Pacific, but it varies in depth: in the PRINCE model it is to shallow; in the PIUB and SOC models it is too deep; and in the AWI and NCAR models it seems about right.

Given such variety in density between models, it is not too surprising that $\Delta^{14} \mathrm{C}$ also varies dramatically on this density surface (Fig. 1.8). Of course, this modeldata comparison was impossible in the models that didn't have this density surface (IGCR, LLNL), and it was not useful when when the density surface was far from reality (CSIRO). For the other models though, the $\Delta^{14} \mathrm{C}$ evaluation on this surface was informative. In the PRINCE model, where the density surface is too shallow by about $500 \mathrm{~m}$, the $\Delta^{14} \mathrm{C}$ on that surface is everywhere too old in the Pacific, by $50 \%$ in the south and $100 \%$ in the north. The Princeton model also exhibits younger waters further north on the eastern side of the Pacific basin, a trend which is not found in the data. Two other models where the Pacific density surface is also deeper than observed show the opposite problem: the SOC model is too young, everywhere by about 70 to $80 \%$ and the zonal mean PIUB model is also too young by about $60 \%$ everywhere. Relative to the the data from Key [1998], the NCAR model offers the closest match (about right in the north, although about $30 \% 0$ too young on the southern end). This may not seem surprising given the skill of the NCAR model to match the observed density. However, AWI $\Delta^{14} \mathrm{C}$ results are less realistic even despite that models ability to get the right depth for the $\sigma_{2}=36.925$ density surface. In the AWI model, there is too much ventilation: the southern end of the $\sigma_{2}$ surface is 30 to $70 \%$ too young, whereas the northern end is about $100 \%$ 
too young. Still though, the AWI model is the only one that reveals a separation of NPDW minimum (the oldest water) from the North American coast, as is suggested by the data. These model-data discrepancies in the Pacific appear too large to be explained simply by inaccuracies in the simulated depth of the $\sigma_{2}$ surface (Fig. 1.9).

The observed vertical structure of $\Delta^{14} \mathrm{C}$ along WOCE section $\mathrm{P} 6$ at $32^{\circ} \mathrm{S}$ in the Pacific offers a signature of the age of northward and southward moving water across this section. In the data, relatively young water $(>-170 \%$ ) moves northward in the deepest part of the section, at around $175^{\circ} \mathrm{W}$, i.e., along the TongaKermadec ridge; conversely, older waters above and in the eastern portion of the section seem to indicate the return path of waters that have spent considerable time in the North Pacific $\left(\Delta^{14} \mathrm{C}<-210 \%\right)$ [Key, 1998]. All of the OCMIP models have difficulty matching both the structure and magnitude of measured ${ }^{14} \mathrm{C}$ on that section (Fig. 1.10). All the 3-D models predict that younger water moves northward in the west. Fewer models (AWI, IPSL, CSIRO, PRINCE) are able to capture the nearly homogeneous, but bimodal structure of the return flow at about $2500 \mathrm{~m}$ ). The WOCE P6 section demonstrates the interest of ${ }^{14} \mathrm{C}$ to improve modeled deepocean circulation.

Modelers trying to simulate ${ }^{14} \mathrm{C}$ in the Atlantic would benefit from further data synthesis efforts to extend the map of bottom water $\Delta^{14} \mathrm{C}$ to the Atlantic. Likewise extending the map of $\Delta^{14} \mathrm{C}$ on the $\sigma_{2}=36.925$ density surface to the Atlantic, would provide a most useful contrast criterion for model validation (see Fig. 1.8). Some of the OCMIP-2 model results should eventually be employed to help test methods used to obtain transport estimates from the WOCE ${ }^{14} \mathrm{C}$ data set [Key, 1998]. 

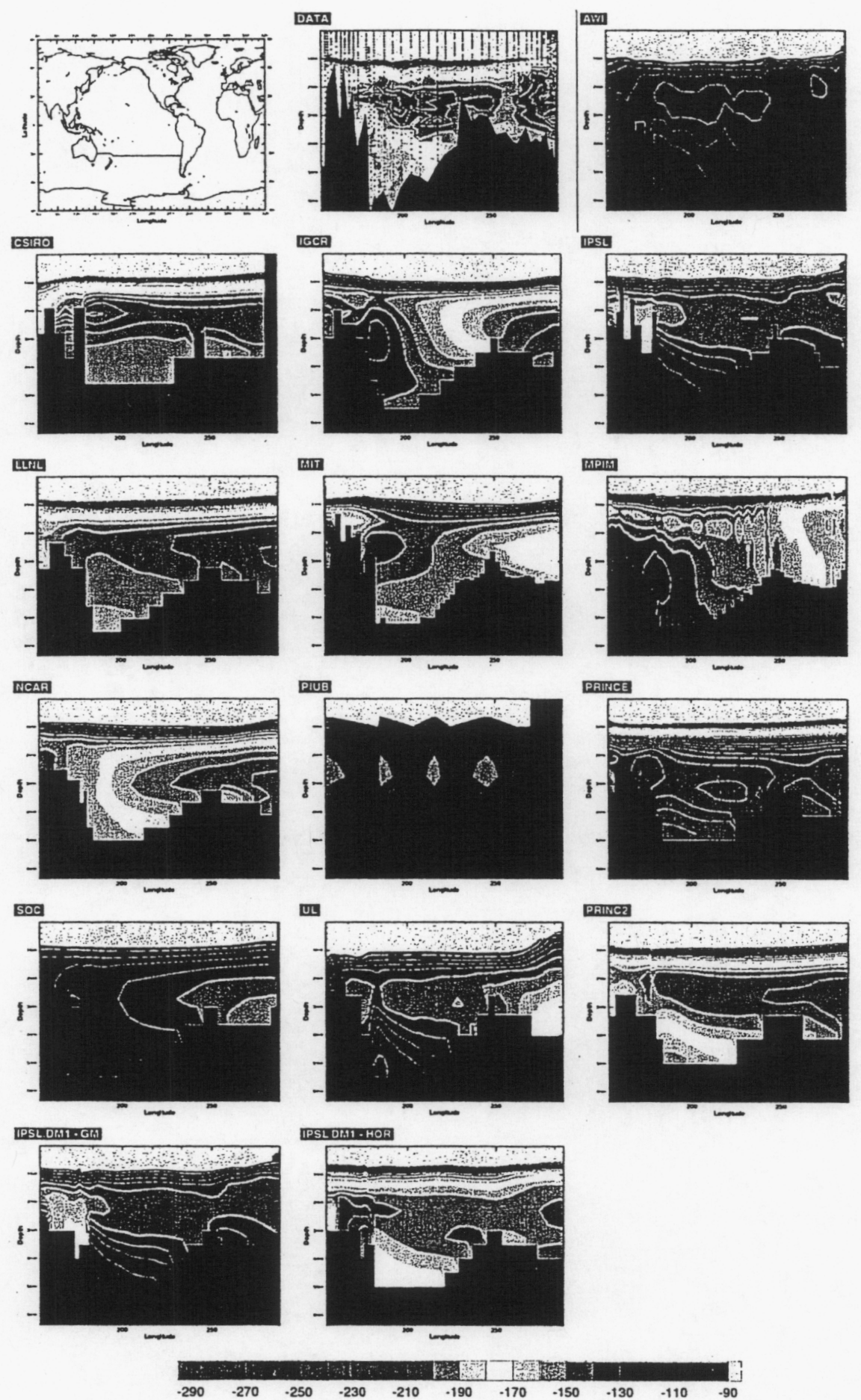

Figure 1.10: Observed radiocarbon on WOCE section P6 in the Pacific Ocean at $32^{\circ} \mathrm{S}$ vs. simulated natural ${ }^{14} \mathrm{C}$ sampled from ten OCMIP-2 models along the same section. 


\section{Natural $\mathrm{CO}_{2}$}

For the natural carbon cycle in OCMIP-2, we separately ran simulations to distinguish effects due to two fundamental processes, which along with ocean circulation control the distribution of natural $\mathrm{CO}_{2}$. The first process relates to the temperaturedependent solubility of $\mathrm{CO}_{2}$. The cold waters which fill the deep ocean from the high latitudes are rich in $\mathrm{CO}_{2}$. Secondly, ocean biota act to reduce surface ocean $\mathrm{CO}_{2}$ through the combined action of planktonic uptake, rapid transport to depth of resulting particulate organic carbon, and subsequent bacterial degradation. Yet the net effect of biota is not simply to pump $\mathrm{CO}_{2}$ downwards, everywhere, as implied by the term biological pump [Volk and Hoffert, 1985]. To avoid ambiguity, we avoid using the term pump, and refer instead to the solubility and biological components.

To separate effects, we made two equilibrium simulations:

1. Abiotic-the solubility component which includes carbon chemistry and realistic gas exchange between surface ocean and atmospheric $\mathrm{CO}_{2}$ (held to $278 \mathrm{ppm}$ for the preindustrial case);

2. Biotic-the solubility plus biological components, together.

We thus determined the effects due to the solubility component (1), the sum of solubility and biological components (2), as well as the biological component by difference, (2)-(1).

\section{Air-Sea fluxes of natural $\mathrm{CO}_{2}$ :}

Resulting sea-to-air fluxes from the two simulations and their difference (the biological pump) are displayed as zonal integrals for the global ocean (Fig. 1.11). The main patterns of sources and sinks of natural $\mathrm{CO}_{2}$ are driven by thermodynamics (heat fluxes) and to a lesser extent, changes in salinity. Thus all solubility simulations exhibit ocean out-gassing in the tropics and uptake in the high latitudes. Additionally, the biological component counteracts the solubility component either by bringing respired $\mathrm{CO}_{2}$ (produced by bacterial degradation of organic matter) to the surface via upwelling and deep convection (mostly in the high latitudes), or by consuming $\mathrm{CO}_{2}$ at the surface via photosynthesis (mostly in the subtropical gyres and the tropics).

\section{North-south transport of natural $\mathrm{CO}_{2}$ :}

Keeling et al. [1989] extrapolated changes in the north-south difference between surface measurements of atmospheric CO2 at Mauna Loa and South Pole to determine a preindustrial difference of $-0.82 \mathrm{ppm}$. They estimated that this preindustrial difference implies a interhemispheric northward transport in the preindustrial atmosphere of about $1 \mathrm{PgC} \mathrm{yr}^{-1}$. They further reasoned that during preindustrial time, the global ocean should have transported an equivalent flux southward. These 
ocean implications from atmospheric data can be compared with direct estimates from ocean carbon cycle transport. During the previous phase of OCMIP, i.e., OCMIP-1, three ocean carbon cycle models were used to investigate this preindustrial carbon transport [Sarmiento et al., 2000]. None of these models produced a southward, pre-industrial, transport of more than $0.1 \mathrm{Pg} \mathrm{C} / y \mathrm{r}$. Simulated interhemispheric ocean transport in OCMIP-1 agreed surprisingly well. It was found that northward carbon transport in the Indian and Pacific Oceans essentially compensated southward transport in the Atlantic. Thus, interhemispheric carbon transport was found not to substantially affect the inter-hemispheric budget for the atmosphere. In contrast with the OCMIP-1 model results, studies which exploit ocean measurements in the Atlantic Ocean suggest that preindustrial interhemispheric ocean transport was substantially higher, from 0.3 to $0.5 \mathrm{Pg} \mathrm{C}$ yr -1 southward [Broecker and Peng, 1992; Keeling and Peng, 1995]; unfortunately, it has not been possible to make a similar data analysis for the Pacific, a larger basin and fewer mèasurements.

For GOSAC, we wanted to verify if the OCMIP- 1 conclusions were robust by performing similar analysis on the more diverse group of OCMIP-2 models. Indeed, we found a much larger range of total southward preindustrial transport, from 0.1 up to $0.7 \mathrm{PgC}^{-1}$ (Fig. 1.12). When broken down by basin (not shown) we found that the asymmetry in north-south transport is is mainly due to transport of the biological component in the Indo-Pacific basin. In the models, the asymmetry in the solubility component, results in substantial net northward flux due to dominance of the Atlantic transport. Conversely, in the biological component there is net southward transport due to dominance of the Indo-Pacific transport. The latter dominates in the models with the largest southward transport (IPSL) but is counter-balanced in models with weaker transport. The IPSL model's strong southward transport is due to large asymmetry in the sea-to-air flux of the biological component in the Pacific (loss of $\mathrm{CO}_{2}$ south of the Equator).

\section{Preindustrial marine component of atmospheric $\mathrm{CO}_{2}$ :}

During OCMIP-2, the simulated sea-to-air $\mathrm{CO}_{2}$ fluxes were used as boundary conditions to two atmospheric tracer transport models (Fig. 1.13). The OCMIP-2 sea-to-air $\mathrm{CO}_{2}$ fluxes induce atmospheric $\mathrm{CO}_{2}$ gradients in lower troposphere of both models. The resulting simulated North Pole - South Pole difference ranges from 0.2 to $0.8 \mathrm{ppm}$; the Mauna Loa (Hawaii, $18^{\circ} \mathrm{N}$ ) - South Pole difference (i.e. (MLO-SPO) is about half that. As expected, ocean models with a large southward $\mathrm{CO}_{2}$ transport induce larger atmospheric gradients. There is a good correlation between the zonal mean atmospheric $\mathrm{pCO}_{2}$ gradient (MLO-SPO) vs. preindustrial ocean transport, except for the IPSL model (Fig. 1.14). The IPSL model has, by far, the largest southward carbon transport across the equator, but not the most negative gradient in atmospheric $\mathrm{CO} 2$.

If we neglect IPSL, and extrapolate linearly, one needs roughly about a 0.8 $\mathrm{PgC} \mathrm{rr}^{-1}$ southward transport to obtain the $-0.8 \mathrm{ppm}$ extrapolated by Keeling 
for the MLO-SPO gradient in atmospheric $\mathrm{CO}_{2}$. Yet the IPSL outlier has -0.7 $\mathrm{PgC}_{\mathrm{yr}}{ }^{-1}$ southward transport but only about $-0.25 \mathrm{ppm}$ for the MLO-SPO atmospheric $\mathrm{CO}_{2}$ gradient. If we use the average northward ocean transport across the tropics (which is related to the integrated tropical transport), instead of the value just at the equator, the correlation improves substantially (Fig. 1.14c).

Furthermore, if we add the $-0.4 \pm 0.1 \mathrm{ppm}$ river effect from Aumont et al. [2001a] to the LLNL ocean only result, one obtains $-0.7+/-1 \mathrm{ppm}$ for the MLO-SPO difference. This roughly explains the value extrapolated by Keeling for that atmospheric $\mathrm{pCO}_{2}$ difference. Furthermore, by applying the same slope as found for the Aumont et al. [2001a] runs (Ocean+River - Ocean), it nearly explains Keeling et al's inferred interhemispheric transport of $1 \mathrm{PgCyr}^{-1}$. This preliminary calculation suggests that some of the OCMIP-2 modeling groups, particularly LLNL, should rerun the OCMIP-2 Biotic simulation while including the river loop. If such large transport can indeed be simulated, we will then need to develop tests to determine if they are realistic. 


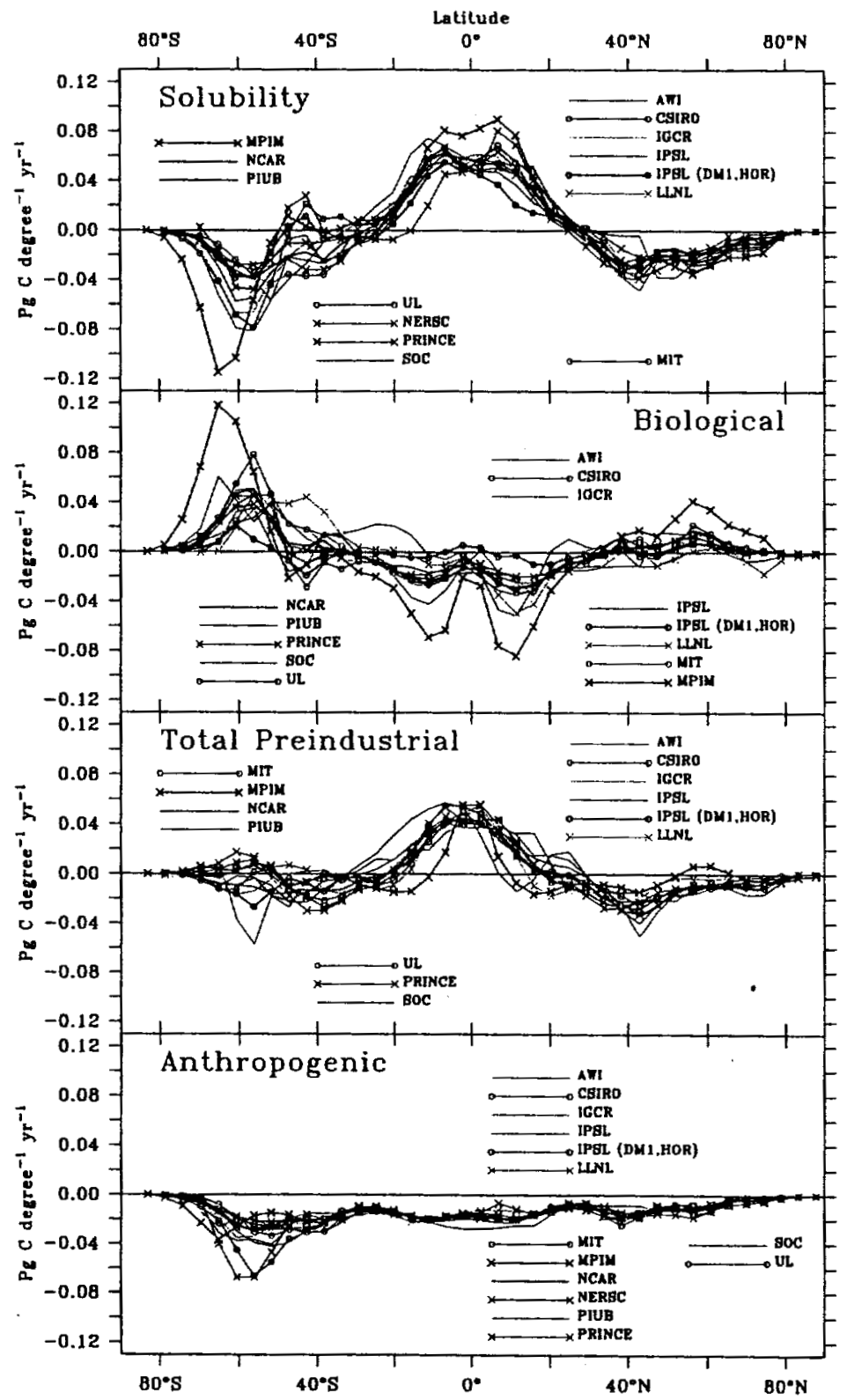

Figure 1.11: The zonally integrated sea-to-air flux of $\mathrm{CO}_{2}$ for the global ocean as predicted by the OCMIP models. The flux is separated into (a) the solubility component, with realistic gas exchange, (b) the biological component only, (c) the sum of $a+b$, i.e., the total natural flux, and (d) the component due to anthropogenic change during 1765 to 1995. The biological component $b$ is determined by difference between the Biotic and Abiotic simulations. 


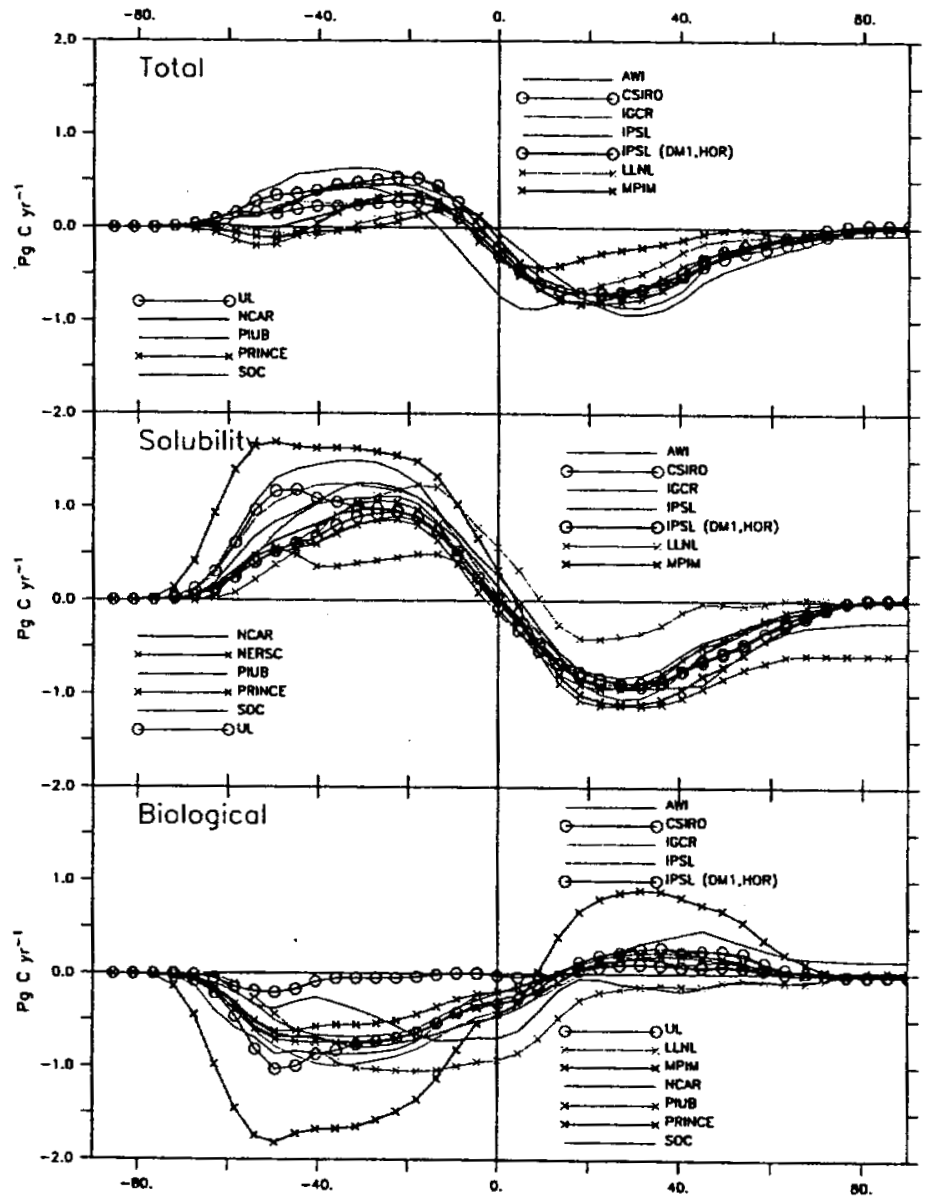

Figure 1.12: The northward tracer transport of natural $\mathrm{CO}_{2}$ simulated by the OCMIP2 models as determined from the divergence of the zonally integrated sea-to-air flux of natural $\mathrm{CO}_{2}$ (Fig. 1.11). 


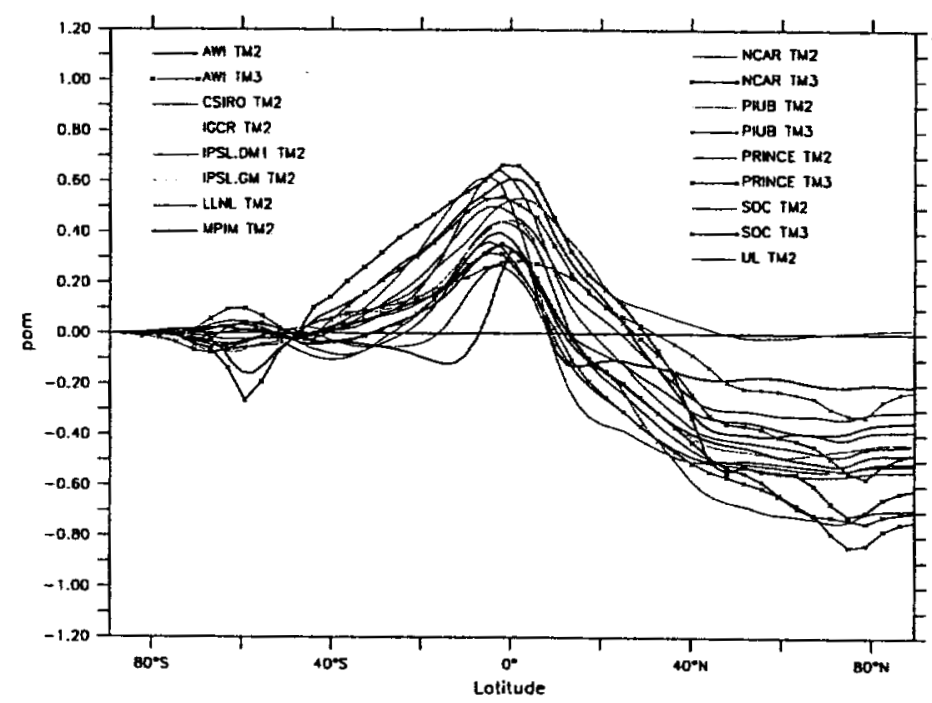

Figure 1.13: The zonal mean atmospheric mixing ratio of $\mathrm{pCO}_{2}$ (ppm) relative to the South Pole as predicted by using the total OCMIP-2 preindustrial sea-to-air $\mathrm{CO}_{2}$ fluxes (Fig. 1.13) as boundary conditions to two atmospheric transport models: TM2 (simulations by T. Naegler) and TM3 (simulations by M. Gloor). 


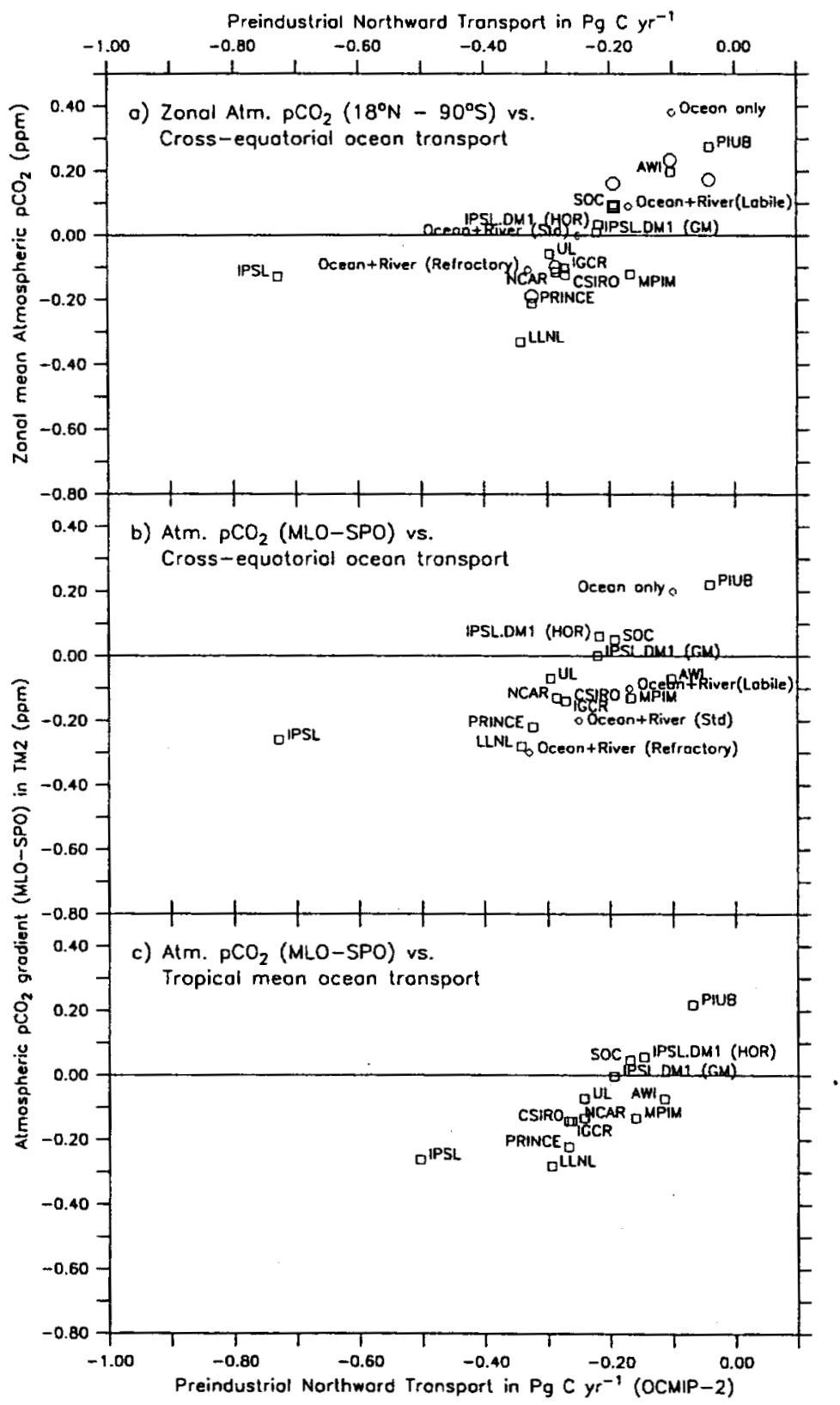

Figure 1.14: Correlation of preindustrial, cross-equatorial, global ocean transport with the resulting atmospheric $\mathrm{pCO}_{2}$ given as (a) the zonal mean difference between $18^{\circ} \mathrm{N}$ and $90^{\circ} \mathrm{S}$ and (b) the MLO-SPO difference. The correlation improves in (c) when the crossequatorial ocean transport is replaced by the mean tropical meridional ocean transport. Results are given for TM2 (red squares) and TM3 (blue circles). Also shown are results from Aumont et al. [2001a] (green diamonds) who also included the effect of the "riverloop" in the version of the IPSL model used during OCMIP-1 (equivalent to IPSL (HOR), run as a sensitivity test in OCMIP-2). . 


\section{Total $\mathrm{CO}_{2}$}

Here we compare model results to modern observations (Fig. 1.15), which include both natural and anthropogenic components. For modern simulated fuxes; we simply added fluxes from the Biotic simulation (solubility plus natural components) to the those due to anthropogenic change (Abiotic Historical - Abiotic Equilibrium simulations); we also used Abiotic Control to remove model drift. The resulting modern simulated fluxes for 1995 were then compared to data-based estimates for the same year. For consistency, the data-based estimates were obtained by multiplying the "observed" estimates of the difference between surface ocean and atmospheric $\mathrm{pCO}_{2}$ (i.e., $\Delta \mathrm{pCO}_{2}$ ), [Takahashi et al., 1999; Takahashi et al., 2002] ) times the OCMIP-2 fields of gas exchange (see caption to Fig. 1.15). Uncertainties in the data-based flux estimates are large due to our poor understanding of the gas exchange coefficient. Conversely, modeled fluxes are not as sensitive to the magnitude of the imposed gas exchange coefficient, because the simulated $\triangle \mathrm{pCO}_{2}$ adjusts to changes in the modeled flux field that is specified a priori. Other data-based uncertainties may also be large.

Overall, the models capture the general north-south (meridional) trends of the observed annual mean sea-air $\mathrm{CO}_{2}$ flux, with large $\mathrm{CO}_{2}$ uptake in the high latitudes, $\mathrm{CO}_{2}$ release in the tropics, and intermediate regions in the subtropics. Regionally, however, models differ. In the largest source region, the Equatorial Pacific, there is disagreement in regards to the structure and intensity of the source term. Most of the models simulate a north-south asymmetry as seen in the observations, but the intensity and longitudinal (zonal) structure of the source varies widely. In the largest sink region, the Southern Ocean, there is little agreement in zonal structure. Such qualitative assessment of the annual mean, global map is useful. However, it does not provide a means to condense detailed qualitative information for the full spatio-temporal distribution.

Hence we also wanted to provide a concise quantitative assessment of overall model performance, including evaluation of seasonal variability, a fundamental constraint. To obtain this goal, we start by computing several summary statistics: the standard deviation of the model $\sigma_{f}$ and the data $s \sigma_{r}$, the correlation coefficient $R$, the centered pattern RMS error $E^{\prime}$, and the overall bias $E$. We then display all five of these summary statistics in an innovative diagram, following the new approach developed for atmospheric model comparison [Taylor, 2001]. This "Taylor" diagram is based on the Taylor's insight that the first four of the summary statistics mentioned above are related through the Law of Cosines. Therefore based on a simple geometry one can display these multiple statistics simultaneously.

Figure 1.16 shows such a Taylor diagram for the global air-sea $\mathrm{CO}_{2}$ fluxes. This figure includes the analysis for the overall spatio-temporal distribution (colored filled ovals). Additionally, it breaks down the different spatial and temporal components separately to show their contribution to the overall error (asterisks colored according to component). The relative position of the different reference points indicates the proportion that each component contributes to the overall ob- 
served variance. Globally, the three components (zonal mean; zonal variability, and seasonal variability) contribute about equally to the overall variability. The models perform well in regards to the zonal mean, with the majority of the models showing a correlation coefficient $R$ of 0.9 or better. Thus they explain at least $81 \%$ of the variance. Conversely, the models do poorly in simulating the observed longitudinal variations in the sea-air $\mathrm{CO}_{2}$ flux (correlation coefficient $R$ between 0.2 and 0.5 for the seasonal models). The skill of the models in reproducing the global seasonal cycle is no better ( $R$ from 0.3 to 0.5 ). Overall, models explain only about 10 to $40 \%$ of the spatio-temporal variability ( $R=0.3$ to 0.7 ).

We were surprised by the poor seasonal representation of the air-sea $\mathrm{CO}_{2}$ fluxes simulated by the OCMIP-2 models. As far as we are aware, this was the first attempt to quantitatively evaluate the skill of any ocean carbon cycle model to simulate seasonal variability on the global scale. The general failure of the models for this basic constraint requires further attention. For instance, it will be necessary to determine, with sensitivity tests in one model, if the cause is largely due to the simplicity of the common OCMIP-2 Biotic model. This basic model has no explicit biology but restores simulated surface phosphate concentrations to the observed monthly climatology; we hypothesize that a basic ecosystem model would perform much better. 

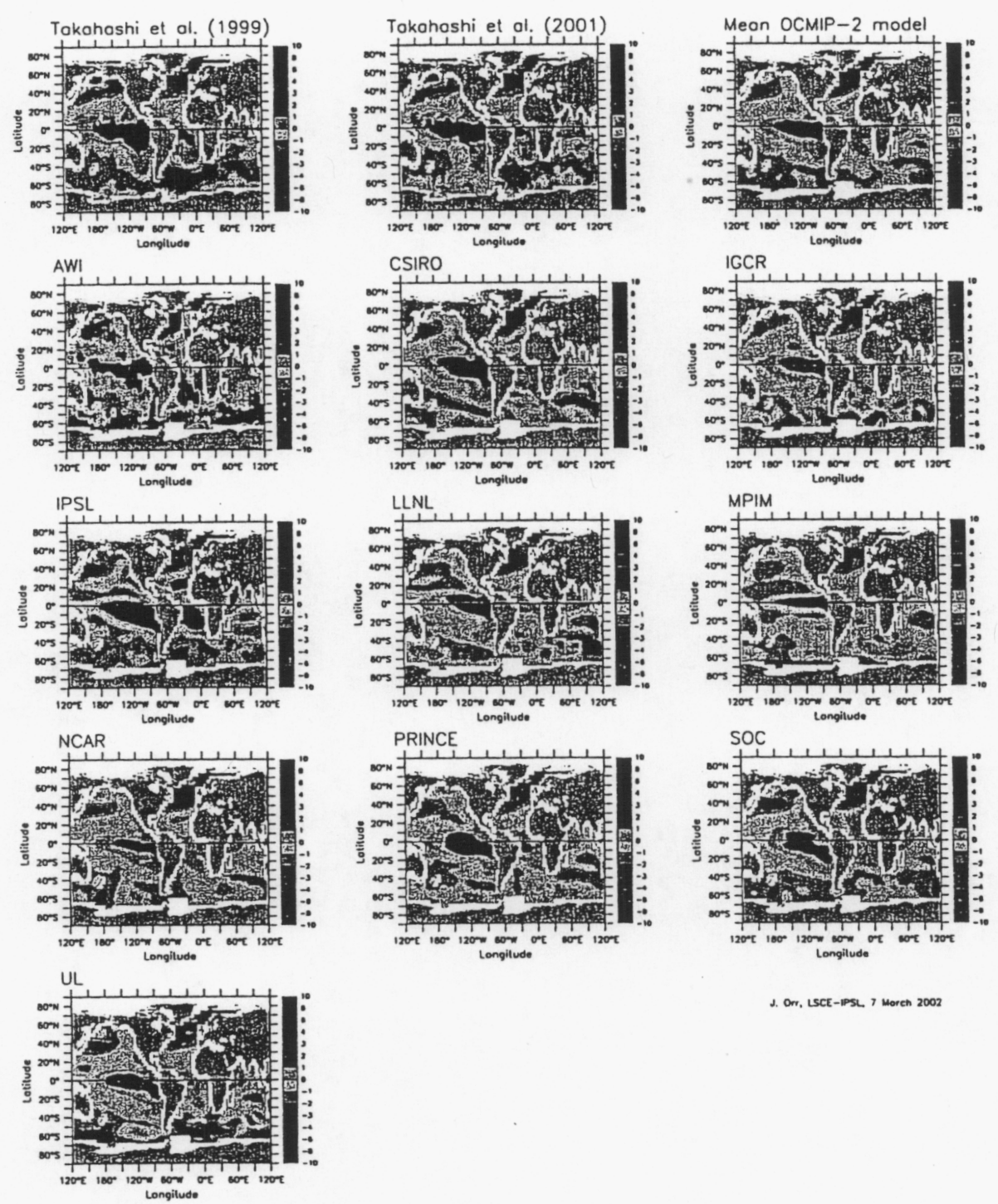

$$
\text { J. Drr. LSEE-1PSL, } 7 \text { Moren } 2002
$$

Figure 1.15: Model and data-based estimates of the annual mean, sea-to-air $\mathrm{CO}_{2}$ flux in 1995. Observed fluxes are based on $\Delta \mathrm{pCO}_{2}$ observations that were interpolated in space and time to a climatological grid [Takahashi et al., 1999; Takahashi et al., 2002]. For consistency with models, these gridded $\triangle \mathrm{pCO}_{2}$ fields were then multiplied by the same gas exchange fields used for the OCMIP-2 simulations. The monthly OCMIP-2 gas exchange field is based on satellite observed winds and the gas exchange formulation of Wanninkhof [1992] (see http://www.ipsl.jussieu.fr/OCMIP). The model flux fields represent the total sea-air flux, obtained by summing the preindustrial state (Biotic Equilibrium rum) plus the anthropogenic perturbation (Abiotic Historical minus Abiotic Equilibrium or Control run). For consistency, all model fields were interpolated to the same $4^{\circ} \times 5^{\circ}$ grid as used for the data. 


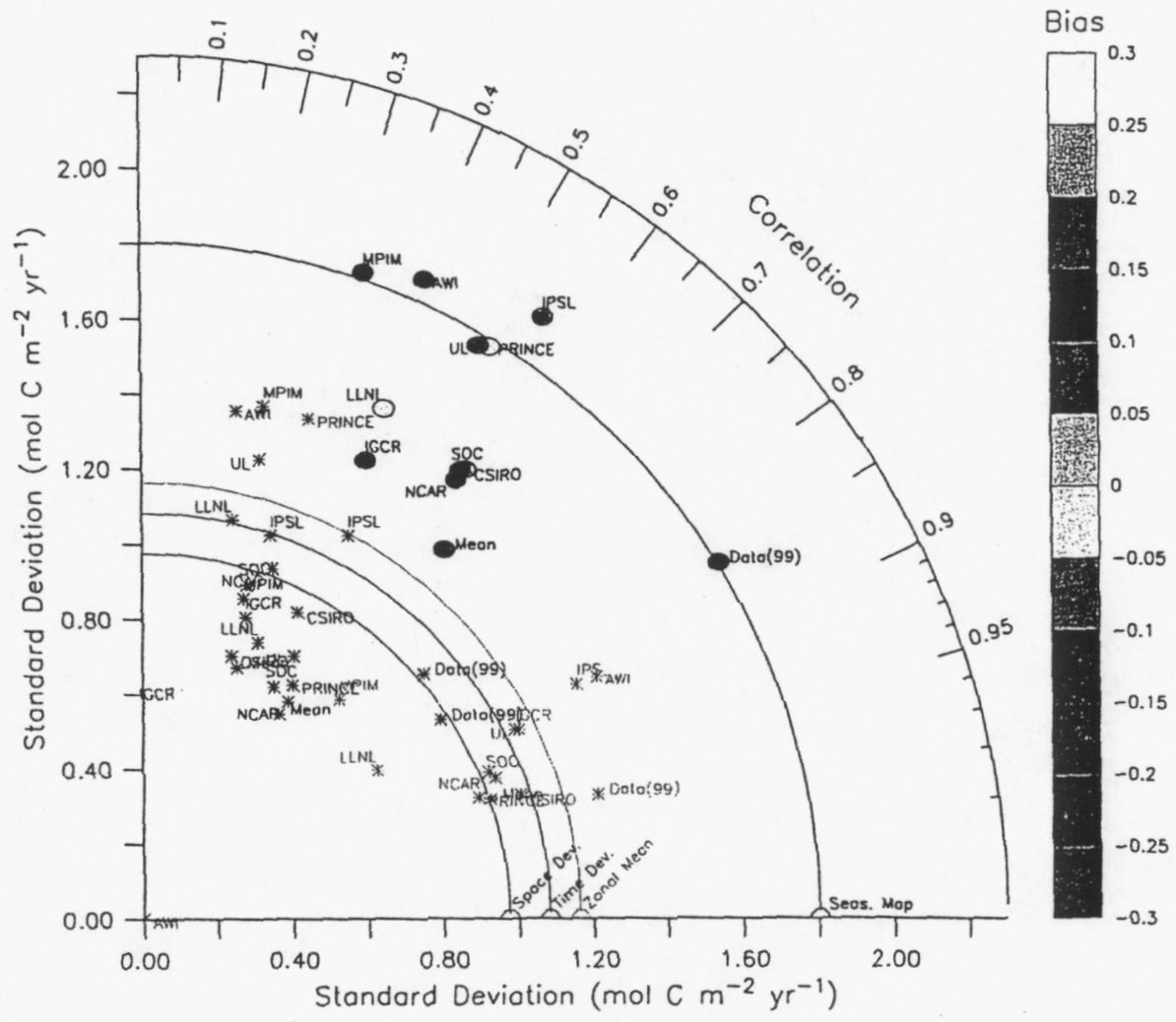

Figure 1.16: Taylor Diagram of the global, seasonal sea-air flux of $\mathrm{CO}_{2}$. To read a Taylor diagram (an $\mathrm{r}-\theta$ or polar plot), one begins by comparing a model's standard deviation $\sigma_{f}$ (the radius $r$ ) to the standard deviation $\sigma_{T}$ of the data. If a model exhibits less overall variance than that of the data, its colored oval has an $r$ which is less than the black reference curve. In this low-variance category fall the CSIRO, IGCR, LLNL, NCAR, SOC, and UL models, and the mean of all the OCMIP-2 models. The older data-based climatology [Takahashi et al., 1999] has the same variance as does the reference, i.e., the more recent climatology [Takahashi et al., 2002]. Second, the angle $\theta$ of the Taylor diagram indicates the correlation coefficient between the model and the data reference. If a model were perfect, it would lie along the $\mathrm{X}$-axis, right on top of the reference point. The reference point is marked "Seas. Map" for the full space-time distribution (black). The other reference points represent analogous analysis but for different components of the space-time distribution: the Annual Zonal Mean (green), the spatial deviation from the Annual Zonal mean (Annual Map - Annual Zonal Mean, red), and the Time deviations from the annual map (Seasonal Map - Annual Map, blue). Third, the distance from the appropriate reference point to a given model represents that model's central pattern root mean square (r.m.s) difference between the two fields $E^{\prime}$. Finally, the overall bias $E$ (a scalar indicating the difference between the spatio-temporal mean of each of the two fields) is indicated by the color which fills each of the ovals; the range for each color is indicated by the color key to the right of the plot. Note that units for $E, E^{\prime}, \sigma_{f}$, and $\sigma_{r}$ are identical (mol m${ }^{-2} \mathrm{yr}^{-1}$ ) and that the overall r.m.s. error $E$ is the quadratic sum of $E$ and $E^{\prime}$ (i.e., $E^{2}=E^{2}+E^{\prime} 2$ ). 


\section{Anthropogenic $\mathrm{CO}_{2}$}

Along with the rise in atmospheric $\mathrm{CO}_{2}$ that has occurred since the onset of the industrial revolution, air-to-sea $\mathrm{CO}_{2}$ fluxes have become more positive everywhere. However, this anthropogenic $\mathrm{CO}_{2}$ perturbation in the ocean is small compared to natural levels of inorganic carbon already present, thereby making direct measurement difficult. To assess model uncertainties and set the stage for improving predictability, GOSAC compared simulations of anthropogenic $\mathrm{CO}_{2}$ in the 13 OCMIP-2 models. An additional 3 sensitivity tests were also analyzed from the IPSL and PRINCE models. Simulations were made by all groups for anthropogenic $\mathrm{CO}_{2}$ uptake during the historical period and into the future, following standard protocols (http://www.ipsl.jussieu.fr/OCMIP).

\section{Modern Anthropogenic $\mathrm{CO}_{2}$ Uptake:}

The OCMIP-2 range for the simulated global uptake for the decade of the 1980's was 1.65 to $2.51 \mathrm{PgC} \mathrm{yr}^{-1}$ (Table 1.2). Thus models agree within $\pm 22 \%(1.99 \pm$ $0.43 \mathrm{PgC} \mathrm{yr}^{-1}$, i.e., half the range over the mean). This range falls within the spread of flux estimates from earlier compilations of 1-, 2-, and 3-D ocean model results: $2.0 \pm 0.8 \mathrm{Pg} \mathrm{Cyr}^{-1}$ [Watson et al.; 1990; Schimel et al., 1995], $2.0 \pm 0.6$ $\mathrm{PgC} \mathrm{yr}^{-1}$ [Siegenthaler and Sarmiento, 1993], and $2.0 \pm 0.5 \mathrm{PgC} \mathrm{Cyr}^{-1}$ [Orr, 1993]. Those earlier assessments included additional uncertainties due to our imperfect

Table 1.2: Change in global air-to-sea flux of $\mathrm{CO}_{2}\left[\mathrm{Pg} \mathrm{C} \mathrm{yr}^{-1}\right]$ since 1765

\begin{tabular}{lccc}
\hline & \multicolumn{3}{c}{ Global Mean Ocean Uptake of Anthropogenic $\mathrm{CO}_{2}$} \\
\cline { 2 - 4 } Model & $1980-1989$ & $1990-1999($ S650) & $1990-1999(\mathrm{C}-$ IS92a) \\
\hline PRINCE & 1.65 & 1.98 & 2.14 \\
IPSL.DM1 (HOR) & 1.67 & 1.98 & 2.16 \\
LLNL & 1.78 & 2.08 & 2.22 \\
CSIRO & 1.78 & 2.11 & 2.32 \\
MIT & 1.91 & 2.29 & \\
NCAR & 1.93 & 2.30 & 2.50 \\
PRINC2 & 1.93 & 2.32 & \\
IPSL (GM) & 1.97 & 2.36 & 2.56 \\
MPIM & 2.01 & 2.43 & 2.60 \\
SOC & 2.01 & 2.39 & 2.62 \\
IPSL.DM1 (GM) & 2.03 & 2.43 & 2.63 \\
IGCR & 2.05 & 2.47 & 2.66 \\
PIUB & 2.11 & 2.52 & 2.73 \\
AWI & 2.14 & 2.58 & 2.75 \\
NERSC & 2.38 & 2.84 & \\
UL & 2.51 & 3.04 & 3.26 \\
\hline
\end{tabular}


understanding of the global distribution of bomb $\mathrm{C}-14$, which is used to calibrate ocean box models. The OCMIP-2 study did not include that uncertainty (there were no box models, and only one of the 3-D models had been tuned a priori with bomb ${ }^{14} \mathrm{C}$ ), but it did include a diverse group of 13 models and 3 additional sensitivity tests. Hence it is noteworthy that the OCMIP-2 agreement remains with $\pm 22 \%$. The OCMIP-2 model range is also somewhat larger than that of 1.6 to $2.1 \mathrm{Pg} \mathrm{C} \mathrm{yr}^{-1}$ from OCMIP-1 [Orr et al., 2001b, 4 models] as would be expected. Finally, the OCMIP-2 range for the 1980's is also consistent with the IPCC's recent data-based assessment of $1.9 \pm 0.6 \mathrm{PgC} \mathrm{yr}^{-1}$ [Houghton et al., 2001, Chapter 3]. Unlike previous assessments, that Third Assessment Report (TAR) from WGl of the IPCC relied on changes in the observed atmospheric $\mathrm{O}_{2}$ budget (N.B. the complete IPCC TAR report is also available online at http:/www.ipcc.ch/pub/tar/wg 1/095.htm).

That Carbon Cycle chapter of the IPCC WG1 TAR report [Houghton et al., 2001, Chapter 3] also assessed the air-sea flux of anthropogenic $\mathrm{CO}_{2}$ for the 1990's. Again, the IPCC relied on changes in the atmospheric $\mathrm{O}_{2}$ budget. They concluded that the decadal mean air-sea flux had actually decreased from the 1980's to the 1990 's (from $1.9 \pm 0.6 \mathrm{PgC} \mathrm{yr}^{-1}$ to $1.7 \pm 0.5 \mathrm{Pg} \mathrm{Cyr}^{-1}$ ) despite an increase in atmospheric $\mathrm{CO}_{2}$. Conversely, the OCMIP-2 air-sea $\mathrm{CO}_{2}$ flux shows the opposite trend, a $24 \%$ increase to $2.38 \pm 0.53 \mathrm{Pg} \mathrm{C} \mathrm{yr}^{-1}$. But the IPCC S650 scenario that was used from 1990 onward, had atmospheric $\mathrm{CO}_{2}$ concentrations that were slightly higher than observed. Higher still were atmospheric $\mathrm{CO}_{2}$ concentrations in the C-IS92a simulations, which produced a 1990's mean of $2.55 \pm 0.56 \mathrm{Pg} \mathrm{C} \mathrm{yr}^{-1}$.

To correct for the differences in atmospheric $\mathrm{CO}_{2}$ during the 1990 's, the OCMIP2 modeling group from IPSL made one additional simulation, changing the atmospheric $\mathrm{CO}_{2}$ forcing during the 1990's to a spline fit through the observed record. We applied that change in global uptake to the other models, based on the consistent temporal trend between any two models (Table 1). That is, we multiplied the resulting IPSL model's 1990s: 1980s uptake ratio times each of the OCMIP-2 models mean uptake during the 1980 's from the historical run. The resulting corrected OCMIP-2 range for the $1990 \mathrm{~s}$ is $2.3 \pm 0.5 \mathrm{Pg} \mathrm{C} \mathrm{yr}^{-1}$. Our adjusted OCMIP-2 estimate for the 1990s is only slightly lower than the estimate for the same period with the $\mathrm{S} 650$ scenario $\left(2.38 \pm 0.53 \mathrm{Pg} \mathrm{Cyr}^{-1}\right)$. Therefore, the adjustment is small, and the OCMIP-2 results still predict an increase in the global ocean $\mathrm{CO}_{2}$ uptake between the 1980's and 1990's, in contradiction with Houghton et al. [2001, Chapter 3].

Furthermore, two independent studies by GOSAC modeling groups also suggest that the most recent IPCC assessment, based on atmospheric $\mathrm{O}_{2}$ and $\mathrm{CO}_{2}$, was susceptible to errors due to global warming, interannual variability, and volcanic eruptions [Plattner et al., 2001b; Bopp et al., 2001]. After correcting for these errors, both these studies also conclude that the most recent IPCC assessment is incorrect, and thus that the air-sea flux in the 1990's was larger than during the 1980's.

Several lines of evidence suggest that the GOSAC/OCMIP-2 range for the modern uptake of anthropogenic $\mathrm{CO}_{2}$ brackets real ocean uptake. First, such 

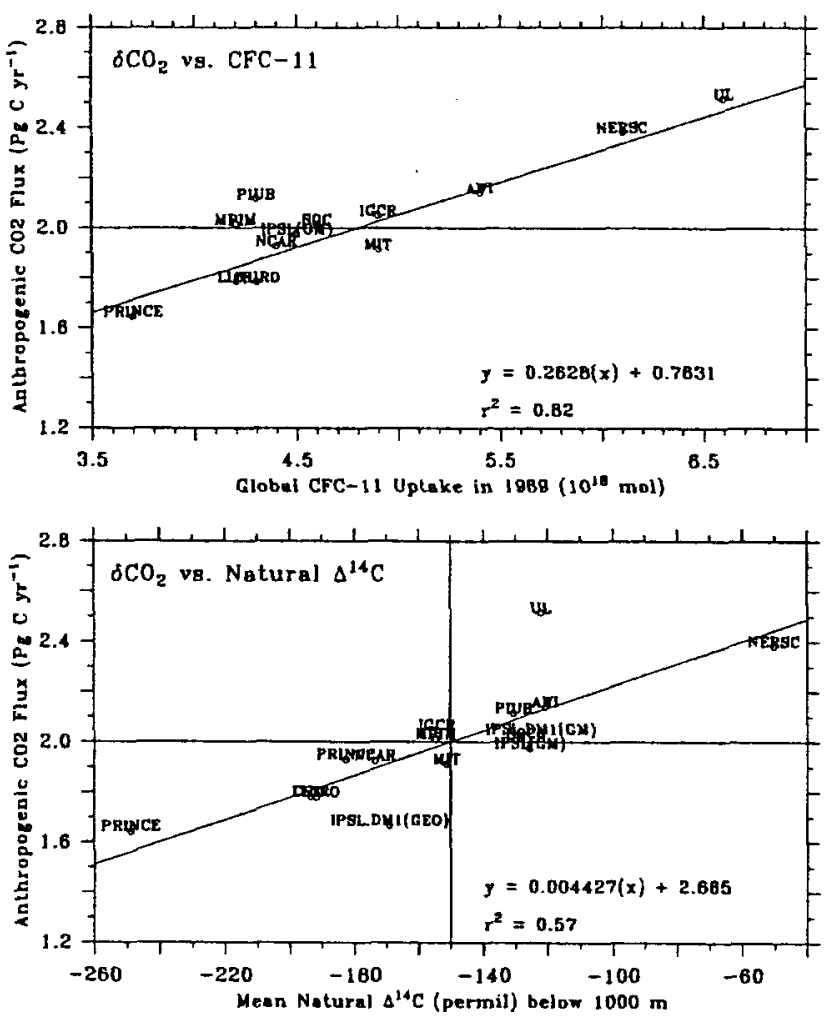

Figure 1.17: Correlation of the global anthropogenic $\mathrm{CO}_{2}$ ocean uptake with global ocean mean natural $\Delta^{14} \mathrm{C}$ and the global uptake of CFC-11.

would be the first expectation given the great diversity of models that participated in OCMIP-2. Second, from the OCMIP-2 model-data tracer evaluations we know

1. that the OCMIP-2 model range for the CFC-11 inventory brackets the real ocean inventory (e.g., see Fig. 1.2, and

2. that the OCMIP-2 models bracket the observed deep-ocean $\Delta^{14} \mathrm{C}$ (Fig. 1.5).

This independent tracer constraints is all the more relevant given that OCMIP-2 has also shown that both tracers show some correlation with global uptake of anthropogenic $\mathrm{CO}_{2}$ (Fig. 1.17). Finally, the OCMIP-2 range of global anthropogenic $\mathrm{CO}_{2}$ uptake brackets data-based estimates for the global inventory of anthropogenic $\mathrm{CO}_{2}$ (C. Sabine, U.S. OCMIP, pers. comm.).

Regional patterns of the modern uptake of anthropogenic $\mathrm{CO}_{2}$ are generally similar among the OCMIP-2 models. The Southem Ocean and the tropics exhibit the largest simulated uptake and the largest model disagreement (Fig. 1.18a); little uptake occurs in the subtropics. The limited area of extratropical northern latitudes permits only moderate uptake despite high area-specific fluxes in the North 
Atlantic. Most of the models simulate that much of the zonally integrated uptake occurs south of $30^{\circ} \mathrm{S}$, an area which occupies about one third of the surface of the entire ocean. Differences in simulated air-sea fluxes are due largely to the modeled exchange between surface and deeper waters, which are older and impoverished in anthropogenic $\mathrm{CO}_{2}$. Models differ in the location and magnitude of upwelling, convection, mode-water formation, and subduction, as exemplified by results from the OCMIP-2 CFC-11 comparison [Dutay et al., 2002].

Figure $1.18 \mathrm{~b}$ represents the storage of anthropogenic $\mathrm{CO}_{2}$, as the zonally integrated column integral. The meridional distribution of storage is smoother than that of uptake (air-sea flux) due to the effect of ocean mixing. All models store most of their anthropogenic $\mathrm{CO}_{2}$ in the subtropics (where uptake is lowest), and they store the least anthropogenic $\mathrm{CO}_{2}$ in the high latitudes and in the tropics (where uptake is highest). Differences in storage are largest south of $30^{\circ} \mathrm{S}$; conversely, north of $30^{\circ} \mathrm{S}$, simulated storage is surprisingly consistent among models despite differences in tropical and northern ocean air-sea fluxes. The OCMIP-2 models all show a consistent pattern of transport of anthropogenic $\mathrm{CO}_{2}$ from the high flux regions (high latitudes, tropics) to the low flux regions (subtropics) (Fig. 1.18c), presumably through the effect of wind-driven "Ekman" transport. However, the magnitude and sign of meridional transport differs substantially among the OCMIP-2 models (Fig. 1.18d). Most of the models suggest net northward transport for the global zonal bands south of $20^{\circ} \mathrm{N}$, and net southward transport for bands north of $20^{\circ} \mathrm{N}$. 


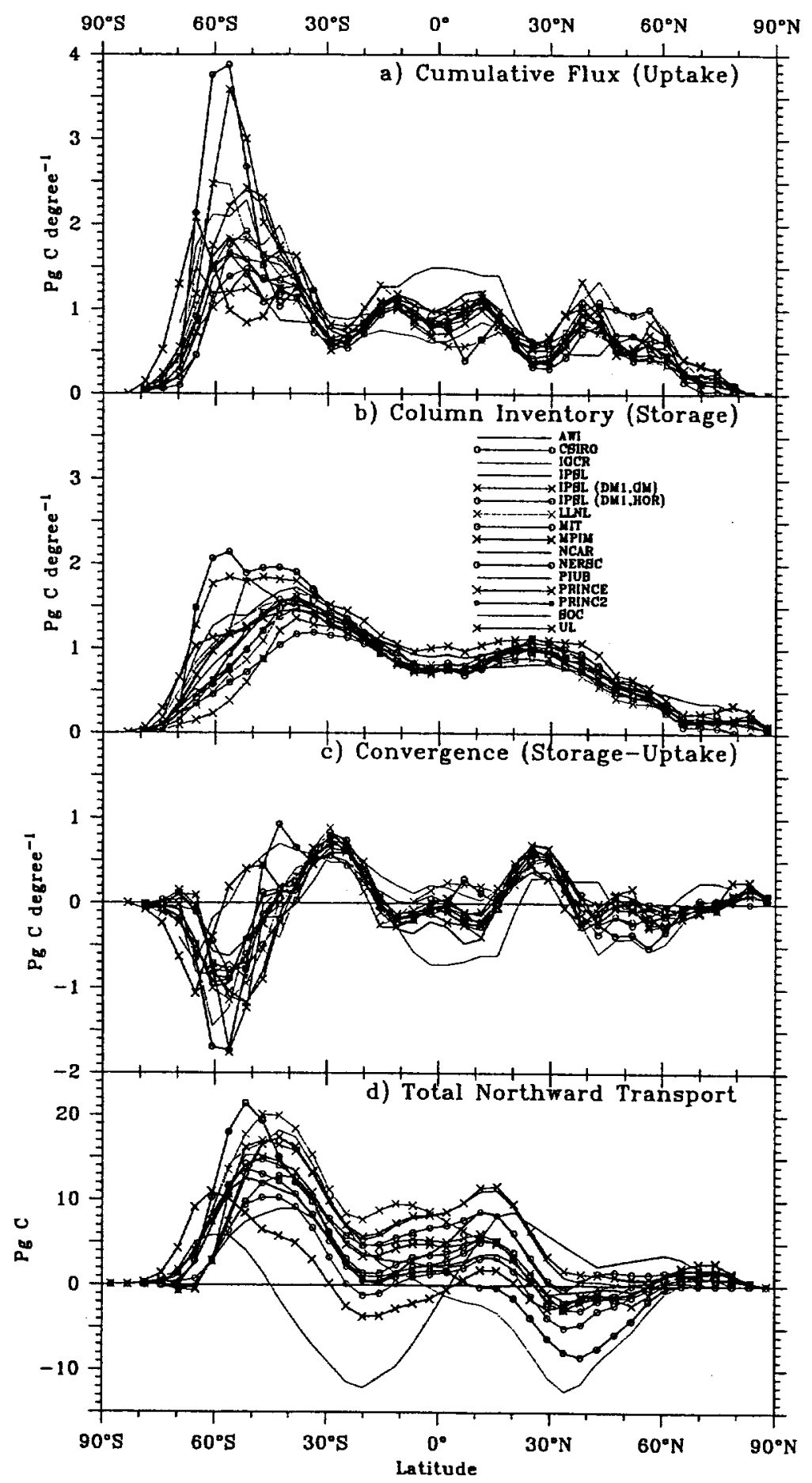

Figure 1.18: Zonally integrated, global, cumulative (a) UPTAKE, i.e., air-sea flux of anthropogenic $\mathrm{CO}_{2}$, (b) STORAGE, i.e., the inventory of anthropogenic carbon in the ocean (vertical column integral of the concentration), from 1765 to 1995, (c) CONVERGENCE of anthropogenic $\mathrm{CO}_{2}$, (i.e., (b) - (a)), and (d) northward TRANSPORT of anthropogenic $\mathrm{CO}_{2}$. 


\section{Future Anthropogenic $\mathrm{CO}_{2}$ Uptake:}

Throughout the historical period, all models agree to within $\pm 22 \%$ about the mean. In both future scenarios, agreement worsened (Fig. 1.19). In year 2100, agreement about the mean was $\pm 30 \%$ for the less severe $S 650$ scenario (where atmospheric $\mathrm{CO}_{2}$ was stabilized at $650 \mathrm{ppm}$ ) and $\pm 33 \%$ for scenario C-IS92a (where atmospheric $\mathrm{CO}_{2}$ reached $800 \mathrm{ppm}$ in 2100 ). For the longer $\mathrm{S} 650 \mathrm{run}$, model agreement remained near $\pm 30 \%$ throughout the rest of the run, reaching at most $\pm 33 \%$ in year 2200.

Model agreement improves noticeably when the high UL and the low PRINCE model estimates are neglected. Exclusion of these results appears justified based on the extreme behavior of these models in regards to their mean deep-ocean natural ${ }^{14} \mathrm{C}$ and $\mathrm{CFC}-11$ uptake (e.g., see Figs. 1.2, 1.5, 1.17). The remaining models agree to within $\pm 18 \%$ during the historical period. Agreement among the reduced set of models remains level at $\pm 18 \%$ through year 2100 , under both future scenarios; this contrasts with the worsening agreement found when all models were included in the analysis. Subsequently, in the $S 650$ run, agreement worsens slightly to $\pm 22 \%$ in 2200 then drops back to $\pm 21 \%$ in 2300 . In summary, the range of simulated uptake for the selected set of models differs substantially from that for the full set. The main reason is that the UL model exhibits up to $30 \%$ larger uptake than do the other models. 


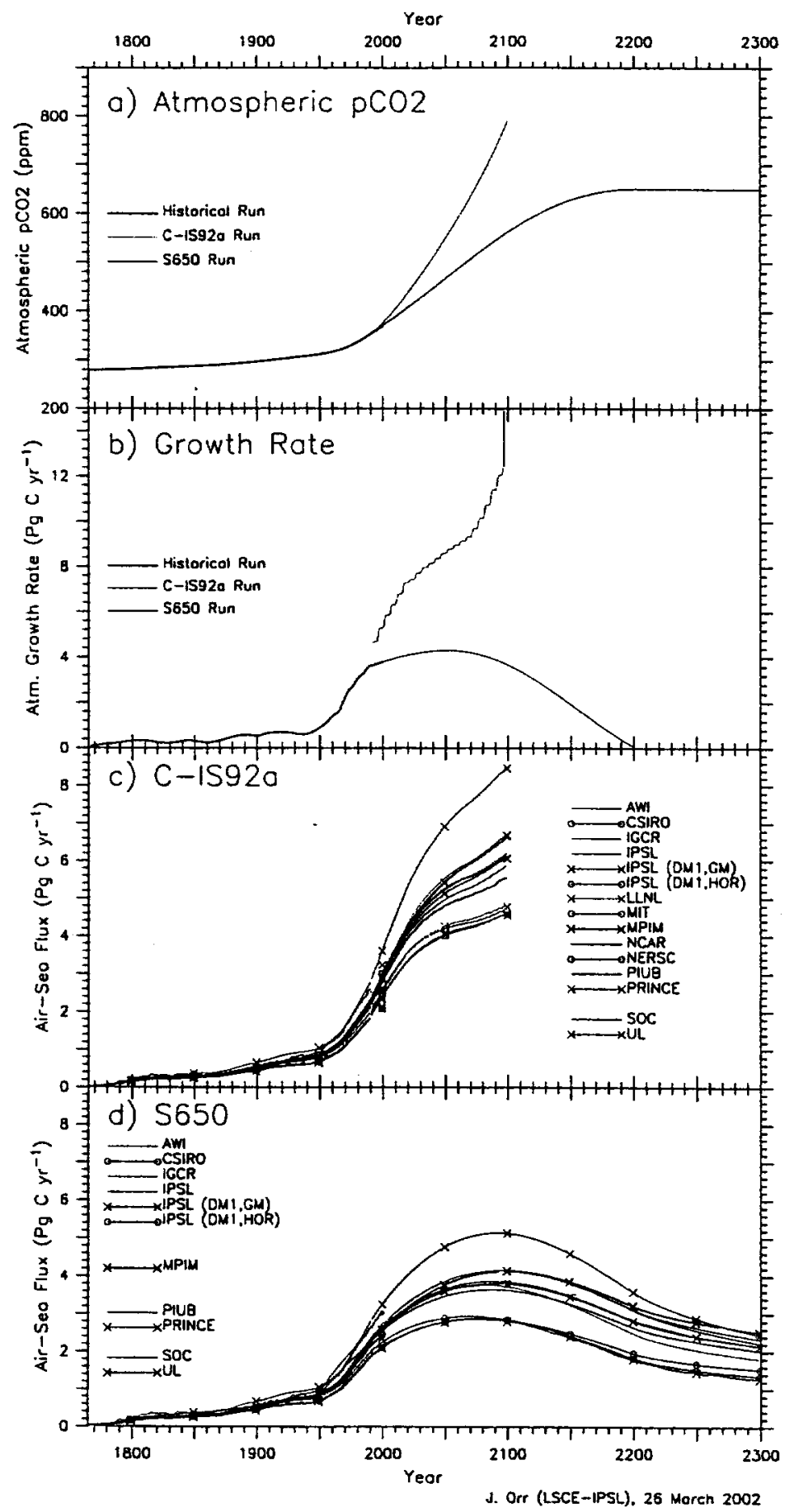

Figure 1.19: History of (a) atmospheric $\mathrm{CO}_{2}$, (b) its growth rate, (c) the resulting simulated ocean uptake of anthropogenic carbon for the historical run (forced by observed atmospheric $\mathrm{CO}_{2}$ during 1765 to 1990) + IPCC future scenario CIS92A (until 2100), and (d) the analogous ocean uptake when models are instead forced by IPCC scenario $\$ 650$ from 1990 to 2300 . 


\section{Injected $\mathrm{CO}_{2}$}

As one means to help mitigate rising levels of atmospheric $\mathrm{CO}_{2}$, it has been proposed to sequester $\mathrm{CO}_{2}$ generated by power plants in the deep ocean, instead of emitting it directly to the atmosphere [Marchetti, 1977] The efficiency of such deep-ocean sequestration remains an open question. Ocean modeling studies provide the only means to estimate ocean sequestration efficiency. If $\mathrm{CO}_{2}$ would be injected in the deep ocean, ocean circulation patterns would transport it typically quite far from the injection point before it would have a chance to reach the surface and be lost to the atmosphere through air-sea gas exchange. Such transport could require from centuries to a millennium, depending on the location of the injection point. Relatively simple 1-D vertical box models have been used to estimate the global efficiency of the ocean in retaining sequestered $\mathrm{CO}_{2}$ [Hoffert et al., 1979]. Such models instantly spread sequestered $\mathrm{CO}_{2}$ globally throughout a given deep-ocean layer and thus are not suitable for estimating the efficiency at different injection sites. Conversely, site-specific injection simulations can be made with 3-D ocean models. Such was done as part of GOSAC. Before this study only one 3-D model had been used to evaluate the efficiency of purposeful deep-ocean $\mathrm{CO}_{2}$ sequestration scenarios. In the first GOSAC simulations, designed to test the Injection HOWTO protocols, results were compared in two models at two sites: simulated efficiencies differed widely [Orr and Aumont, 1999]. Then GOSAC led a more extensive international effort to estimate both global and site-specific efficiencies. We made standard simulations in a eight of the OCMIP models. The GOSAC model comparison has provided a range of efficiency estimates.

\section{Injection Simulations:}

To conserve computing resources, the GOSAC injection protocol relied on two simplifications: model simulations neglected the influence of marine biota [Bacastow and Dewey, 1996; Orr and Aumont, 1999, a 5\% effect]; and simulations carried only 1 tracer, DIC. Thus we also ignored changes in alkalinity due to calcite dissolution, a negligible effect for these century-scale simulations [Archer et al., 1998]. With the standard fields of OCMIP-2 gas exchange, models were integrated to obtain preindustrial conditions (atmospheric $\mathrm{pCO}_{2}=278 \mathrm{ppm}$ ), then forced to follow observed atmospheric $\mathrm{CO}_{2}$ during 1765-2000. Subsequently during 2000-2500, models were forced to follow IPCC future scenario S650, which eventually stabilizes atmospheric $\mathrm{pCO}_{2}$ at $650 \mathrm{ppm}$. Injection occurred only during years 20002100 , with $0.1 \mathrm{Pg} \mathrm{C} \mathrm{yr}^{-1}$ being injected just offshore at each of seven sites (Bay of Biscay, Bombay, Jakarta, New York, Rio de Janeiro, San Francisco, and Tokyo).

For each injection simulation, we used ten separate DIC tracers: seven were used to track, individually, the seven DIC plumes extending from the seven injection sites; the three others were used to account for a control run, invasion of anthropogenic $\mathrm{CO}_{2}$, and a permanent sequestration scenario. Orr and Aumont [1999] found that nonlinearities due to this multi-tracer approach were negligible, 

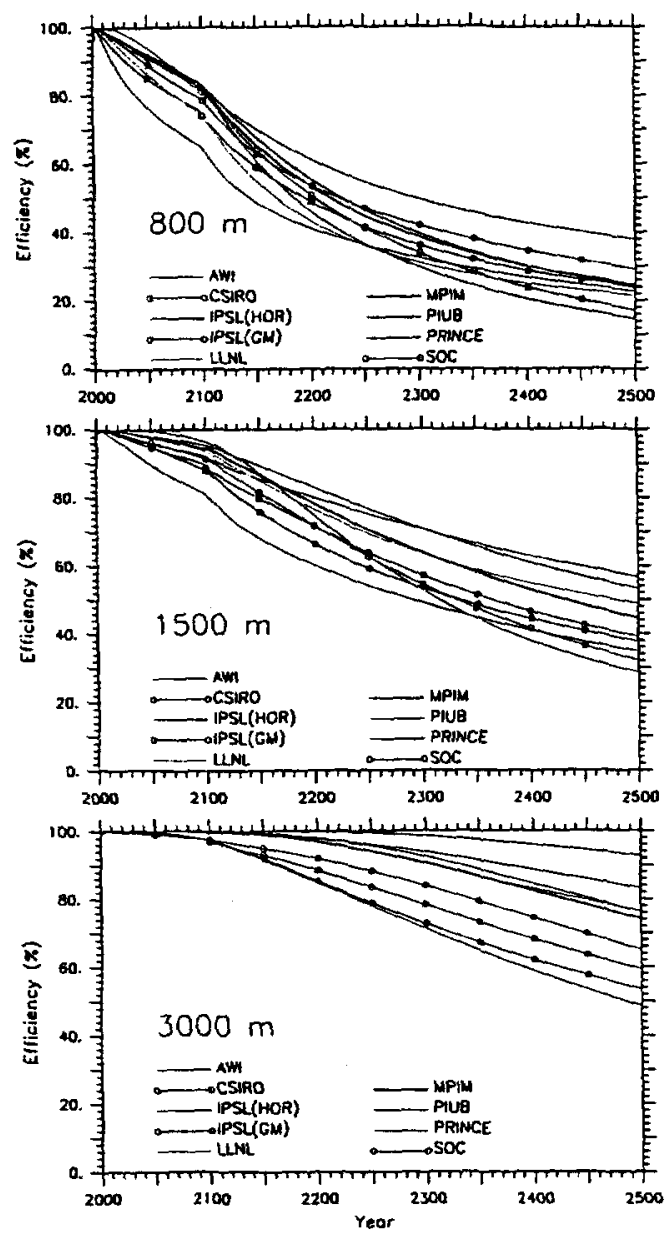

Figure 1.20: The Injection Efficiency $E i$ (the mass of injected $\mathrm{CO}_{2}$ that remains in the ocean / the total injected since the start of injection) for injection at (a) $800 \mathrm{~m}$, (b) 1500 $\mathrm{m}$, and (c) $3000 \mathrm{~m}$. The efficiency calculated in this way is useful to compare models that have all been forced to follow the same trajectory of atmospheric $\mathrm{CO}_{2}$ Efficiencies differ only due to leakage of injected $\mathrm{CO}_{2}$, not also due to different rates of ocean uptake of anthropogenic $\mathrm{CO}_{2}$ Conversely, earlier studies were interested in determining net benefit. In our test case study [Orr and Aumont, 1999], atmospheric $\mathrm{CO}_{2}$ was determined by a predefined emissions scenario and ocean air-sea $\mathrm{CO}_{2}$ fluxes were used instead of a predefined atmospheric $\mathrm{CO}_{2}$ trajectory. Efficiencies in the latter study were calculated as (1) the Total Efficiency Et (reduction in atmospheric $\mathrm{CO}_{2} /$ reduction in emissions) and (2) the Permanent Efficiency $E p$ (Total Efficiency / Total Efficiency for permanent sequestration). Our global efficiencies are not perfectly comparable. However our $E \dot{i}$ is similar in magnitude to their $E p$; and it is substantially larger than their $E t$. 

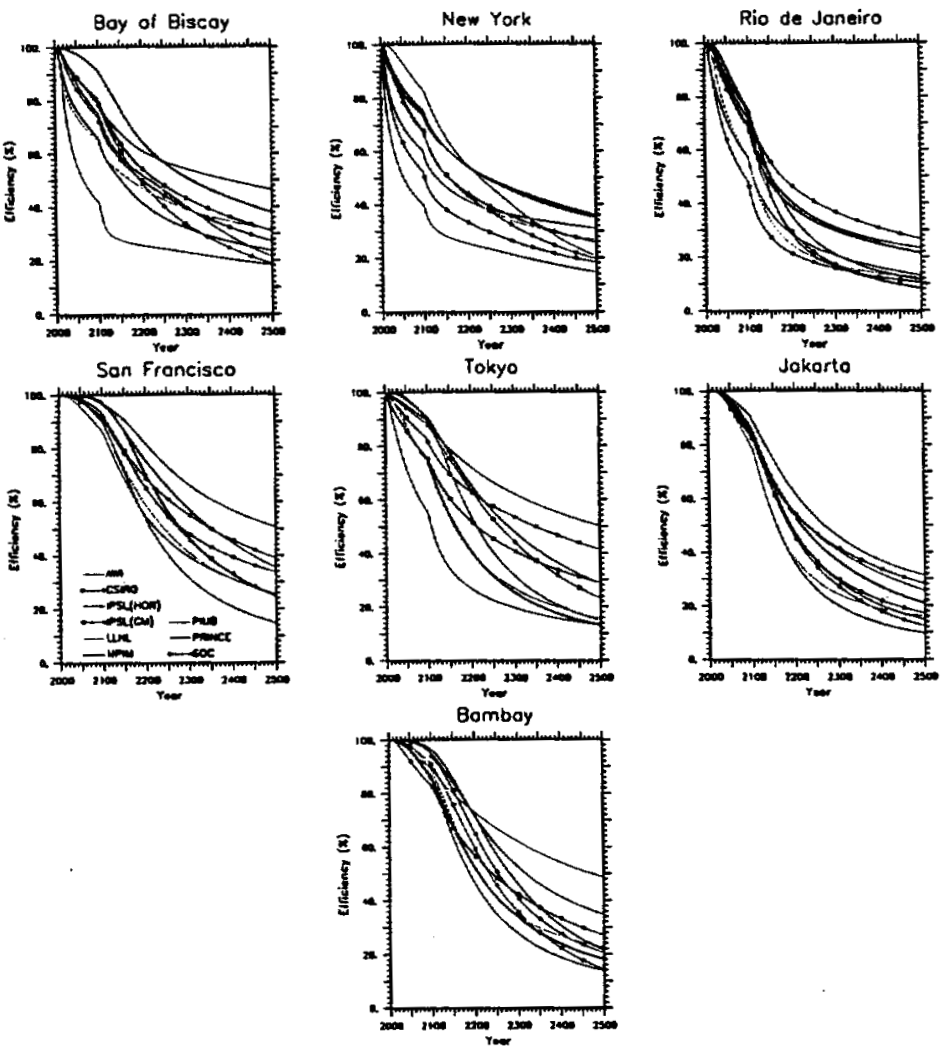

Figure 1.21: Injection efficiencies $E i$ for the $800-\mathrm{m}$ injection at each of the seven injection sites.

relative to a single-tracer approach. Detailed protocols, boundary conditions, and example code for making these simulations were produced for this study. They remain available as the Injection-HOWTO document (see the OCMIP Web page at http://www.ipsl.jussieu.fr/OCMIP).

\section{Injection Results:}

Simulations confirmed expectations that deeper injection is more efficient (Fig. 1.20). Injection at $3000 \mathrm{~m}$ is at least $85 \%$ efficient in all models in year 2200 (i.e., 100 years after the end of the 100-year injection period); at the same time, 1500 - $\mathrm{m}$ injection is $60-80 \%$ efficient and $800-\mathrm{m}$ injection is $42-61 \%$ efficient. A sensitivity test in the SOC model reveals that continuing injection after year 2100 increases global efficiency from $66 \%$ to $77 \%$ in 2200 and from $38 \%$ to $58 \%$ in 2500 .

Most of the models simulate that for the 1500-m injection, the Pacific (San Francisco, Tokyo) sites are more efficient than those in the Atlantic (New York, Bay of Biscay, and Rio de Janeiro), and that injection in the Indian Ocean yields 

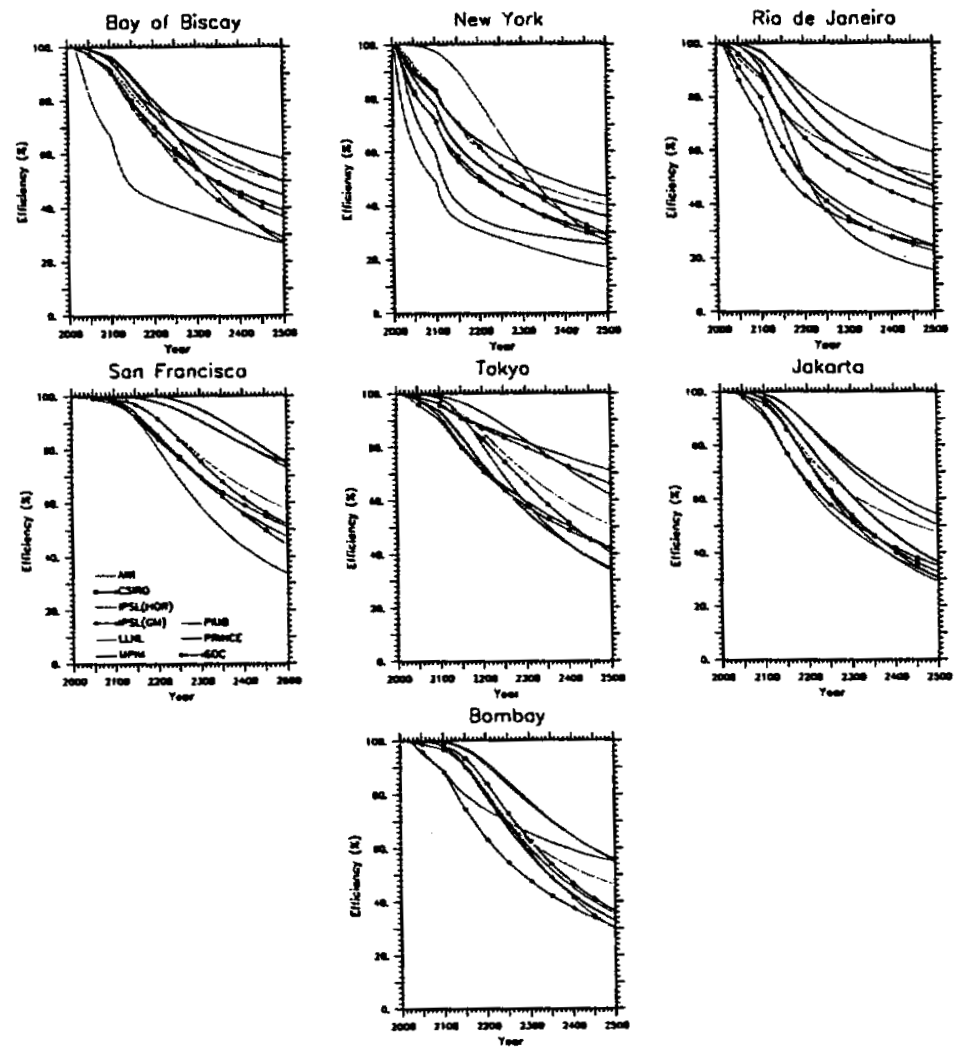

Figure 1.22: Injection efficiencies $E i$ for the $1500-\mathrm{m}$ injection at each of the seven injection sites.

intermediate efficiencies (Figs. 1.21, 1.22, and 1.23). All but the zonal-average model (PIUB) simulate that for the 1500-m injection, San Francisco is most efficient. Five of the eight of the models simulate that for the $1500-\mathrm{m}$ injection, New York is least efficient, and that much of what is injected there is transported northward and lost from the North Atlantic (Fig. 1.24).

Around half of $\mathrm{CO}_{2}$ from the $800-\mathrm{m}$ and $1500-\mathrm{m}$ injections is lost from the northern hemisphere, whereas most of $\mathrm{CO}_{2}$ from the $3000-\mathrm{m}$ injection is lost south of $30^{\circ} \mathrm{S}$ (Fig. 1.24). This is notable because five of the seven injection sites are located in the Northern Hemisphere. The effect of ocean mixing has, with time, nearly homogenized the distribution in the deep-ocean (compare to Fig. 1.26 and Fig. 1.27) enhancing loss from the Southern Ocean (Fig. 1.24), which dominates deep-water ventilation in all the models. Although the southern region occupies about $31 \%$ of the surface area of the global ocean, loss is enhanced there owing to generally more efficient exchange between the surface and deep ocean.

For the 3000-m injection, all sites were more efficient, and injection site effi- 

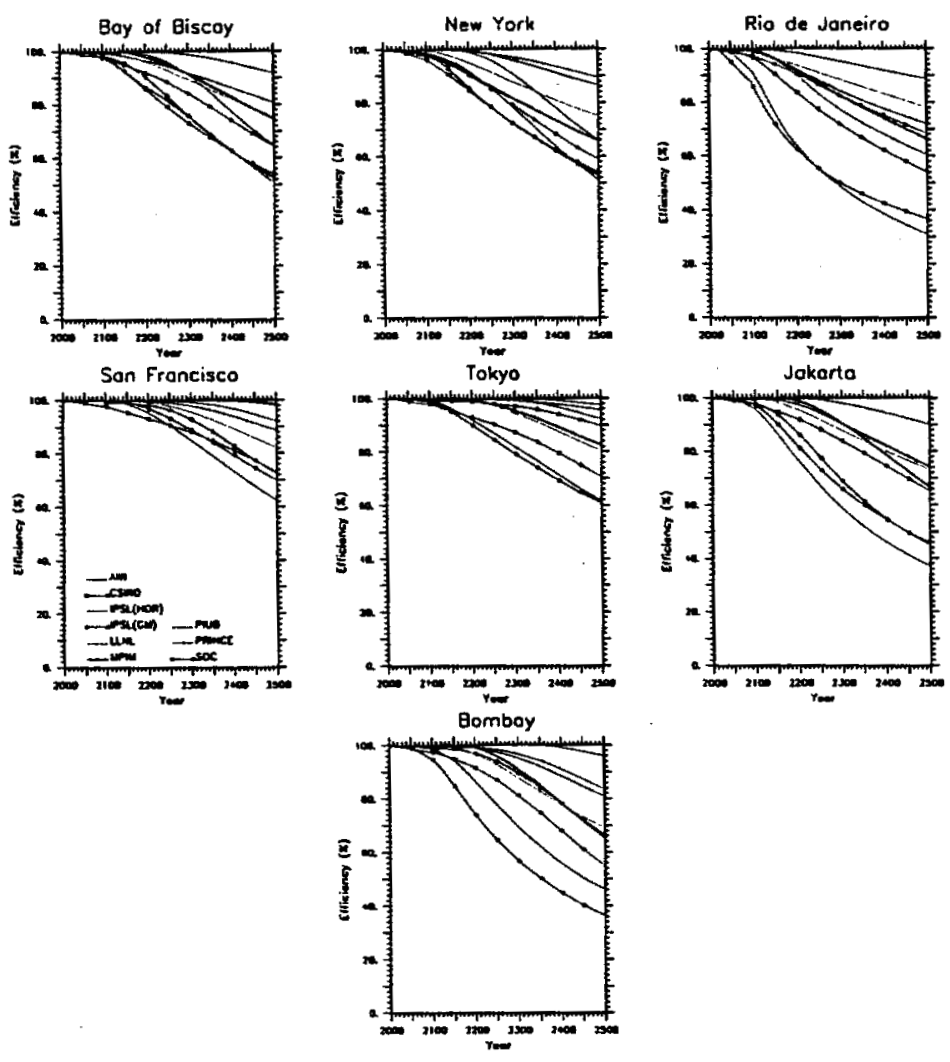

Figure 1.23: Injection efficiencies $E i$ for the $3000-\mathrm{m}$ injection at each of the seven injection sites.

ciencies were more tightly grouped for each model (Fig. 1.23). Western boundary sites (New York and Tokyo) improved more in efficiency relative to other sites. For injection at $3000 \mathrm{~m}$ off New York, less $\mathrm{CO}_{2}$ was able to escape from the North Atlantic. Instead more of it moves southward, along a longer pathway, for eventual loss from the Southern Ocean. All other sites in the $1500-\mathrm{m}$ and $3000-\mathrm{m}$ injection simulations lost most of their $\mathrm{CO}_{2}$ from the Southern Ocean (Fig. 1.24). Some of these results are described in Orr et al. [2001a]. 


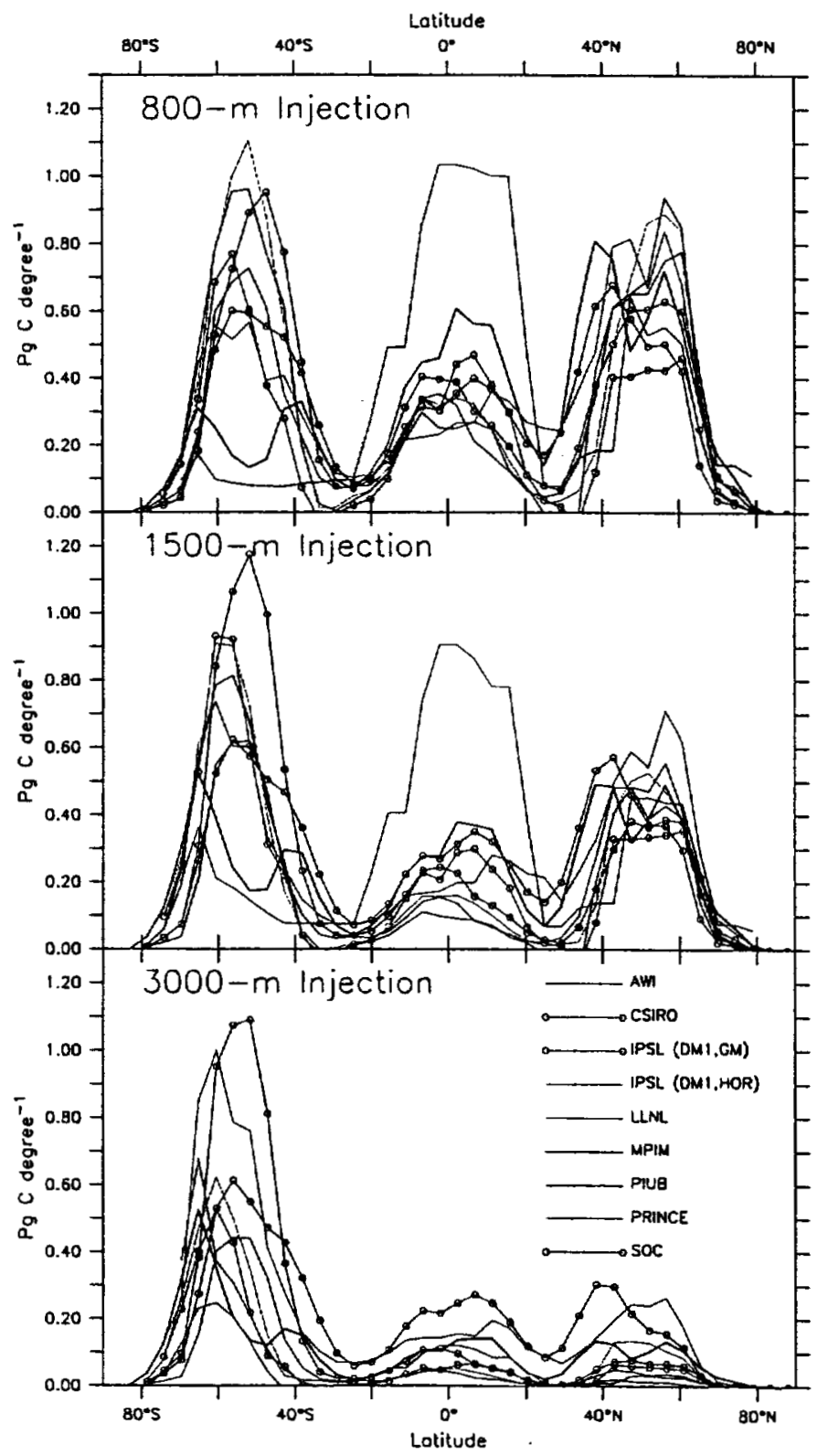

Figure 1.24: Zonal integral cumulative LOSS of injected $\mathrm{CO}_{2}$ (in $\mathrm{PgC}$ degree ${ }^{-1}$ ) from the ocean to the atmosphere by the end of the simulation (i.e., total lost during 2000-2500). 


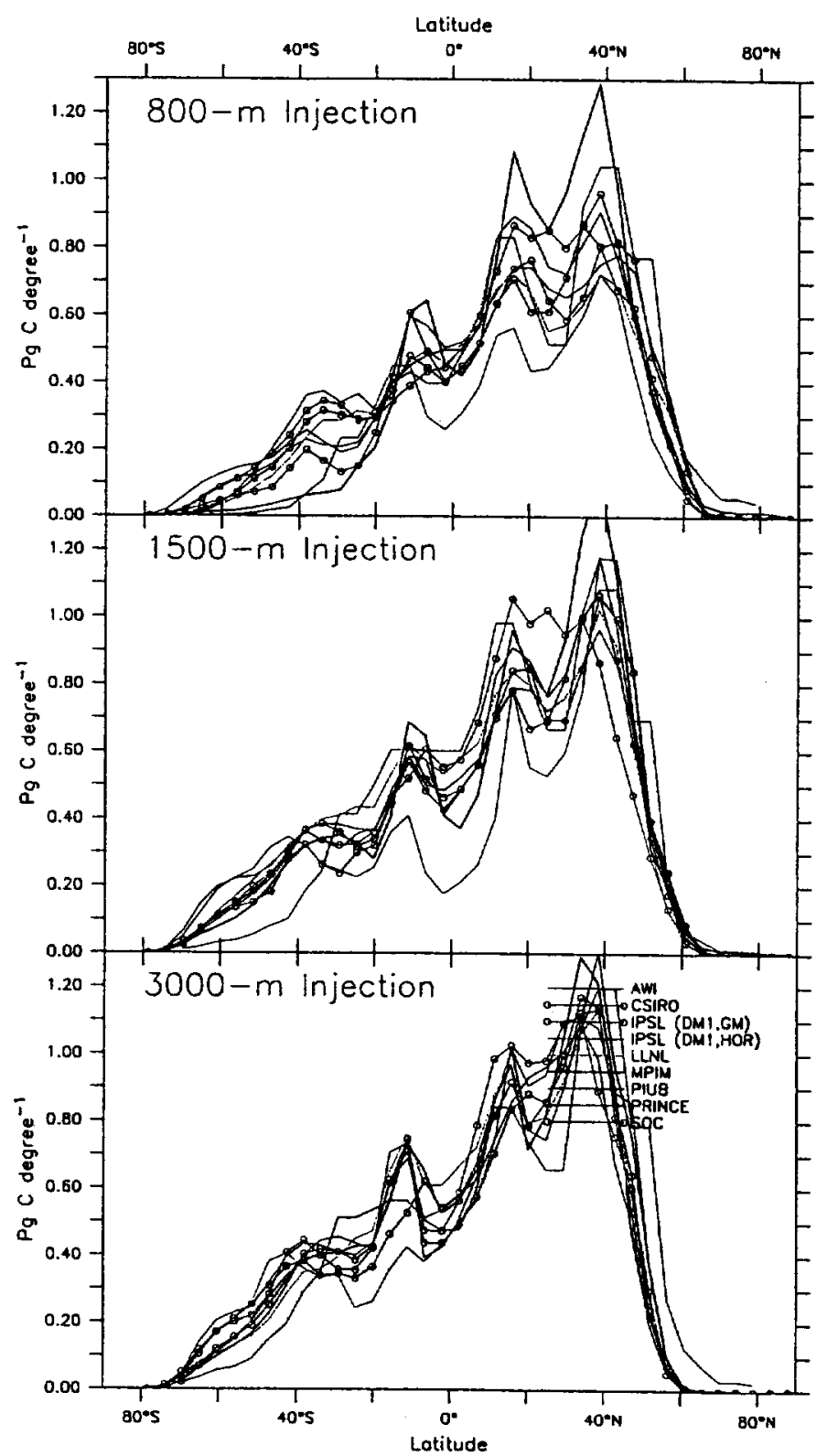

Figure 1.25: Zonal integral cumulative STORAGE of injected $\mathrm{CO}_{2}$ (column integral in $\mathrm{Pg} \mathrm{C}$ degree $^{-1}$ ) in year 2100 , in the last year of the 100 -year injection period. Relatively little of the injected $\mathrm{CO}_{2}$ has been lost from the $1500-\mathrm{m}$ and $3000-\mathrm{m}$ injection scenario. 


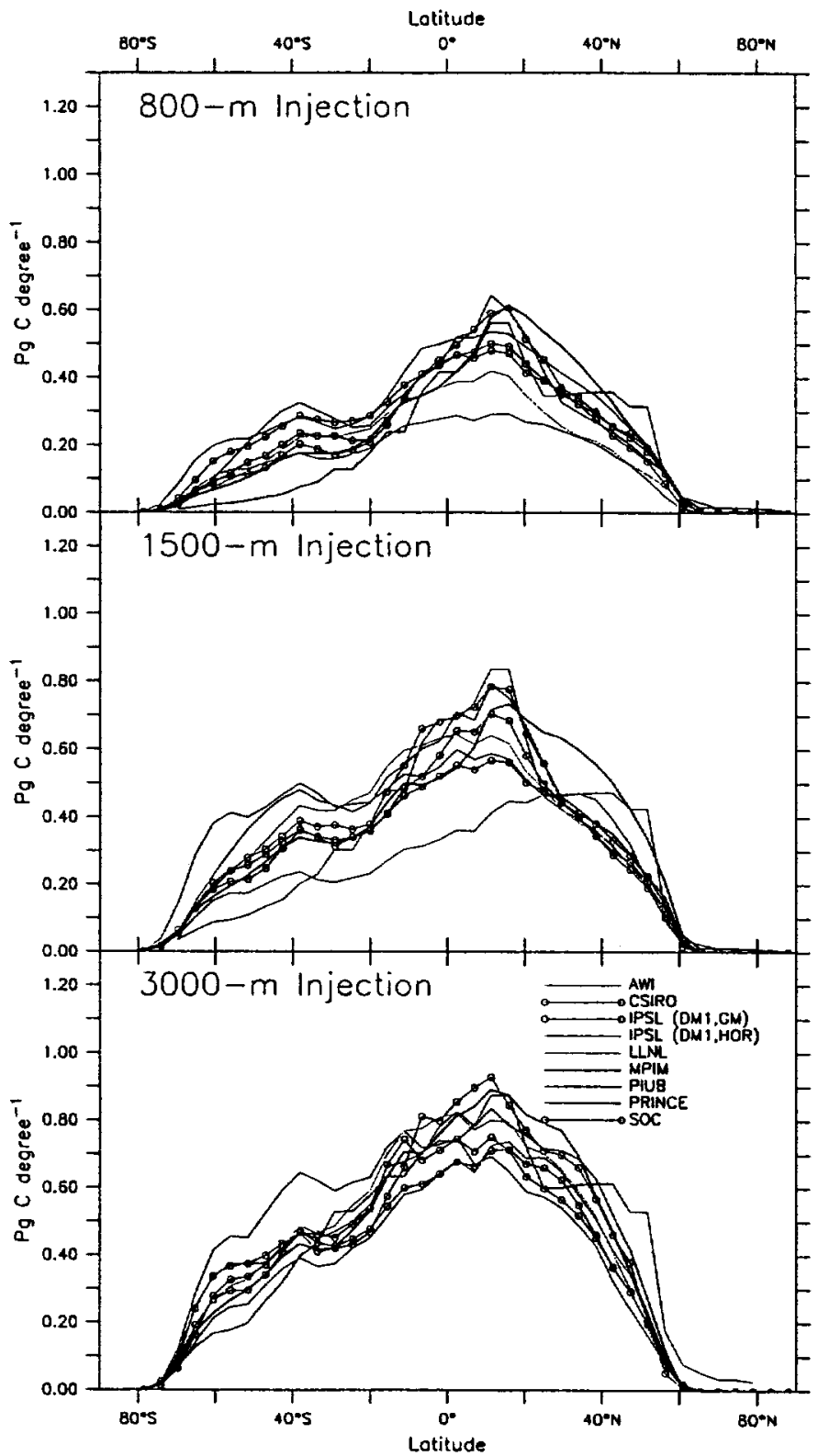

Figure 1.26: Zonal integral cumulative STORAGE of injected $\mathrm{CO}_{2}$ (column integral in $\mathrm{PgC}$ degree ${ }^{-1}$ ) in year 2200,100 years after the end of the 100 -year injection period. Relatively little of the injected $\mathrm{CO}_{2}$ has been lost from the 3000-m injection scenario. 


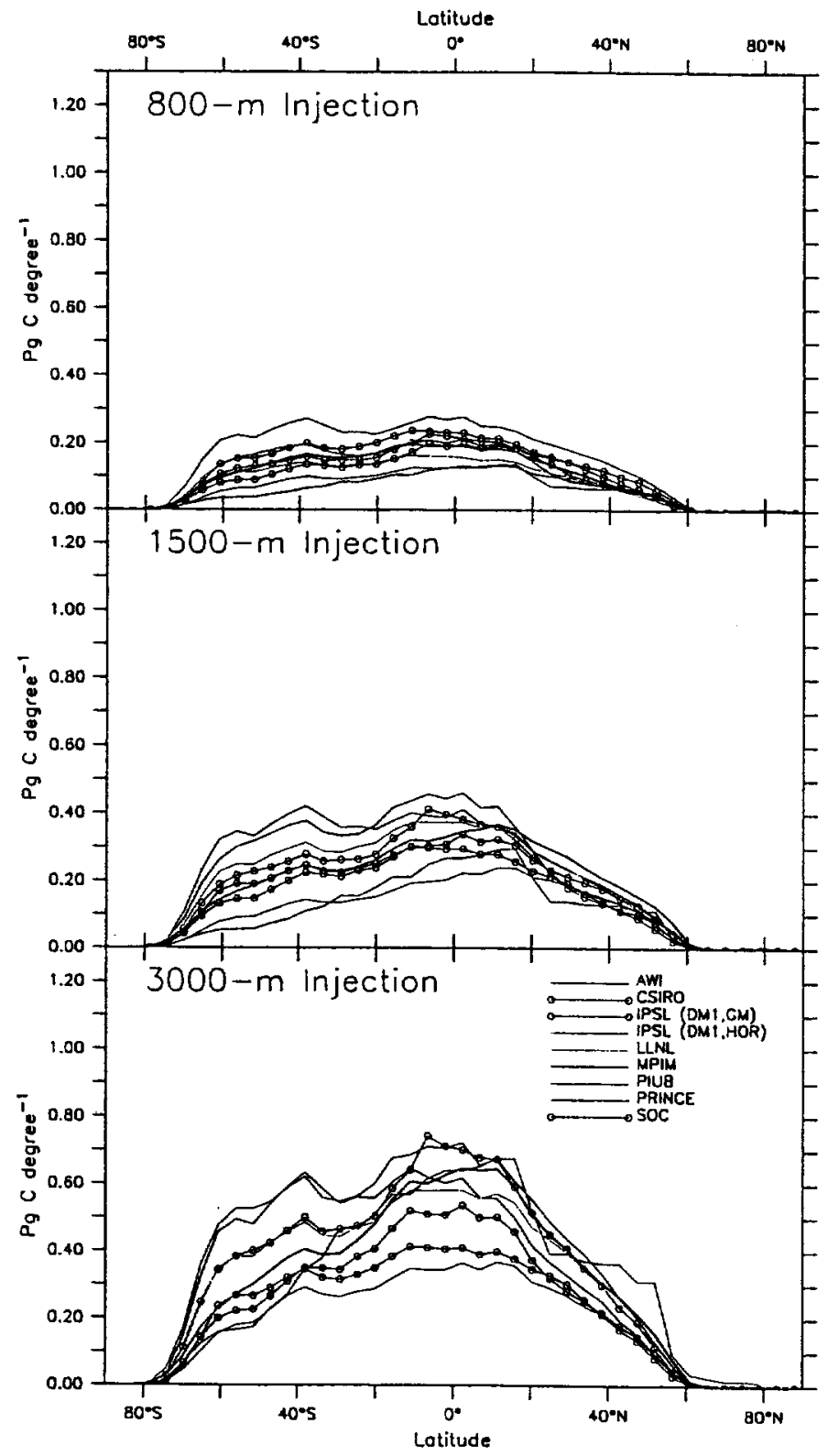

Figure 1.27: Zonal integral cumulative STORAGE of injected $\mathrm{CO}_{2}$ (column integral in $\mathrm{PgC}$ degree $^{-1}$ ) in year 2500 , i.e., the end of the simulation. 


\section{Evaluation of Injection Results:}

To evaluate model performance, we have recourse to constituents dissolved in seawater whose concentrations are affected by ocean circulation and for which there exist extensive measurements throughout the world ocean. These are commonly called tracers by the oceanographic community. If a model's simulated ocean tracer distribution corresponds reasonably well with measured distributions then we can lend more confidence to that model prediction. Conversely, if there is little correspondence, then that model's prediction is less likely to correspond with real ocean behavior. Radiocarbon is a useful ocean tracer because it has been measured throughout the ocean as the ${ }^{14} \mathrm{C} /{ }^{12} \mathrm{C}$ ratio (expressed in $\Delta$ notation, i.e., relative to the preindustrial atmosphere of $0 \% 0$ ). Its radioactive decay provides an estimate of the age of deep waters, which may be related to injection efficiency. As part of OCMIP, we compared simulations of natural $\triangle^{14} \mathrm{C}$ in the models with the global $\triangle{ }^{14} \mathrm{C}$ data set from WOCE and GEOSECS. Overall, the PRINCE model is characterized by deep waters which are too old, whereas the AWI model's deep ocean is too young. Furthermore, for the $3000-\mathrm{m}$ injection, there is some correlation between injection efficiency and the global mean deep-ocean natural ${ }^{14} \mathrm{C}$, i.e., below $1000 \mathrm{~m}$ (Fig. 1.28). Therefore these two extreme models would probably also bracket the real behavior of the global ocean, if purposeful $\mathrm{CO}_{2}$ injection were actually carried out under the same scenario at 3000-m. On the other hand, for the 800-m and 1500-m injections, there appears little or no relationship between their global injection efficiency and the mean deep-ocean ${ }^{14} \mathrm{C}$.

Surprisingly, there is strong correlation $\left(R^{2}=0.81\right)$ between the global inventory of CFC-11 and the global efficiency of the 3000-m injection (Fig. 1.28a). Furthermore, there is no correlation with the global CFC-11 inventory for 800$\mathrm{m}$ injection and only a slight correlation $\left(R^{2}=0.31\right)$ for the $1500-\mathrm{m}$ injection. Although, we expected to find some correlation with natural ${ }^{14} \mathrm{C}$, a tracer of deepocean circulation, $\mathrm{CFC}-11$ is a man-made transient tracer that only started being released to the atmosphere in the 1930's. The correlation of the 3000-m injection efficiency with the global uptake of CFC-11 $\left(R^{2}=0.81\right)$ is even stronger than it is for natural $\Delta^{14} \mathrm{C}\left(R^{2}=0.57\right)$. There appear at least two reasons why. One reason may be that the global subduction rate, which limits the rate of global ocean uptake of CFC-11, is equal and opposite to the global obduction rate, which probably limits loss to the atmosphere of $\mathrm{CO}_{2}$ injected into the deep ocean. Regionally this also makes sense because most of this CFC- 11 uptake and most of the loss of $\mathrm{CO}_{2}$ injected at $3000 \mathrm{~m}$ occur in the Southern Ocean. The second reason is that both CFC-11 and injected $\mathrm{CO}_{2}$ are transient tracers, and natural ${ }^{14} \mathrm{C}$ is not a transient tracer. The second reason by itself does not explain the increase in correlation with injection depth, but it does reinforce the first reason to help explain the better correlation of the 3000-m injection efficiency with CFC-11 than with natural $\Delta^{14} \mathrm{C}$.

As for observational constraints, the global mean $\triangle{ }^{14} \mathrm{C}$ below $1000 \mathrm{~m}$ is about $-150 \%$ based on the observed GEOSECS mean presented in Toggweiler et al. 

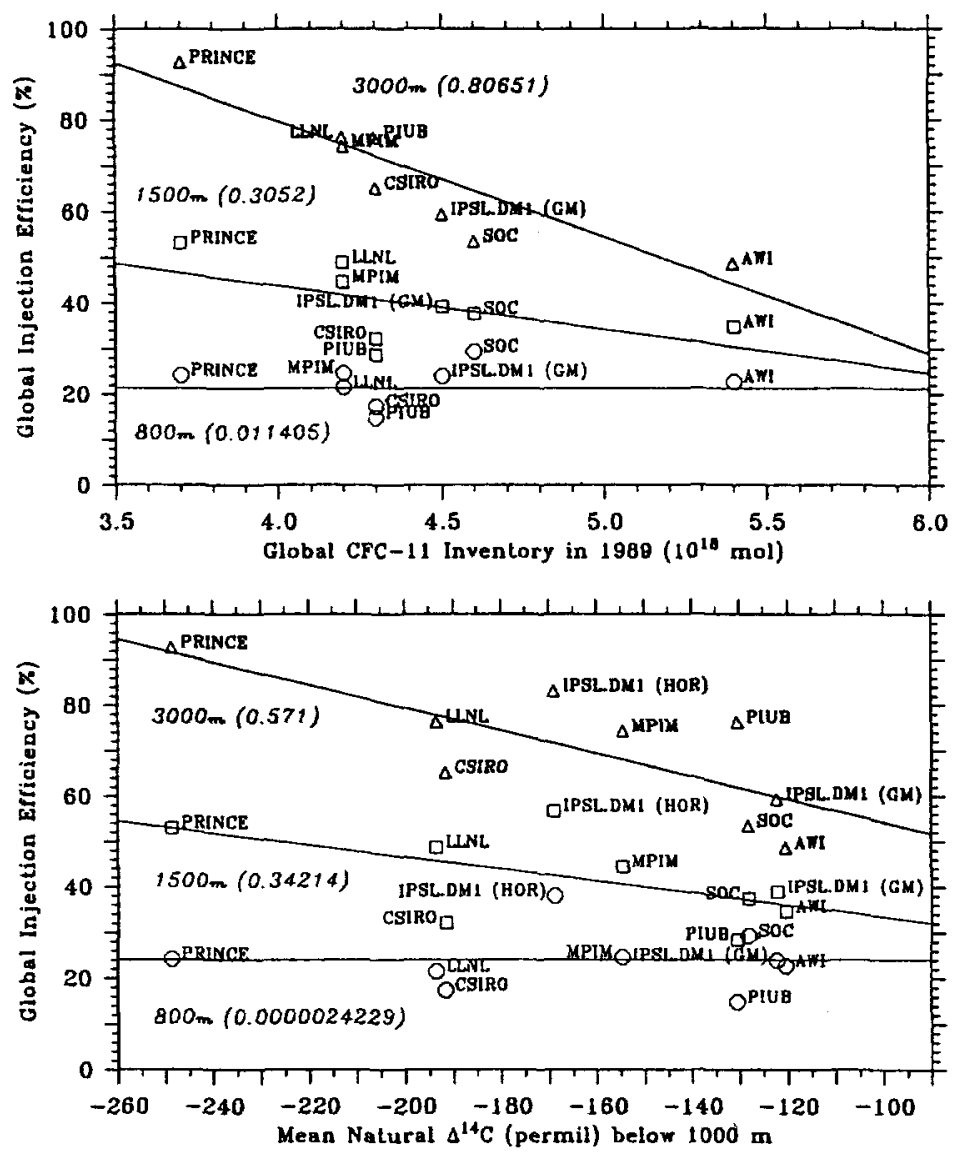

Figure 1.28: Comparison of the simulated global efficiencies in year 2499 for injection at $800 \mathrm{~m}$ (blue), $1500 \mathrm{~m}$ (red) and $3000 \mathrm{~m}$ (black) with simulated CFC-11 and $\Delta^{14} \mathrm{C}$. The top panel shows the correlation with the global ocean inventory of CFC-11 [Dutay et al., 2002]. The bottom panel shows correlation with the global mean $\Delta^{14} \mathrm{C}$ below $1000 \mathrm{~m}$ (weighted by volume). For both $\triangle^{14} \mathrm{C}$ and $\mathrm{CFC}-11$, there is good correlation for the 3000-m injection, little correlation for the $1500-\mathrm{m}$ injection, and no correlation for the $800-\mathrm{m}$ injection.

[1989]; the models clearly bracket $-150 \%$. There is not yet an observational constraint for the global inventory for CFC-11; however, the OCMIP-2 CFC-11 modeldata comparison along available sections suggests that the models also bracket the CFC-11 observations. Therefore based on these observational constraints from two tracers, the GOSAC/OCMIP-2 simulated efficiencies would be likely to bracket real ocean behavior given the same $3000-\mathrm{m}$ injection scenario. This argument is weaker for the $1500-\mathrm{m}$ injection, but it reinforces the suggestion that diversity of models is likely to produce a range of results that brackets real ocean behavior. For the $800-\mathrm{m}$ injection, model diversity appears to be the only argument. 
Another tracer which bears some qualitative resemblance to injected $\mathrm{CO}_{2}$ is Helium-3. This isotope is measured as the ${ }^{3} \mathrm{He} /{ }^{4} \mathrm{He}$ and reported in the classic $\delta$ notation, i.e., as $\delta^{3} \mathrm{He}$. As for ${ }^{14} \mathrm{C}$, WOCE has also helped to produce a global database for $\delta^{3} \mathrm{He}$. Oceanographic $\delta^{3} \mathrm{He}$ measurements offer an independent constraint to help characterize ocean circulation. As opposed to the relatively homogeneous sea-surface input of ${ }^{14} \mathrm{C},{ }^{3} \mathrm{He}$ is naturally injected at point sources in the deep ocean and is eventually lost to the atmosphere through air-sea gas exchange. Because of this qualitative similarity to injected $\mathrm{CO}_{2}, \mathrm{GOSAC}$ also made $\delta^{3} \mathrm{He}$ simulations and compared results to observations. 


\section{Helium-3}

The unique boundary condition of ${ }^{3} \mathrm{He}$, injection from the ocean floor, due to deepocean hydrothermal activity, means it has the potential to offer insight into deepocean circulation. For the GOSAC simulations, natural ${ }^{3} \mathrm{He}$ was injected along axes of mid-ocean ridges, with fluxes that were linearly proportional to observed spreading rates [Farley et al., 1995]. These authors were the first to make $\delta^{3} \mathrm{He}$

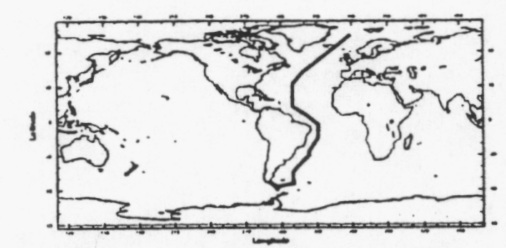

DATA

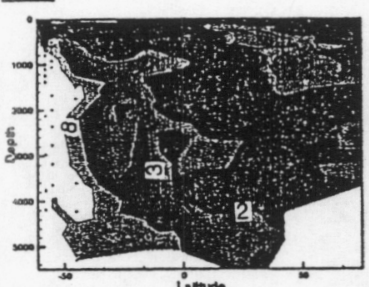

MPIM

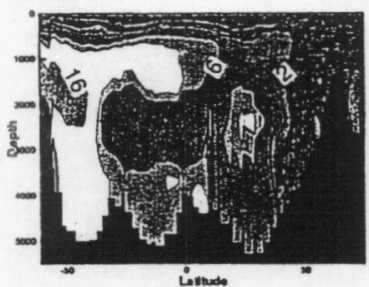

IPSL (HOA]

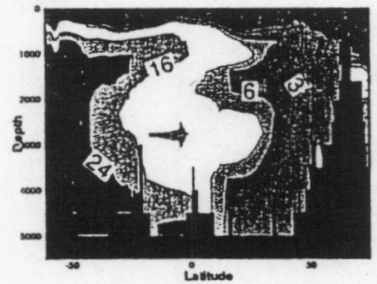

CSIRO

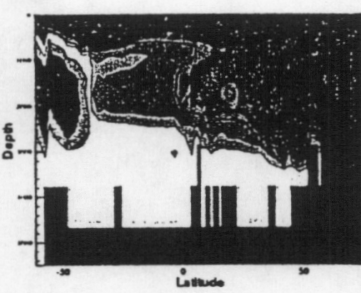

SOC

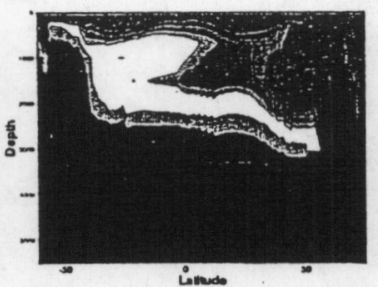

[IPSLIISO)

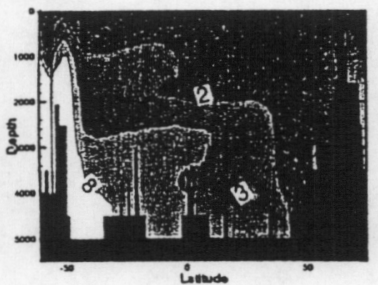

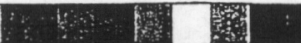

$022368 \quad 162432 \%$

IGCA

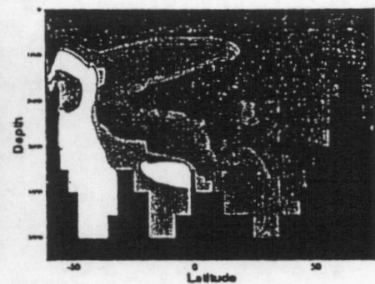

UL

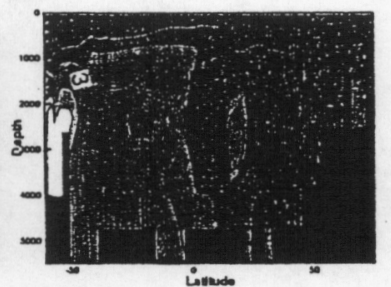

[PSLIGTI]

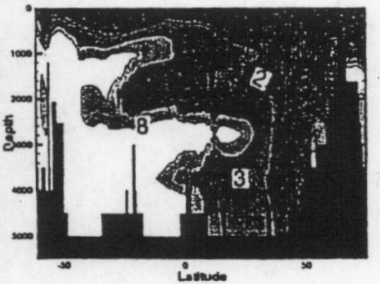

Figure 1.29: Observed vs. simulated $\delta^{3} \mathrm{He}$ along the Western Atlantic GEOSECS section.

simulations in a global ocean circulation model, a previous version of the MPIM model. They concluded that their boundary condition (basically the same approach that we used in GOSAC) was too simple because their simulations produced excessive ${ }^{3} \mathrm{He}$ concentrations in the Atlantic basin. To explore this possibility a little further, we made sensitivity studies in the IPSL model in addition to the standard 
comparison for GOSAC. One of our goals was to study if our simplified modeling approach was adequate to produce the large scale $\delta^{3} \mathrm{He}$ distribution in the Pacific, Indian, and Atlantic basins.

\section{$\delta^{3} \mathrm{He}$ in the West Atlantic:}

In the Western Atlantic, all the models exhibit some ventilation of the upper portion of NADW (Fig. 1.29. However, only two of the models simulate ${ }^{3} \mathrm{He}$ concentrations that are everywhere as low as the observations. The first of these is the UL model, which exhibits bottom water ${ }^{3} \mathrm{He}$ levels that are similar to the observations, even slightly lower for waters south of $20^{\circ} \mathrm{S}$. The second is the one of the sensitivity runs made with the IPSL model.

Those sensitivity tests also reveal that the modeled North Atlantic $\delta^{3} \mathrm{He}$ distribution is highly sensitive to a model's formulation for the sub-grid scale mixing. With lateral mixing oriented only along horizontal surfaces, the IPSL-HOR model's deep North Atlantic is too rich in ${ }^{3} \mathrm{He}$. The other extreme is the IPSLISO model, with lateral mixing oriented along density surfaces (isopycnals); its $\delta^{3} \mathrm{He}$ approaches that of the observations in the Upper North Atlantic Deep Water (UNADW, 1000-2500m). But deeper down, $\delta^{3} \mathrm{He}$ in IPSL-ISO remains too high, indicative of poor ventilation of IPSL-ISO's the Lower North Atlantic Deep Water (LNADW, $3000-4000 \mathrm{~m}$ ). Poor ventilation of LNADW is a characteristic shared by all the OCMIP forward models (Fig. 1.4). Furthermore including the more complex Gent and McWilliams [1990] parameterization in the IPSL model (IPSLGM) $\delta^{3} \mathrm{He}$ levels between the lower values of IPSL-ISO and the higher values than IPSL-HOR.

The near agreement of the UL and IPSL-ISO $\delta^{3} \mathrm{He}$ results with the observations indicates that it is possible to simulate reasonable levels of $\delta^{3} \mathrm{He}$ in the Atlantic basin, when using a simple boundary condition that is proportional to the ridge spreading rate [Farley et al., 1995]. However, that is not to say that such globally consistent formulation is correct for the Atlantic basin. On the contrary, we find from the OCMIP-2 tracer simulations that the UL model has excessive ventilation of the deep North Atlantic. basin. Natural $\Delta^{14} \mathrm{C}$ indicates that the UL model's deep Atlantic is much too young (Figs. 1.6 and 1.5). Furthermore, the UL CFC-11 in the deep western Atlantic is also excessive (Fig. 1.4. UL exhibits the highest global CFC-11 inventory of all the OCMIP-2 models (Fig. 1.17); it also exhibits the highest anthropogenic $\mathrm{CO}_{2}$ uptake. The IPSL-ISO model's success with simulating $\delta^{3} \mathrm{He}$ in the UNADW must also be tempered with knowledge of its skill in simulating natural ${ }^{14} \mathrm{C}$. This model also produces deep-ocean natural ${ }^{14} \mathrm{C}$ much younger even than the standard IPSL model, i.e., IPSL-GM which is shown in Figure 1.6. 

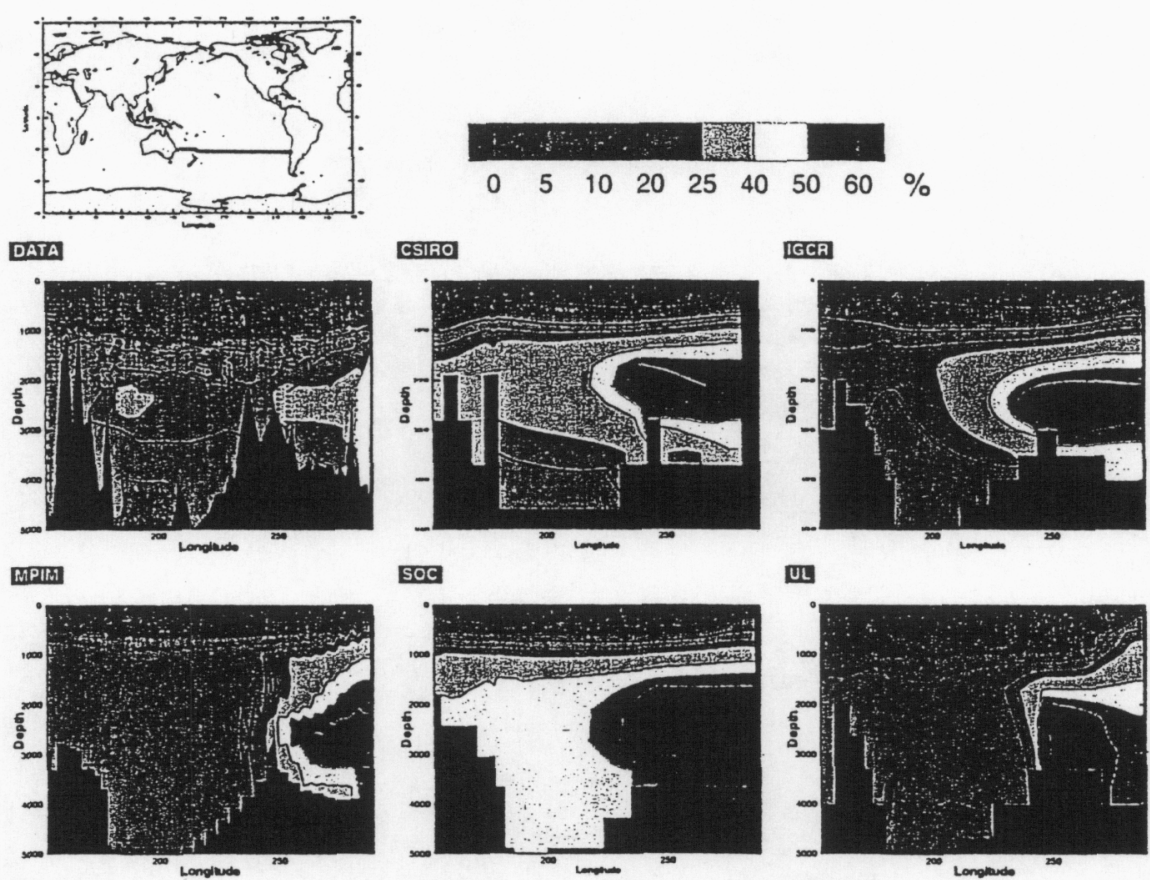

sod

UU
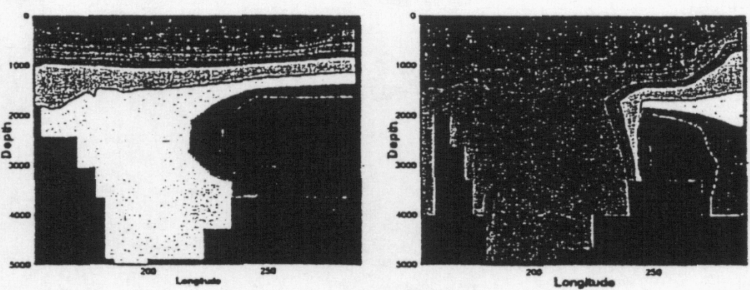

[IPSL[ISO]
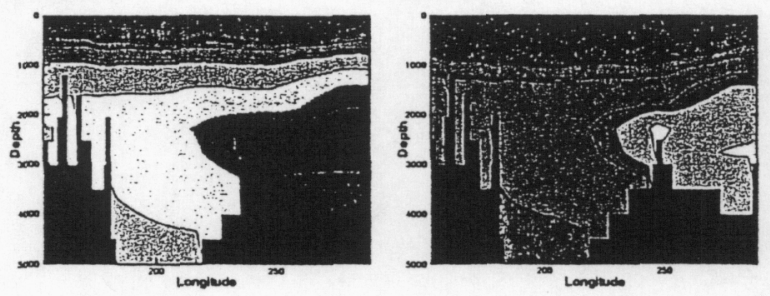

[PSLI(GMI)

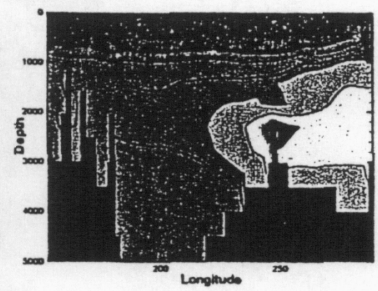

Figure 1.30: Observed vs. simulated $\delta^{3} \mathrm{He}$ on WOCE section P6 in the Pacific Ocean at $32^{\circ} \mathrm{S}$.

\section{$\delta^{3} \mathrm{He}$ in the South Pacific (WOCE P6):}

As an example of the GOSAC evaluation of the large-scale distribution of $\delta^{3} \mathrm{He}$, Figure 1.30 shows the model data comparison for the WOCE P6 section along $32^{\circ} \mathrm{S}$ in the Pacific. Overall, simulated patterns of $\delta^{3} \mathrm{He}$ in the GOSAC/OCMIP-2 models appear somewhat similar to the data. However, simulated $\delta^{3} \mathrm{He}$ levels in the eastern basin are generally too large. Results are qualitatively similar to the natural $\Delta^{14} \mathrm{C}$ along the same section (Fig. 1.10), i.e., we see generally similar patterns. However, there is little similarity concerning the systematically high $\delta^{3} \mathrm{He}$ signature in the eastern basin. Furthermore, the magnitude of $\delta^{3} \mathrm{He}$ in the models is generally too high. If the ${ }^{3} \mathrm{He}$ source function is correct, a general excess of 
$\delta^{3} \mathrm{He}$ would suggest that simulated deep-ocean circulation or ventilation was systematically too sluggish. Conversely, natural ${ }^{14} \mathrm{C}$, with its better-known boundary condition, indicates that none of the models involved in the ${ }^{3} \mathrm{He}$ comparison have deep waters that are much older than those in the real ocean. The overall correlation between $\delta^{3} \mathrm{He}$ and natural $\triangle^{14} \mathrm{C}$ requires further exploration. It is currently being investigated as a continuation project of OCMIP-2. This work should help improve our understanding of the source function used to drive such $\delta^{3} \mathrm{He}$ simulations. 


\section{References}

Archer, D., H. S. Kheshgi, and E. Maier-Reimer, Dynamics of fossil fuel $\mathrm{CO}_{2}$ neutralization by marine $\mathrm{CaCO}_{3}$, Global Biogeochem. Cycles, 12, 259-276, 1998.

Aumont, O., J. C. Orr, D. Jamous, P. Monfray, O. Marti, and G. Madec, A degradation approach to accelerate simulations to steady state in a 3-D tracer transport model of the global ocean, Clim. Dyn., 14, 101-116, 1998.

Aumont, O., J. C. Orr, P. Monfray, W. Ludwig, P. Amiotte-Suchet, and J.-L. Probst, Riverine-driven interhemispheric transport of carbon, Global Biogeochem. Cycles, 15, 2001.

Bacastow, R. B. and R. K. Dewey, Effectiveness of $\mathrm{CO}_{2}$ sequestration in the postindustrial ocean, Energy Convers. Mgmt., 37, 1079-1086, 1996.

Bopp, L., C. L. Quere, M. Heimann, and P. Monfray, Oceanic oxygen outgassing with climate change: Implications for the carbon budget, in IGBP Open Science Conference, Amsterdam, Poster in Session: Recent developments in Basin- to Global-Scale Ocean Carbon Cycle Modeling, 2001.

Broecker, W. S. and T.-H. Peng, Interhemispheric transport of carbon dioxide by ocean circulation, Nature, 356, 587-589, 1992.

Broecker, W. S., S. Sutherland, W. Smethie, T.-H. Peng, and G. Östlund, Oceanic radiocarbon: Separation of the natural and bomb components, Global Biogeochem. Cycles, 9, 263-288, 1995.

Dutay, J.-C., J. Bullister, S. C. Doney, J. C. Orr, R. G. Najjar, K. Caldeira, J.-M. Campin, H. Drange, M. Follows, Y. Gao, N. Gruber, M. W. Hecht, A. Ishida, F. Joos, K. Lindsay, G. Madec, E. Maier-Reimer, J. C. Marshall, R. Matear, P. Monfray, A. Mouchet, G. K. Plattner, J. L. Sarmiento, R. Schlitzer, R. D. Slater, I. J. Totterdell, M.-F. Weirig, Y. Yamanaka, and A. Yool, Evaluation of ocean model ventilation with CFC-11: Comparison of 13 global ocean models, Ocean Modelling, 4(2), 89-120, 2002.

Farley, K. A., E. Maier-Reimer, P. Schlosser, and W. S. Broecker, Constraints on mantle ${ }^{3} \mathrm{He}$ fluxes and deep-sea circulation from an oceanic general circulation model, J. Geophys. Res., 100(B3), 3829-3839, 1995.

Gent, P. R. and J. C. McWilliams, Isopycnal mixing in ocean circulation models, J. Phys. Oceanogr., 20, 150-155, 1990.

Hoffert, M. I., Y.-C. Wey, A. J. Callegari, and W. S. Broecker, Atmospheric repsonse to deep-sea injections of fossil-fuel carbon dioxide, Climatic Change, $2,53-68,1979$. 
Houghton, J. T., Y. Ding, D. J. Griggs, M. Noguer, P. J. van der Linden, X. Dai, K. Maskell, and C. A. Johnson, editors, Climate Change 2001: the Scientific Basis, Cambridge University Press, Port Chester, NY, 2001.

Keeling, R. F. and T.-H. Peng, Transport of heat, $\mathrm{O}_{2}$, and $\mathrm{CO}_{2}$ byt the atlantic's thermohaline circulation, Philos. Trans. R. Soc. London, Ser. B, 348, 133142, 1995.

Key, R. M., Early results from the WOCE radiocarbon program, in TYKKI Workshop, Tokyo, Japan, Japan Science and Technology Agency, 1998.

Marchetti, C., On geoengineering and the $\mathrm{CO}_{2}$ problem, Clim. Change, 1, 59-68, 1977.

Orr, J. C., Accord between ocean models predicting uptake of anthropogenic $\mathrm{CO}_{2}$, Water, Air, Soil Pollut., 70, 465-481, 1993.

Orr, J. C. and O. Aumont, Exploring the capacity of the ocean to retain artificially sequestered $\mathrm{CO}_{2}$, in Greenhouse Gas Control Technologies, edited by B. Eliasson, P. Reimer, and A. Wokaun, pp. 281-286, Elsevier Science Ltd., 1999.

Or, J. C., O. Aumont, A. Yool, K. Plattner, F. Joos, E. Maier-Reimer, M.-F. Weirig, R. Schlitzer, K. Caldeira, M. Wickett, and R. Matear, Ocean $\mathrm{CO}_{2}$ sequestration efficiency from 3-D ocean model comparison, in Proceedings of the Fifth Int. Conf. on Greenhouse Gas Control Technologies, pp. 469-474, CSIRO, $2001 a$.

Orr, J. C., P. Monfray, E. Maier-Reimer, U. Mikolajewicz, J. Palmer, N. K. Taylor, J. R. Toggweiler, J. L. Sarmiento, C. L. Quéré, N. Gruber, C. L. Sabine, R. M. Key, and J. Boutin, Estimates of anthropogenic carbon uptake from four three-dimensionsal global ocean models, Global Biogeochem. Cycles, $15(1), 43-60,2001 b$.

Plattner, G.-K., F. Joos, and T. F. Stocker, Revision of the global carbon budget due to changing air-sea oxygen fluxes, Global Biogeochem. Cycles, submitted, 2001.

Sarmiento, J. L., P. Monfray, E. Maier-Reimer, O. Aumont, R. Murnane, and J. C. Orr, Sea-air $\mathrm{CO}_{2}$ fluxes and carbon transport: A comparison of three ocean general circulation models, Global Biogeochem. Cycles, 14(4), 1267-1281, 2000.

Schimel, D., I. G. Enting, M. Heimann, T. M. L. Wigley, D. Raynaud, D. Alves, and U. Siegenthaler, $\mathrm{CO}_{2}$ and the carbon cycle, in Climate Change 1994, edited by J. T. Houghton, L. G. M. Filho, H. L. J. Bruce, B. A. Callander, E. Haites, N. Harris, and K. Maskell, pp. 35-71, Press Synd. of Univ. of Cambridge, Cambridge, England, 1995. 
Siegenthaler, U. and J. L. Sarmiento, Atmospheric carbon dioxide and the ocean, Nature, 365, 119-125, 1993.

Takahashi, T., S. C. Sutherland, C. Sweeney, A. Poisson, N. Metzl, B. Tilbrook, N. Bates, R. H. Wanninkhof, R. A. Feely, C. Sabine, J. Olafsson, and Y. Noriji, Global sea-air $\mathrm{CO}_{2}$ flux based on climatological surface ocean $\mathrm{pCO}_{2}$ and seasonal biological and temperature effects, Deep-Sea Res., in press, 2002.

Takahashi, T., R. H. Wanninkhof, R. A. Feely, R. F. Weiss, D. W. Chipman, N. Bates, J. Olafsson, C. Sabine, and S. C. Sutherland, Net sea-air $\mathrm{CO}_{2}$ flux over the global oceans: an improved estimate based on the sea-air $\mathrm{pCO}_{2}$ difference, in paper presented at 2nd International Symposium, $\mathrm{CO}_{2}$ in the Oceans-the 12th Global Environment, pp. 9-15, Tsukuba, Japan, Cent. Global Env. Res., N. Inst. Env. Stud., 1999.

Taylor, K. E., Summarizing multiple aspects of model performance in single diagram, J. Geophys. Res., 106, 2001.

Toggweiler, J. R., K. Dixon, and K. Bryan, Simulations of radiocarbon in a coarse resolution world ocean model 1 . Steady state prebomb distributions, J. Geophys. Res., 94, 8217-8242, 1989.

Volk, T. and M. I. Hoffert, Ocean carbon pumps: analysis of relative strengths and efficiencies in ocean-driven atmospheric $\mathrm{CO}_{2}$ changes, in The Carbon Cycle and Atmospheric $\mathrm{CO}_{2}$ : Natural Variations Archean to present, edited by E. T. S. gnd W. S. Broecker, volume 32 of Geophysical Monograph series, pp. 99-110, AGU, Washington, 1985.

Wanninkhof, R., Relationship between wind speed and gas exchange over the ocean, J. Geophys. Res., 97, 7373-7382, 1992.

Watson, R. T., H. Rodhe, H. Oeschger, and U. Siegenthaler, Greenhouse gases and aerosols, in Climate Change. The IPCC Scientific Assessment, edited by J. T. Houghton, G. J. Jeankins, and J. J. Ephraums, pp. 1-40, Cambridge Univ. Press, New York, 1990. 


\section{Individual Reports}




\subsection{Partner 1: IPSL (LSCE and LODyC)}

PI: Dr. James Orr

Contributors: Dr. Olivier Aumont, Mr. Patrick Brockmann, Dr. J.Cl. Dutay, Dr. Gurvan Madec, Dr. Patrick Monfray Dr. Anne Stoens

\section{Introduction}

IPSL is a consortium of seven French laboratories, of which LSCE and LODyC are members. For GOSAC, the LODyC is a Subcontractor to LSCE. The LODyC helps in running and interpreting results predicted by the IPSL circulation model (OPA), which was built at LODyC. The IPSL coordinated GOSAC and OCMIP-2 and has led the centralized "base" analysis as well as development of the analysis tools.

\section{Model description}

For OCMIP-2 simulations we use a 3-D tracer transport model (i.e., an offline model) driven by dynamic fields of advection and turbulence determined from a global version of the ocean general circulation model (OGCM) developed at LODyC. The online OGCM uses the code known as OPA, i.e., Océan Parallelisé [Chartier, 1985; Andrich, 1988; Madec and Crépon, 1991; Madec et al., 1991a; Madec et al., 1991b; Blanke and Delecluse, 1993]. The first global version is described by Marti [1992]; more recent developments have been detailed by Delecluse [1994], Madec and Imbard [1996], and [Aumont et al., 1999a].

The offline model, originally constructed by Marti [1992] from OPA5, has been modified to be consistent with OPA8. OPA uses a $C$ grid [Arakawa, 1972]. Vertically, there are 30 layers, varying from $10 \mathrm{~m}$ at the surface to about $500 \mathrm{~m}$ at depth. Horizontal resolution averages $1.5^{\circ} \times 2.0^{\circ}$, but is not rectangular in the northem hemisphere. The grid's northern singularity is pushed over Asia, out of the computational domain [Madec and Imbard, 1996]. This approach allows larger grid spacing in the north, thereby permitting longer time steps without resorting to Fourier filtering and its inherent problems. The contorted grid is orthogonal and defined such that OPA maintains numerical accuracy to the second order [Marti et al., 1992; Madec and Imbard, 1996].

OPA was forced semi-diagnostically in order to make simulations practical. That is, potential temperature $(\theta)$ and salinity $(S)$ are restored to seasonal observations [Levitus, 1982] throughout the water column over much of the ocean. Yet Toggweiler et al. [1989] show that comparable robust-diagnostic forcing in their global version of the Bryan and Cox [1972] model results in a deep ocean circulation which is everywhere too sluggish, as seen with their simulations for natural ${ }^{14} \mathrm{C}$. We have not found the same results for for OPA [Aumont et al., 1998]. In their robust-diagnostic simulation, Toggweiler et al. [1989] restore $\theta$ and $S$ throughout the water column, everywhere, with a time constant of $50 \mathrm{yr}$; with the semi- 
diagnostic approach for OPA7, $\theta$ and $S$ are forced toward the observations with a time constant of $1 \mathrm{yr}$. Furthermore OPA is prognostic in the mixed layer and the equator [Fujio and Imasato, 1991]. Finally, restoring in OPA is likewise relaxed in the high latitudes (where data is sparse) and horizontally within $1000 \mathrm{~km}$ of any land-ocean boundary (at all levels).

Vertical turbulence is determined prognostically via the Turbulent Kinetic Energy (TKE) model [Gaspar et al., 1990] which was modified for implantation into OPA by Blanke and Delecluse [1993]. TKE is computed from heat fluxes and wind stress at the surface; at depth it is inversely related to the Brünt-Vaisaila frequency (water column stability). Horizontally, eddy diffusion of tracers is defined a priori, with an explicit diffusion coefficient of $2000 \mathrm{~m}^{2} \mathrm{~s}^{-1}$.

The active tracers $\theta$ and $S$ are advected in the online model according to the 2nd order accurate CTCS (centered-in-time, centered-in-space) scheme. Offline simulations of passive tracers such as $\mathrm{CO}_{2}$ are normally made with the MPDATA scheme [Smolarkiewicz, 1982; Smolarkiewicz, 1983; Smolarkiewicz and Clark, 1986] implemented in OPA with two iterations to correct for numerical diffusion [Marti, 1992].

\section{Work completed}

Like the other GOSAC model groups, IPSL has

1. participated in discussing simulations protocols;

2. adapted our model to make the standard GOSAC/OCMIP-2 simulations;

3. made the CFC, Biotic, Abiotic, Biotic, Injection, and $\mathrm{He}-3$ simulations (see Table 1.1);

4. submitted output from these standard simulations for centralized analysis and storage in the OCMIP-2 model output archive; and

5. participated in discussions and revisions of the published paper describing the OCMIP-2 CFC-11 comparison [Dutay et al,, 2002]. This paper involved all 13 OCMIP-2 modeling groups; the lead author is from IPSL/LSCE.

\section{As GOSAC coordinator, IPSL has also}

1. acted as the international OCMIP-2 coordinator, promoting interaction between GOSAC and other non-European OCMIP-2 members;

2. constructed and maintained the OCMIP web page at http://www/ipsl.jussieu.fr/OCMIP;

3. led development of the simulation protocols and related documents, for the CFC simulations, [Orr et al., 1999a], the Abiotic simulations (Equilibrium, Historical, Future, Pulse, and Control runs) [Orr et al., 1999b], the Biotic simulation (Equilibrium run) [Najjar and Orr, 1999], the Injection simulations (C800, C1500, C3000, and E1500 runs) [Aumont and Orr, 1999], and the $\delta^{3} \mathrm{He}$ simulation [Dutay et al., 2001c]; 
4. developed and released two stable versions of the GOSAC analysis package (GAP 1.0 and 2.0) to provide for centralized, consistent analysis for all model output;

5. built the OCMIP Model Output Database (MOD) from the standard model output of each of the 13 OCMIP modeling groups;

6. led centralized analysis of the CFC, Abiotic, Injection, and Helium simulations;

7. organized and led four international OCMIP meetings:

(a) the initial GOSAC/OCMIP-2 "kick-off" meeting (San Diego, February 1998),

(b) the 1st OCMIP-2 International Workshop (Gif-sur-Yvette, France, June, 1999),

(c) the 2nd International OCMIP-2 Workshop (Princeton, USA, July, 2000), and

(d) the Final OCMIP-2 Workshop (Amsterdam, June, 2001);

8. helped author oral presentations describing the results of OCMIP at international meetings [Aumont et al., 1999b; Dutay et al., 1999; Monfray et al., 1999; Orr, 1999b; Sabine et al., 1999; Brockmann et al., 2000; Orr et al., 2000];

9. held a special poster session devoted to OCMIP at the IGBP Open Science Conference in 2001 [Aumont et al., 2001b; Brockmann and Hankin, 2001; Dutay et al., 2001a; Dutay et al., 2001b; Gruber et al., 2001; Monfray et al., 2001; Naegler et al., 2001; Najjar et al., 2001; Orr et al., 2001 b; Orr et al., 2001 ; Orr et al., 2001c];

10. contributed Newsletter articles concerning OCMIP progress and results [Orr, 1997; Orr et al., 1997; Orr and Najjar, 1998; Orr, 1999c; Orr, 1999a; Orr and Dutay, 1999; Orr, 2001]; and

11. published the first papers describing OCMIP results [Dutay et al., 2002; Orr and Aumont, 1999; Orr, 1999d; Orr et al., 2001b; Orr et al., 2001a].

\section{Outlook}

Plans are that IPSL will continue to exploit the rich OCMIP-2 model output database that was generated during GOSAC. Also planned is a special OCMIP section in the journal Global Biogeochemical Cycles is planned, with submissions in May 2002 of final versions of 6 manuscripts from the OCMIP poster session mentioned above. 
Several additional GOSAC/OCMIP-2 papers will be submitted this year in a planned special issue to Global Biogeochemical Cycles. Portions of the OCMIP2 data are available electronically and the full database should be available soon, once all quality control is completed.

\section{References}

Andrich, P., OPA - A multitasked Ocean General Circulation Model, Reference manual, LODyC, Université Paris VI, Paris, FRANCE, 1988.

Arakawa, A., Design of the UCLA general circulation model, numerical simulation of weather and climate, Technical Report 7, University of California, Dept. of Meteorology, 1972.

Aumont, O., J. Orr, P. Monfray, G. Madec, and E. Maier-Reimer, Nutrient trapping in the equatorial Pacific: the ocean circulation solution, Global Biogeochem. Cycles, 13, 351-370, 1999a.

Aumont, O. and J. C. Orr, Injection-HOWTO. Internal OCMIP Report, LSCE/CEA Saclay, Gif-sur-Yvette, France, 17 pp., 1999.

Aumont, O., J. C. Orr, D. Jamous, P. Monfray, O. Marti, and G. Madec, A degradation approach to accelerate simulations to steady state in a 3-D tracer transport model of the global ocean, Clim. Dyn., 14, 101-116, 1998.

Aumont, O., J. C. Orr, P. Monfray, W. Ludwig, P. Amiotte-Suchet, and J.-L. Probst, Riverine-driven interhemispheric transport of carbon, Global Biogeochem. Cycles, 15, 2001 a.

Aumont, O., J. C. Orr, P. Monfray, J. L. Sarmiento, R. Murnane, E. Maier-Reimer, W. Ludwig, and J. I Probst, The ocean's role in interhemispheric transport of carbon, in IUGG Meeting, pp. A252-A253, Birmingham, UK, $1999 b$.

Aumont, O., J. C. Orr, A. Yool, K. Plattner, F. Joos, E. Maier-Reimer, M.-F. Weirig, R. Schlitzer, K. Caldeira, M. Wickett, and R. Matear, Efficiency of purposeful co2 injection in the deep ocean: Comparison of seven ocean models, in IGBP Open Science Conference, Amsterdam, Poster in Session: Recent developments in Basin- to Global-Scale Ocean Carbon Cycle Modeling, $2001 b$.

Blanke, B. and P. Delecluse, Low frequency variability of the tropical Atlantic ocean simulated by a general circulation model with mixed layer physics, $J$. Phys. Oceanogr., 23, 1363-1388, 1993.

Brockmann, P., J. C. Or, O. Aumont, P. Monfray, R. G. Najjar, F. Louanchi, R. Schlitzer, M.-F. Weirig, R. J. Matear, A. Lenton, Y. Yamanaka, A. Ishida, K. Caldeira, M. Wickett, M. Follows, E. Maier-Reimer, K. Lindsay, 
S. C. Doney, G.-K. Plattner, F. Joos, T. F. Stocker, R. Slater, N. Gruber, J. Sarmiento, R. Key, A. Yool, and I. J. Totterdell, Constraining oceanic uptake of anthropogenic co2 through 3-d model-data comparison, in AGU Fall Meeting, EOS, volume 81(48), San Francisco, November 2000/Supplement, 2000.

Brockmann, P. and S. Hankin, Visualization, analysis, and comparison of climate models with data: a practical approach using Ferret and Tecplot, in IGBP Open Science Conference, Amsterdam, Poster in Session: Recent developments in Basin- to Global-Scale Ocean Carbon Cycle Modeling, 2001.

Bryan, K. and M. D. Cox, An approximate equation of state for numerical models of ocean circulation, J. Phys. Oceanogr., 2, 510-514, 1972.

Chartier, M., Un modèle numérique tridimensionnel aux équations primitives de la circulation générale de l'océan, Dissertation, Université Pierre et Marie Curie, CEA Report R-5372, 1985.

Delecluse, P., Modelling the ocean circulation, in Long-Term Climatic Variations, edited by J.-C. Duplessy and M. T. Spyridakis, NATO ASI I22, pp. 73-106, Springer-Verlag, Berlin, 1994.

Dutay, J.-C., J. Bullister, S. Doney, J. Orr, R. Najjar, K. Caldeira, J.-M. Campin, H. Drange, M. Follows, Y. Gao, N. Gruber, M. Hecht, A. Ishida, F. Joos, K. Lindsay, G. Madec, E.Maier-Reimer, J. Marshall, R. Matear, P. Monfray, A. Mouchet, G.-K. Plattner, J. Sarmiento, R. Schlitzer, R. Slater, I. Totterdell, M.-F. Weirig, Y. Yamanaka, and A. Yool, Evaluation of ocean model ventilation with CFC-11: comparison of 13 global ocean models, in IGBP Open Science Conference, Amsterdam, Poster in Session: Recent developments in Basin- to Global-Scale Ocean Carbon Cycle Modeling, $2001 a$.

Dutay, J.-C., J. Bullister, S. C. Doney, J. C. Or, R. G. Najjar, K. Caldeira, J.-M. Campin, H. Drange, M. Follows, Y. Gao, N. Gruber, M. W. Hecht, A. Ishida, F. Joos, K. Lindsay, G. Madec, E. Maier-Reimer, J. C. Marshall, R. Matear, P. Monfray, A. Mouchet, G. K. Plattner, J. L. Sarmiento, R. Schlitzer, R. D. Slater, I. J. Totterdell, M.-F. Weirig, Y. Yamanaka, and A. Yool, Evaluation of ocean model ventilation with CFC-11: Comparison of 13 global ocean models, Ocean Modelling, 4(2), 89-120, 2002.

Dutay, J.-C., J. Bullister, J. C. Orr, R. G. Najjar, M. Follows, R. Matear, S. Doney, E. Maier-Reimer, Y. Yamanaka, H. Drange, A. Yool, J.-M. Campin, M.-F. Weirig, N. Gruber, and K. Caldeira, Comparisons of simulations of CFC-11 and CFC-12 during OCMIP, in IUGG Meeting, p. A253, Birmingham, UK, 1999. 
Dutay, J.-C., P. Jean-Baptiste, J. Orr, and M.-F. Weirig, Feasibility study to simulate natural helium-3 during OCMIP-2, in IGBP Open Science Conference, Amsterdam, Poster in Session: Recent developments in Basin- to Global-Scale Ocean Carbon Cycle Modeling, $2001 b$.

Dutay, J.-C., M.-F. Weirig, P. Jean-Baptiste, E. Maier-Reimer, and J. Orr, Helium HOWTO. Internal OCMIP Report, LSCE/CEA Saclay, Gif-sur-Yvette, France, 11 pp., $2001 c$.

Fujio, S. and N. N. Imasato, Diagnostic calculation for circulation and water mass movement in the deep Pacific, J. Geophys. Res., 96, 759-774, 1991.

Gaspar, P., Y. Gregorius, and J.-M. Lefevre, A simple eddy kinetic energy model for simulations of oceanic vertical mixing tests at Station Papa and LongTerm Upper Ocean Study Site, J. Geophys. Res., 95, 16179-16193, 1990.

Gruber, N., J. Bullister, J.-C. Dutay, J. C. Orr, C. Sabine, and R. Slater, What the CFCs can tell us about the ocean uptake of anthropogenic $\mathrm{CO}_{2}$, in IGBP Open Science Conference, Amsterdam, Poster in Session: Recent developments in Basin- to Global-Scale Ocean Carbon Cycle Modeling, 2001.

Levitus, S., Climatological atlas of the world ocean, Prof. Pap. 13, Natl. Oceanic and Atmos. Admin., US Gov Printing Office, Washington DC, 1982.

Madec, G., M. Chartier, and M. Crépon, The effect of thermohaline forcing variability on deep water formation in the western Mediterranean Sea: a high resolution three-dimensional study, Dyn. Atmos. Ocean, 15, 301-332, 1991 a.

Madec, G., M. Chartier, P. Delecluse, and M. Crépon, A three-dimensional numerical study of deep water formation in the Northwestern Mediterranean Sea, $J$. Phys. Oceanogr., 21, 1349-1371, 19916.

Madec, G. and M. Crépon, Thermohaline-driven deep water formation in the Northwestern Mediterranean Sea, in Deep Convection and Deep Water Formation in the Oceans, edited by P. C. Chu and J. C. Gascard, pp. 241-265, Elsevier, 1991.

Madec, G. and M. Imbard, A global ocean mesh to overcome the North Pole singularity, Clim. Dyn., 12, 381-388, 1996.

Marti, O., Etude de l'océan mondial: Modélisation de la circulation et du transport des traceurs anthropiques, Ph.D. thesis, Université Paris VI, Paris, FRANCE, 1992.

Marti, O., G. Madec, and P. Delecluse, Comment on "Net diffusivity in ocean general circulation models with non uniform grids" by F.L. Yin and I. Y. Fung, J. Geophys. Res., 97, 12763-12766, 1992. 
Monfray, P., L. Bopp. C. Le Quéré, and J. C. Orr, Ocean carbon-cycle simulations of global change and interannual variability: Future emphasis for OCMIP, in IUGG Meeting, p. A253, Birmingham, UK, 1999.

Monfray, P., J. C. Or, O. Aumont, Y. Yool, I. Totterdell, K. Plattner, F. Joos, E. Maier-Reimer, M.-F. Weirig, R. Schlitzer, A. Ishida, Y. Yamanaka, S. C. Doney, K. Lindsay, I. L. Sarmiento, R. D. Slater, R. G. Najjar, F. Louanchi, and $\mathrm{X}$. Jin, Air-sea fluxes and north-south ocean transport of $\mathrm{CO}_{2}$ and $\mathrm{O}_{2}: \mathrm{Re}-$ sults from the Ocean Carbon-Cycle Model Intercomparison Project, in IGBP Open Science Conference, Amsterdam, Poster in Session: Recent developments in Basin- to Global-Scale Ocean Carbon Cycle Modeling, 2001.

Naegler, T., P. Ciais, P. Bousquet, P. Peylin, M. Ramonet, J. C. Orr, and N. Metzl, Evaluation of ocean carbon cycje models and delta $\mathrm{pCO}_{2} 2$ maps for the indian ocean through comparison of the simulated atmospheric concentrations with measurement data, in IGBP Open Science Conference, Amsterdam, Poster in Session: Recent developments in Basin- to Global-Scale Ocean Carbon Cycle Modeling, 2001.

Najjar, R. and J. C. Or, Biotic-HOWTO. Internal OCMIP Report, LSCE/CEA Saclay, Gif-sur-Yvette, France, 15 pp., 1999.

Najjar, R. G., X. Jin, F. Louanchi, K. C. S. C. Doney, J. C. Or, J. L. Sarmiento, E. Maier-Reimer, M.-F. W. G. K. Plattner, and A. Yool, A comparison of export production simulated by several ocean carbon cycle models, in IGBP Open Science Conference, Amsterdam, Poster in Session: Recent developments in Basin- to Global-Scale Ocean Carbon Cycle Modeling, 2001.

Orr, J. C., Ocean carbon-cycle models: exploring the differences, Research GAIM, l(1), 8-10, 1997.

Orr, J. C., Ocean Carbon-Cycle Model Intercomparison Project (OCMIP), Research GAIM, 2(2), 7, 1999a.

Orr, J. C., The ocean carbon-cycle model intercomparison project (OCMIP): An overview, in IUGG Meeting, p. A252, Birmingham, UK, $1999 b$.

Orr, J. C., Ocean circulation and the Ocean Carbon-Cycle Model Intercomparison Project, International WOCE Newsletter, 35, 24-25, 1999 c.

Orr, J. C., On ocean carbon-cycle model comparison, Tellus, 51B, 509-510, 1999 d.

Orr, J. C., OCMIP evaluation of deep-ocean circulation, Research GAIM, 4(2), 5, $12-13,2001$.

Orr, J. C. and O. Aumont, Exploring the capacity of the ocean to retain artificially sequestered $\mathrm{CO}_{2}$, in Greenhouse Gas Control Technologies, edited by B. Eliasson, P. Reimer, and A. Wokaun, pp. 281-286, Elsevier Science Ltd., 1999. 
Or, J. C., O. Aumont, A. Yool, G.-K. Plattner, F. Joos, E. Maier-Reimer, M.-F. Weirig, R. Schlitzer, K. Caldeira, M. Wickett, and R. J. Matear, The ocean's efficiency in retaining purposefully injected $\mathrm{CO}_{2}$, in AGU Fall Meeting, EOS, volume 81(48), San Francisco, November 2000/Supplement, 2000.

Or, J. C., O. Aumont, A. Yool, K. Plattner, F. Joos, E. Maier-Reimer, M.-F. Weirig, R. Schlitzer, K. Caldeira, M. Wickett, and R. Matear, Ocean $\mathrm{CO}_{2}$ sequestration efficiency from 3-D ocean model comparison, in Proceedings of the Fifth Int. Conf. on Greenhouse Gas Control Technologies, pp. 469-474, CSIRO, $2001 a$.

Orr, J. C. and J.-C. Dutay, OCMIP mid-project workshop, Research GAIM, 3(1), $4-5,1999$.

Orr, J. C., J.-C. Dutay, R. Najjar, J. Bullister, and P. Brockmann, CFC-HOWTO. Internal OCMIP Report, LSCE/CEA Saclay, Gif-sur-Yvette, France, 12 pp., $1999 a$.

Orr, J. C., N. Gruber, R. G. Najjar, and the OCMIP Group, The ocean carbon-cycle model intercomparison project, in IGBP Open Science Conference, Amsterdam, Invited oral presentation, $2001 b$.

Or, J. C., P. Monfray, O. Aumont, A. Yool, I. Totterdell, K. Plattner, F. Joos, E. Maier-Reimer, M.-F. Weirig, R. Schlitzer, K. Caldeira, M. Wickett, R. Matear, M. Follows, Y. G. H. Drange, A. Ishida, Y. Yamanaka, S. Doney, K. L. J. L. Sarmiento, R. D. Slater, R. M. Key, N. Gruber, C. Sabine, and R. Najjar, Simulations of historical and future anthropogenic $\mathrm{CO}_{2}$ uptake from 12 global ocean models, in IGBP Open Science Conference, Amsterdam, Poster in Session: Recent developments in Basin- to Global-Scale Ocean Carbon Cycle Modeling, 2001c.

Or, J. C., P. Monfray, E. Maier-Reimer, U. Mikolajewicz, J. Palmer, N. K. Taylor, J. R. Toggweiler, J. L. Sarmiento, C. L. Quéré, N. Gruber, C. L. Sabine, R. M. Key, and J. Boutin, Estimates of anthropogenic carbon uptake from four three-dimensionsal global ocean models, Global Biogeochem. Cycles, $15(1), 43-60,2001 d$.

Orr, J. C., P. Monfray, J. L. Sarmiento, E. Maier-Reimer, J. R. Palmer, and R. G. Najjar, Transition time for ocean carbon-cycle model comparison, Research GAIM, I(2), 8-10, 1997.

Orr, J. C., R. Najjar, C. L. Sabine, and F. Joos, Abiotic-HOWTO. Internal OCMIP Report, LSCE/CEA Saclay, Gif-sur-Yvette, France, 25 pp., $1999 b$.

Orr, J. C. and R. G. Najjar, OCMIP-2 in progress, Research GAIM, 2(1), 9, 1998. 
Or, J. C., O. A. R. M. Key, A. Yool, I. Totterdell, K. Plattner, E. M.-R. F. Joos, M.-F. Weirig, R. Schlitzer, M. W. K. Caldeira, R. Matear, M. Follows, Y. Gao, H. Drange, Y. Y. A. Ishida, S. Doney, K. Lindsay, J. L. Sarmiento, and R. D. Slater, Ocmip evaluation of deep-ocean circulation, in IGBP Open Science Conference, Amsterdam, Poster in Session: Recent developments in Basinto Global-Scale Ocean Carbon Cycle Modeling, 2001e.

Sabine, C. L., R. M. Key, and J. C. Or, Evaluation of model and measurementbased anthropogenic carbon tracer distributions, in IUGG Meeting, p. A253, Birmingham, UK, 1999.

Sarmiento, J. L., P. Monfray, E. Maier-Reimer, O. Aumont, R. Murnane, and J. C. Orr, Sea-air $\mathrm{CO}_{2}$ fluxes and carbon transport: A comparison of three ocean general circulation models, Global Biogeochem. Cycles, 14(4), 1267-1281, 2000 .

Smolarkiewicz, K. P., The multidimensional Crowley advection scheme, Mon. Weather Rev., 110, 1968-1983, 1982.

Smolarkiewicz, K. P., A simple positive advection scheme with small implicit diffusion, Mon. Weather Rev., 111, 479-486, 1983.

Smolarkiewicz, K. P. and T. L. Clark, The multidimensional positive definite advection transport algorithm: further development and applications, $J$. of Comp. Phys., 67, 396-438, 1986.

Toggweiler, J. R., K. Dixon, and K. Bryan, Simulations of radiocarbon in a coarse resolution world ocean model 1 . Steady state prebomb distributions, J. Geophys. Res., 94, 8217-8242, 1989. 


\subsection{Partner 2: SOC}

PI's: Prof. Patrick Holligan and Prof. Michael Fasham

Contributors: Dr. Ian Totterdell and Dr. Andrew Yool

\section{Introduction}

This report describes the work accomplished by the GOSAC group at the School of Ocean and Earth Sciences (SOES) at the University of Southampton and by the associated partner, the George Deacon Division (GDD); both groups are located at Southampton Oceanography Centre in Southampton. Since most of the work has been done in close collaboration between the SOES and GDD partners, the rest of this report will refer to the two groups collectively as SOC. The group uses the ocean general circulation model (GCM) from the UK Met. Office (UKMO) to run simulations. The model is described below. We are grateful to UKMO staff at the Hadley Centre, especially Steve Spall and Chris Jones, for assistance given.

The SOES group consists of Professor Patrick Holligan (Principal Investigator) and Dr. Andrew Yool. Dr. Yool was employed from 2nd March 1998 to 31st December 2000 (inclusive) as a post-doctoral research assistant working full-time on (and wholly funded by) the GOSAC project.

The GDD group consists of Prof. Michael Fasham (Principal Investigator) and Dr. Ian Totterdell. This group advises on the running of the model and how it can best be adapted for the GOSAC simulations, but receives no funding from the GOSAC project.

\section{Model Description}

The model used by the SOC group in this project is the ocean component of the coupled ocean-atmosphere model developed by the Hadley Centre for Climate Research and Prediction, part of the U.K. Meteorological Office. The version of the Hadley Centre model used for the GOSAC simulations is HadCM $3 \mathrm{~L}$, a coarseresolution form of the HadCM3 model [Gordon, 1998]. Details of the model are given below.

The U.K. Met. Office implementation of the primitive equation model described by Bryan [1969] and Cox [1984] is global with a realistic approximation to continental coastlines and bottom topography. The horizontal grid is regular; the resolution used for the GOSAC simulations is 2.5 degrees latitude by 3.75 degrees longitude. The grid points corresponding to the North Pole (96 points at latitude +90 degrees) are designated as land to avoid numerical problems. There are twenty levels in the vertical with thicknesses increasing from $10 \mathrm{~m}$ (upper four levels) to $615.3 \mathrm{~m}$ (lower seven levels). The time-step used for both the ocean dynamics and for tracer transports is 24 hours. The model uses a 'leap-frog' or centred-Euler scheme to advance the fields forward in time. A Robert filter is used each timestep 
to prevent divergence of the resulting two solutions; a mixing factor of 0.001 is used. The model is an 'online' model.

The water density is calculated using the equation of state adopted by UNESCO [1981]. The barotropic solution found is that for a rigid-lid ocean. The horizontal momentum diffusion, or numerical viscosity, has a coefficient of the form

$$
X(1+\cos (\text { latitude }))
$$

where $X$ is $1.5 \times 10^{5} \mathrm{~m}^{2} \mathrm{~s}^{-1}$.

An upwind scheme is used for advection. Sub-grid-scale mixing is alongisopycnal, with a diffusion coefficient of $1000 \mathrm{~m}^{2} \mathrm{~s}^{-1}$. Use of the eddy parameterization scheme of Gent and McWilliams [1990] allows there to be no explicit horizontal diffusion; the thickness diffusion coefficient used is $1000 \mathrm{~m}^{2} \mathrm{~s}^{-1}$. Vertical diffusion and eddy viscosity coefficients are set using a scheme which depends on the Richardson number [Pacanowski and Philander, 1981]. The Richardson number-dependent coefficient has the value $5.5 \times 10^{-3} \mathrm{~m}^{2} \mathrm{~s}^{-1}$, and the background value increases linearly with depth from $1.0 \times 10^{-5} \mathrm{~m}^{2} \mathrm{~s}^{-1}$ at the surface to $\left.1.5 \times 10^{-4}\right) \mathrm{m}^{2} \mathrm{~s}^{-1}$ at $5000 \mathrm{~m}$. For stability, the maximum allowed value of vertical mixing is $0.01 \mathrm{~m}^{2} \mathrm{~s}^{-1}$. In the mixed layer the vertical diffusion coefficient is set using a simplified (quadratic) version of the scheme of Large et al. [1994]. The critical Richardson number used is 0.3 and the maximum allowed depth of the boundary layer is $80 \mathrm{~m}$.

Tracers are also mixed near the surface using a bulk mixed layer scheme [Kraus and Turner, 1967], where 70 percent of the wind mixing energy is used at the top of the water column and it decays exponentially with a depth-scale of $100 \mathrm{~m}$. If a grid box's water column becomes gravitationally unstable, e.g., because of wintertime surface cooling, it is convected fully at the end of each timestep using the scheme of Rahmstorf [1993].

The ocean surface is forced with the monthly mean climatological heat fluxes [Esbensen and Kushnir, 1981], wind stress [Hellerman and Rosenstein, 1983] and the freshwater fluxes for precipitation [Jaeger, 1976] and evaporation [Esbensen and Kushnir, 1981]. In addition, ocean surface values of temperature and salinity are relaxed towards the monthly mean climatological fields [Levitus and Boyer, 1994]; the strength of the temperature restoring is $40.90 \mathrm{~W} \mathrm{~m}^{-2} \mathrm{~K}^{-1}$.

Usually, a pseudo-ice model is used which shuts off the transfer of gases and momentum between the atmosphere and the ocean when the sea surface temperature is below -1.8 degrees $C$. However, in the CFC simulations completed this year, a seasonal ice-cover mask was provided to all participating groups, and that was used instead of the pseudo-ice model (having been interpolated to the model grid).

Version 4.4 of the ocean model was used for the OCMIP-2 simulations. However this version of the model has been superceded at the UKMO and is no longer supported, so any future follow-on runs will have to be made using later versions. Both versions 4.5.1 and 5.3 of the ocean model give similar, but not identical, circulations to version 4.4 . 


\section{Work completed}

The Southampton Oceanography Centre partners in the GOSAC project have met the deadlines of the current OCMIP timetable in full in all three years of the project. For each simulation, modifications to the base-code of the ocean model had to be written and tested for compatibility. The new code allowed the GCM to be consistent with the OCMIP protocols for the simulation in each case, and to produce the outputs required for analysis.

In February 1998 Dr. Totterdell attended the first GOSAC planning meeting during the AGU Ocean Sciences meeting in San Diego, where the timetable for the simulations was discussed, as well as collaboration with the non-European groups in OCMIP. After Dr. Yool had taken up his post he and Dr. Totterdell received extensive training in running the ocean model and modifying its base-code. The CFC simulation was completed and submitted during the first year of the project (it was found during the second year that there was a slight error in the CFC results submitted by the SOC group, but the error was corrected and the results quickly resubmitted). Dr. Totterdell represented the SOC group at the Cluster meeting organized in Brussels by the EU at the end of November.

In the second year, the following Abiotic simulations were completed and submitted : Equilibrium, Historical, Future-S650, Future-IS92a and Pulse. Of these, the Future-IS92a simulation was an optional extra to the core OCMIP schedule. The strict convergence criterion for the equilibrium simulation (an air-sea flux of less than $0.01 \mathrm{Pg} \mathrm{C} \mathrm{yr}^{-1}$ ) was considerably more stringent than usually used with the ocean model and extensive work was required to enable it to be satisfied, described in a later section. In addition to the runs listed above, a number of simulations were also completed during 1999 but the results were not processed and submitted until the third year. These included the Biotic Equilibrium and Injection C1500 simulations and also control runs for the Abiotic Pulse and Abiotic Historical simulations. During this year Dr's. Yool and Totterdell attended the second OCMIP-2 workshop near Paris in May, and took part in discussions.

During the third year the remaining simulations were completed: Injection C800, Injection C3000 and Injection E1500, all of which were optional extras to the core OCMIP schedule. The results from these simulations and those completed in the last months of 1999 were processed and submitted. Unfortunately there was some confusion about the exact emissions scenario to be used for the Injection E1500 run, and it was later requested that the simulation be repeated with a different scenario. This has been done, but the new results have not fully been processed yet. An additional injection simulation was also performed, allowing the C1500 simulation to run on to year 2500 instead of the usual 2100 and so enabling the longer-term behavior of the injected carbon to be studied. Also in the third year, Dr's. Yool and Totterdell attended the third OCMIP-2 workshop, held at Princeton University in July. Dr. Yool also presented a poster ('How much $\mathrm{CO}_{2}$ will the oceans absorb? Perspectives from three classes of model') including results from the SOC OCMIP simulations at the JGOFS conference in Bergen during April 
2000.

During the extension period after the three years of the project the protocol for the He 3 simulation became available. SOC was one of the groups which coded up this simulation and ran it to equilibrium. The results were processed and submitted by September 2001. During July 2001 Dr. Totterdell attended the final OCMIP-2 workshop in Amsterdam, and presented a poster in the OCMIP poster-cluster at the IGBP conference with which the workshop coincided.

\section{Special considerations}

The equilibrium criterion prescribed for the Equilibrium simulations was a net airsea flux of $\mathrm{CO}_{2}$ less that $0.01 \mathrm{Pg} \mathrm{Cyr}^{-1}$. Aside from the final duration of model spin-up required to reach this target (approximately 8000 simulated years), considerable trouble was encountered in meeting this condition with the ocean model used by the group, although it was eventually achieved. The trouble stemmed from the parameterization of freshwater fluxes at the ocean surface and the resulting virtual fluxes diagnosed by the ocean GCM. These fluxes affected the modeled concentrations of dissolved inorganic carbon (DIC) directly, and also indirectly via their effects on modeled salinity (which is used to determine surface alkalinity). The standard parameterization of these fluxes led to a virtual flux of DIC which exceeded the criterion. Adjustments to this parameterization which were coincidentally being introduced to an updated version of the ocean GCM were found to reduce the global virtual flux of DIC to a level well within the equilibrium criterion.

\section{Brief scientific results}

Analyses have been carried out on the simulations. For the Abiotic runs, Fig. 2.1 shows the geographical distribution of the air-to-sea flux of $\mathrm{CO}_{2}$ in the Equilibrium simulation. Fig. 2.2 shows the total annual air-to-sea fluxes of $\mathrm{CO}_{2}$ during the Historical, Future-S650 and Future-IS92a simulations.

Fig. 2.3 shows the atmospheric and surface ocean partial pressures of $\mathrm{CO}_{2}$ from the Pulse simulation. Those curves clearly demonstrate that the timescale for surface ocean DIC to reach equilibrium with atmospheric $\mathrm{CO}_{2}$ is relatively short (timescales of about 1 year), whereas transfer to the deep ocean requires much longer (timescales of centuries to millennia).

By subtracting the DIC from appropriate control runs from that in the Historical and Future simulations, it is possible to calculate the anthropogenic component. Fig. 2.4 shows surface concentrations of anthropogenic $\mathrm{CO}_{2}$, the total inventory and the penetration depth, all for simulated year 1998. Most of the storage can be seen to be in the North Atlantic and between $20^{\circ}$ and $50^{\circ}$ S. Fig. 2.5 shows a zonal-mean section of the anthropogenic carbon, plus a section and inventory from $20^{\circ} \mathrm{W}$ in the North Atlantic. Carbon and CFC data have been collected along this line by SOC scientists, and the model results are being compared to their results. 

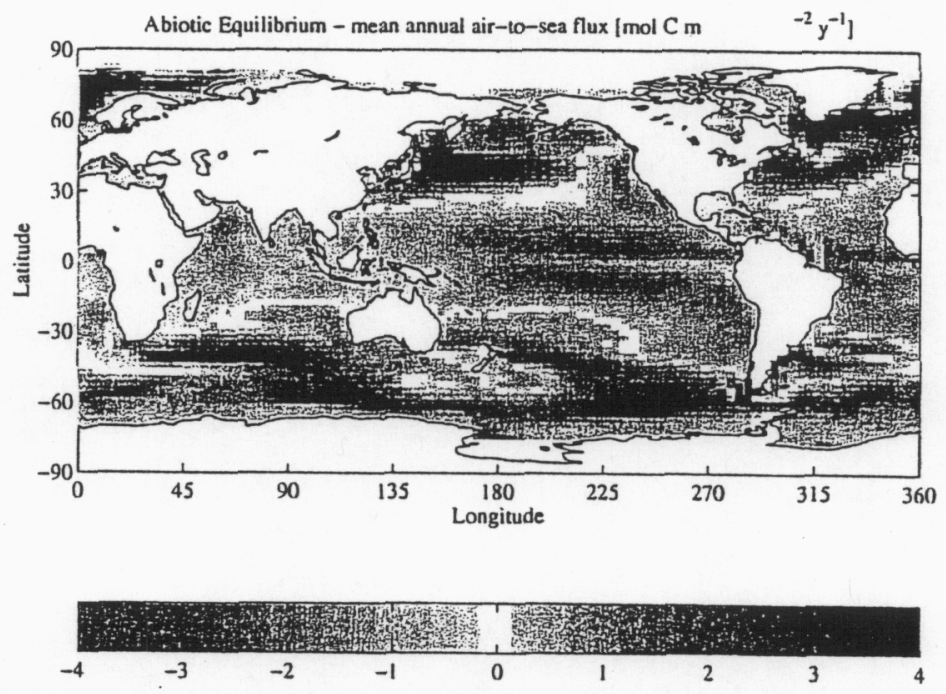

Figure 2.1: Abiotic Equilibrium-mean annual air-to-sea flux [ $\mathrm{mol} \mathrm{C} \mathrm{m} \mathrm{m}^{-2} \mathrm{yr}^{-1}$ ]

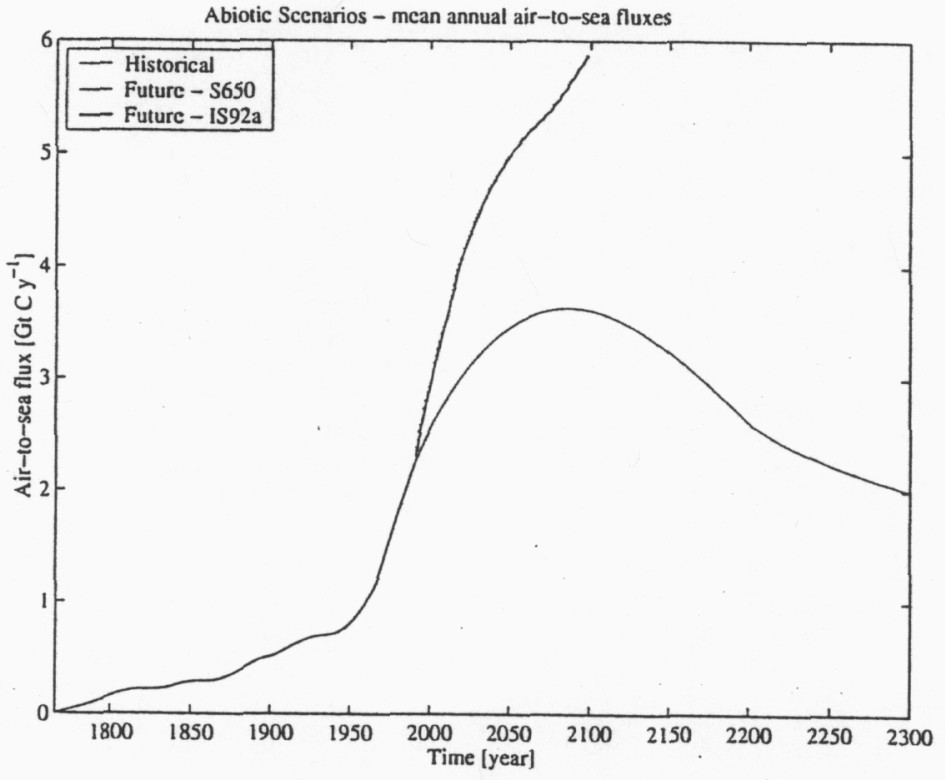

Figure 2.2: Abiotic Scenario--mean annual air-to-sea fluxes $\left[\mathrm{PgC}^{-1} r^{-1}\right]$ 


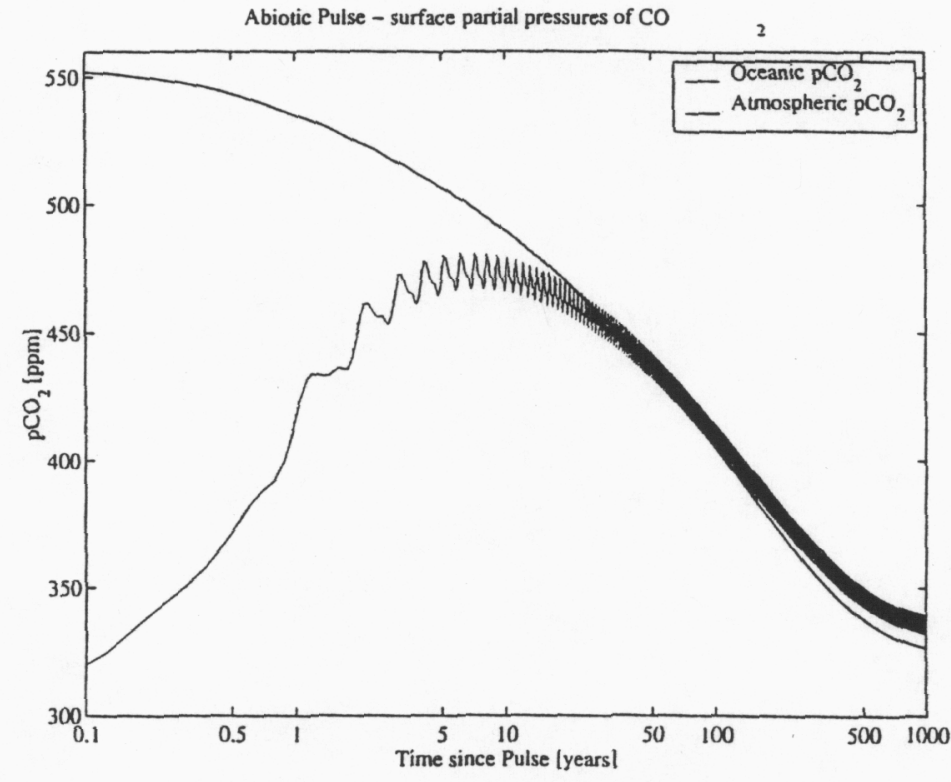

Figure 2.3: Abiotic Pulse-surface $\mathrm{pCO}_{2}[\mathrm{ppm}]$

Some results from the Biotic Equilibrium simulation are presented. Fig. 2.6 shows the sinking flux of particulate organic phosphate (POP). The same simulation produces a large contrast in the zonally-averaged concentrations of oxygen for the Atlantic (upper) and Pacific (lower) basins (Fig. 2.7).

Although not required for the OCMIP project, Dr. Yool ran a Historical and Future-IS92a simulation from the end of the Biotic Equilibrium run. A comparison between the uptake of anthropogenic $\mathrm{CO}_{2}$ in that run, in the Abiotic runs and in the HadOCC model (described in Palmer and Totterdell 2001, Deep-Sea Research I, v48, 1169-1198) formed the basis of Dr. Yool's poster at the JGOFS conference in Bergen. A further version of this study, extended to include climate-change feedbacks, was presented by Dr. Totterdell at '2001: An Ocean Odyssey' in Mar del Plata, Argentina during October 2001, and will be written up for publication.

Finally for $\mathrm{CO}_{2}$ injection run, we present the modeled gain of the seven injection sites for simulation $\mathrm{C} 1500$ (Fig. 2.8). Our model clearly shows the variation between the examined sites, with San Francisco being most efficient and New York being least efficient.

Comparisons with other models show that the deep water ventilation of the ocean model used by the SOC group is quite low. This leads to high concentrations of $\delta^{3} \mathrm{He}$ in the deep water, low CFC concentrations, and an 'old' oxygen age. 

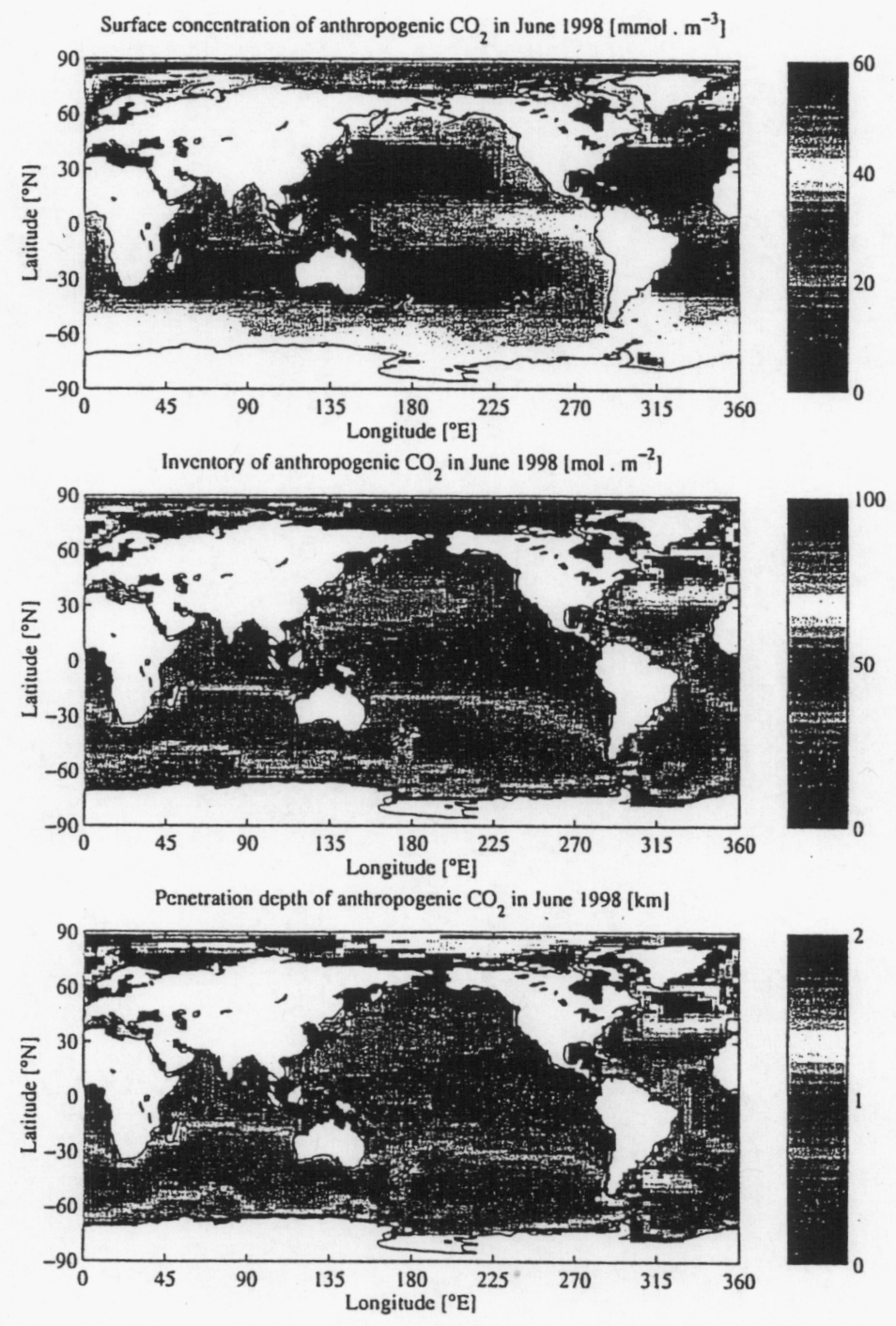

Figure 2.4: Anthropogenic carbon from the abiotic simulations 


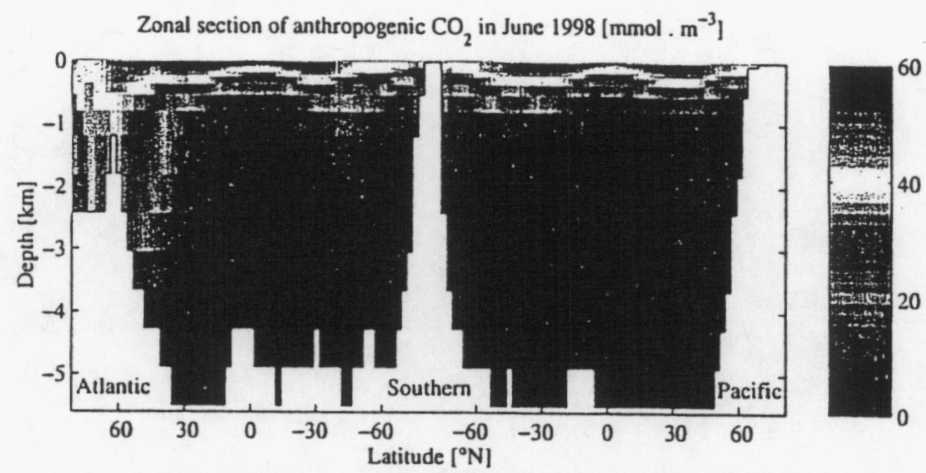

Anthropogenic $\mathrm{CO}_{2}$ concentration along section $20^{\circ} \mathrm{W}$ in June $1998\left[\mathrm{mmol} . \mathrm{m}^{-3}\right.$ ]

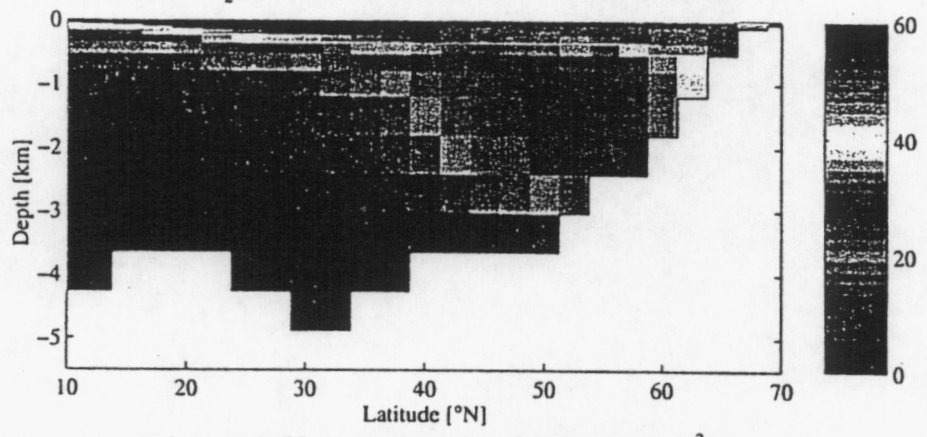
Anthropogenic $\mathrm{CO}_{2}$ inventory along section $20^{\circ} \mathrm{W}\left[\mathrm{mol} \mathrm{m} \mathrm{m}^{-2}\right]$

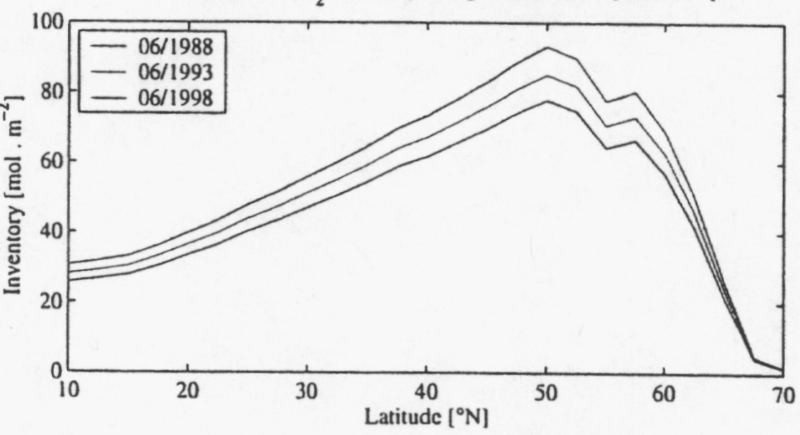

Figure 2.5: Anthropogenic carbon sections from the abiotic simulations 


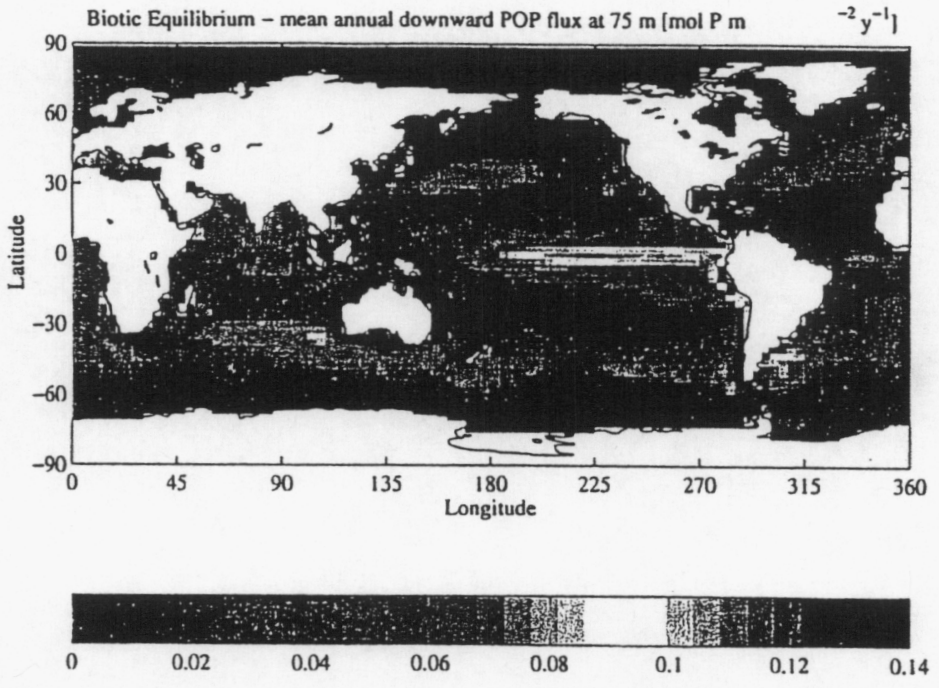

Figure 2.6: Biotic Equilibrium-mean annual downward POP flux at $75 \mathrm{~m}\left[\mathrm{~mol} \mathrm{P} \mathrm{m}^{-2}\right.$ $\mathrm{yr}^{-1}$ ]

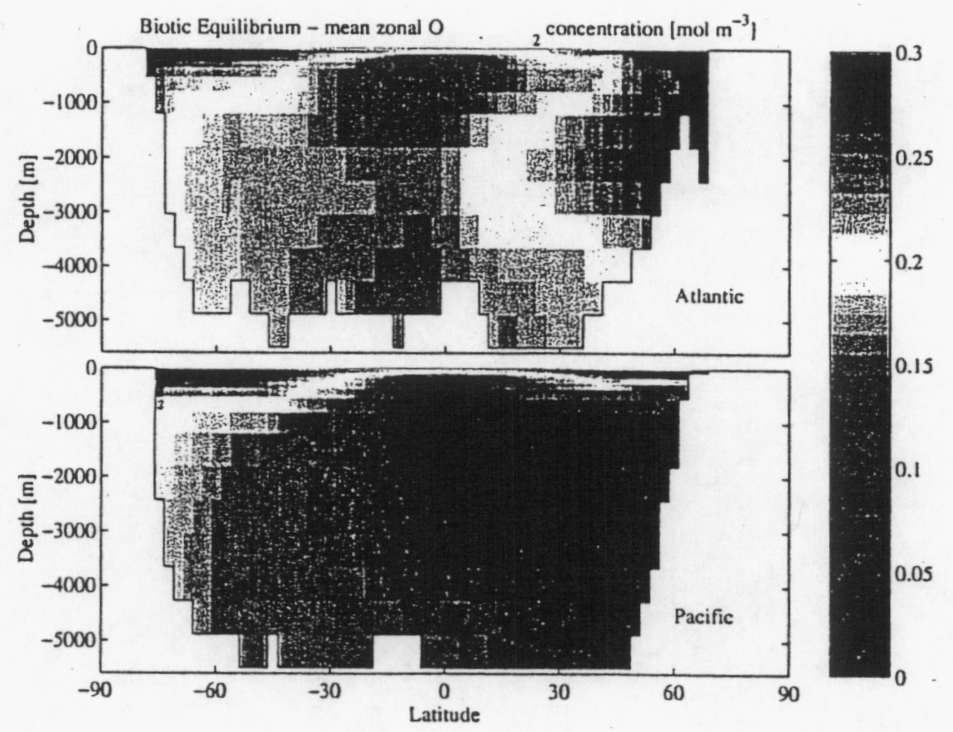

Figure 2.7: Biotic Equilibrium-mean zonal $\mathrm{O}_{2}$ concentration $\left[\mathrm{mol} \mathrm{m}^{-3}\right.$ ] 


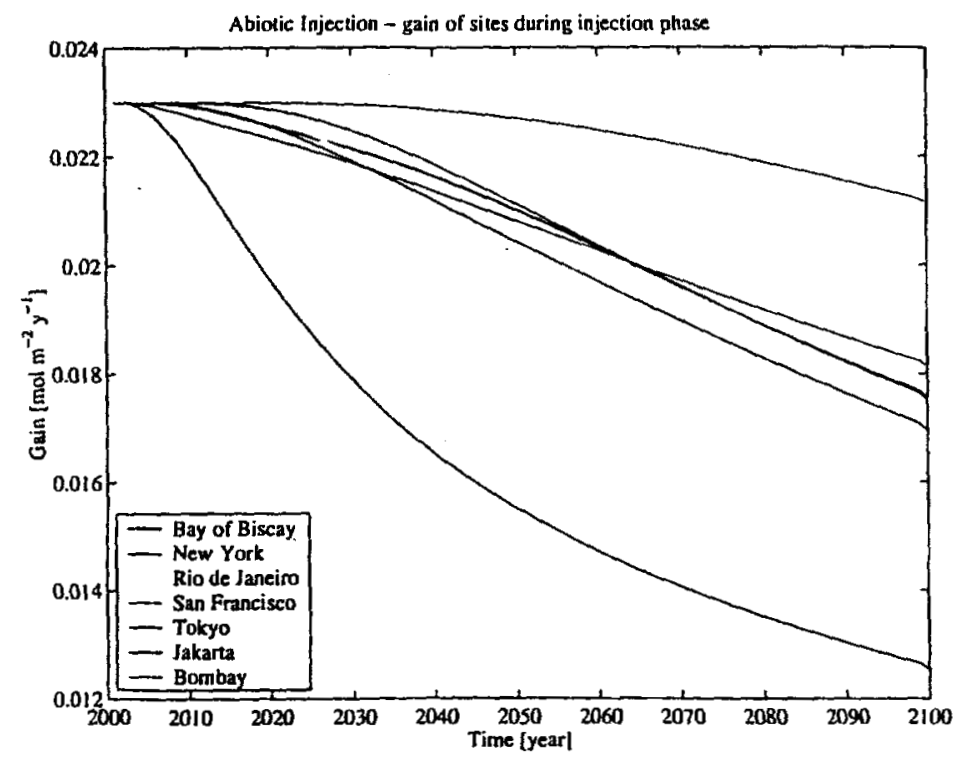

Figure 2.8: Injection—gain per site during injection period 


\section{References}

Bryan, K., A numerical method for the study of the circulation of the world ocean, J. Comput. Phys., 4(3), 347-376, 1969.

Cox, M. D., A primitive equation, 3-dimensional model of the ocean, GFDL Ocean Group Technical Report 1, Geophysical Fluid Dynamics Laboratory, Princeton, New Jersey, 143 pp., 1984.

Esbensen, S. K. and Y. Kushnir, The heat budget of the global ocean: an atlas based on estimates from marine surface observations, Report 29, Clim. Res. Inst., Oregon State Univ., Corvallis, 1981.

Gent, P. R. and J. C. McWilliams, Isopycnal mixing in ocean circulation models, J. Phys. Oceanogr., 20, 150-155, 1990.

Gordon, C., The simulation of sst, sea ice extents and ocean heat transports in a version of the hadley centre coupled model without flux adjustments, Clim. Dyn., submitted, -, 1998.

Hellerman, S. and M. Rosenstein, Normal monthly wind stress over the world ocean with error estimates, J. Phys. Oceanogr., 13, 1093-1104, 1983.

Jaeger, L., Monatskarten des Niederschlags für die ganze Erde, Technical Report 139, D. Wetterdienst, 1976.

Kraus, E. and J. Turner, A one dimensional model of the seasonal thermocline, part II, Tellus, 19, 98-105, 1967.

Large, W. G., J. C. Mcwilliams, and S. C. Doney, Oceanic vertical mixing: a review and a model with nonlocal boundary layer parameterization, Rev. Geophys., 32(4), 363-403, 1994.

Levitus, S. and T. P. Boyer, NOAA Atlas NESDIS 2: World ocean atlas 1994, Vol. 4, Temperature, Technical report, Natl. Oceanic and Atmos. Admin., address = Silver Spring., Md., 1994.

Pacanowski, R. and S. G. H. Philander, Parametrization of vertical mixing in numerical models of tropical ocean, J. Phys. Oceanogr., 11, 1443-1451, 1981.

Rahmstorf, S., A fast and complete convection scheme for ocean models, Ocean Modelling, 101, 9-11, 1993.

UNESCO, 10th report of the joint panel on ocean tables and standards, Technical Papers in Marine Science 36, UNESCO, 1981. 


\subsection{Partner 3: AWI}

PI: Dr. Reiner Schlitzer

Contributor: Dr. Marie-France Weirig

\section{Model Description}

The AWI model used in this study follows the approach of Schlitzer [1993] and Schlitzer [1995]. It has recently been extended to include biogeochemical nutrient and carbon cycles [Schlitzer, 2001]. In many aspects, the AWI model differs substantially from other models participating in the GOSAC project. Unlike dynamical models that use approximations to the momentum equation and external forcing at the sea-surface to calculate the time-varying ocean circulation by applying a time-stepping procedure, the AWI model has a steady 3-D flow field representing the steady-state, annual mean circulation of the ocean. An initial model flow field is obtained from geostrophic calculations based on available historical hydrographic data. A given current flow field together with current fresh-water and heat fluxes and biogeochemical productivity and remineralization parameters is used to simulate global ocean hydrography and nutrient, oxygen and carbon distributions (forward model). The adjoint of the forward model is then applied to analyze the model-data misfits and derive modified flows, air-sea fluxes and biogeochemical parameters so that when they are used in the following simulation, simulated property fields become closer to reality. This iterative optimization procedure is repeated until there is no further progress. The overall goal of the model calculations is to find a steady global ocean flow field (representing the climatological mean circulation), air-sea fluxes and biogeochemical fluxes that correctly reproduce the observed hydrography and tracer fields and at the same time has vertical velocity shears that are close to geostrophic shear estimates.

The model is implemented on a variable resolution grid. The horizontal resolution ranges from $5^{\circ} \times 4^{\circ}$ (longitude $\times$ latitude) in open ocean areas to $2.5^{\circ} \times 2^{\circ}$ in regions with narrow currents (Drake Passage, Atlantic part of the Antarctic Circumpolar Current (ACC), Indonesian and Caribbean archipelagos), along coastal boundaries with strong currents (Florida Current, Gulf Stream, Brazil Current, Agulhas Current, Kuroshio), over steep topography (Greenland-Iceland-Scotland overflow region) and in areas with pronounced coastal up- or downwelling. In all cases the refinements are implemented in the direction of the strongest property gradients (usually perpendicular to fronts and currents) to better trace changes in ocean properties.

The model has 26 vertical layers, with thickness progressively increasing from $60 \mathrm{~m}$ at the surface to approximately $500 \mathrm{~m}$ at $5000 \mathrm{~m}$ depth. Realistic topography, based on the US Navy bathymetric data, is averaged over grid cells. Model depths over ridges and in narrow channels are adjusted manually to respect sill and channel depths. The model has three open boundaries, along which ocean properties and transports are prescribed in each model layer. These are the exits of the 
Mediterranean Sea, Red Sea and Persian Gulf. Thus these three marginal seas are not modeled explicitly, although their impact on the global circulation is taken into account.

The model grid described above represents a compromise between the desire to resolve ocean currents and productivity patterns as closely as possible and the large computational burden imposed by the optimization procedure used to drive the model towards the observations. Given present computer resources this required a relatively coarse model grid. Using a variable resolution grid has the advantage to allow better representation of smaller scale features at least in some crucial parts of the model domain without the need to accommodate the higher resolution over the whole model domain. Overall, resolution of the present model is much coarser compared to eddy-resolving dynamical models but is comparable to or better than that used in other models applied for global ocean biogeochemical and circulation studies.

For the property simulations, we used a weighted-mean advection scheme (fupw $=0.7$ ) that combines the numerical robustness of the upwind scheme (fupw=1) with the low artificial mixing of the centered-in-space approach (fupw $=0.5$ ).

\section{Work completed}

We have performed all required GOSAC model simulations according to the work programme and have submitted the results in a timely fashion to the project coordinator. The model runs conducted include simulations of global ocean CFC and radiocarbon distributions, which for GOSAC served as model validation runs. Abiotic simulations for ${ }^{14} \mathrm{C}$ and DIC were performed in order to establish the equilibrium values for ${ }^{14} \mathrm{C}$ at a pre-industrial state. We also made the OCMIP Biotic simulation, computing equilibrium concentrations for the 5 tracers: $\mathrm{DIC}, \mathrm{PO}_{4}^{3-}$, DOP, $\mathrm{O}_{2}$ and Alkalinity. In addition, we made the GOSAC simulations for ${ }^{14} \mathrm{C}$ and DIC for the historical industrial period (1765 to 2000) in order to investigate the effect of nuclear weapons tests on surface ${ }^{14} \mathrm{C}$ concentrations. Furthermore carbon simulations for two future scenarios (CIS92a and S650) were performed and results analyzed. In addition, we made the GOSAC/OCMIP simulation for the impulse response function. Where data was available, the AWI model's simulated fields were analyzed and compared with observations using the "Electronic Atlas of WOCE Hydrographic and Tracer Data eWOCE" [Schlitzer, 2000].

We performed the abiotic simulations computing concentrations of $\mathrm{CO}_{2}$ and ${ }^{14} \mathrm{C}$ for different future scenarios. In this context it was necessary to also make control runs for the scenarios in order to elimnate model drift. We performed simulations of the diverse injection scenarios prescribed by the GOSAC/OCMIP team in order to find the optimal site for anthropogenic $\mathrm{CO}_{2}$ sequestration. Before submitting our results, we analyzed our results by comparing them with available data or by checking if they are consistent and plausible.

Prior to the final release of the GOSAC HOWTO's for deep Helium calculations, we performed mantle Helium simulations and presented them at the 2nd 
OCMIP Workshop (Princeton, USA). We contributed to the write-up of the final Helium HOWTO's, which differed somewhat from our original procedures. A re-calculation of the Helium fields with the AWI model could not be performed because Dr. M.-F. Weirig had left the AWI at the end of her GOSAC contract.

\section{AWI Model Simulations: Special Considerations}

As described above, the AWI-model differs considerably from the other GOSAC models. Therefore, some comments specific to the AWI GOSAC simulations are in order. In the AWI model, a steady-state flow field representing the mean circulation of the ocean is used for the simulations. This steady flow field has been established previously by driving the model close to observed hydrographic, oxygen, nutrient and carbon distributions [Schlitzer, 1999]. Technically, this fitting of the model to data was achieved by means of the adjoint method. For the GOSAC simulations this steady 3-D circulation is used and standard GOSAC boundary conditions and gas-exchange procedures are applied to calculate the evolution of property distribution under boundary conditions that change with time. As a consequence of the steady flow field, the AWI model cannot reproduce the seasonal cycle, and annual mean values are used for seasonally varying parameters, as for example piston velocities and total atmospheric pressure in the gas exchange procedures. The inability of the model to explicitly model summertime stratification and wintertime deep convection together with the small mixing coefficients used in the model are seen as principal causes for the relatively patchy field of air-sea fluxes found in the CFC and carbon simulations.

The first simulations of the second GOSAC year were performed in order to determine equilibrium concentrations of DIC and ${ }^{14} \mathrm{C}$ under abiotic conditions. Following the GOSAC guidelines, procedures for gas exchange and calculation of the surface concentration of $\mathrm{CO}_{2}$ have been implemented. For the computation of the equilibrium values of DIC under biotic conditions (i.e., the Biotic Run which includes both solubility and biological components), we also used the gas exchange parameters as specified in the GOSAC/OCMIP HOWTO documents. However, modeling of dissolved and particulate organic carbon distributions (DOC and POC) differs slightly from the GOSAC procedures. In the AWI model, biogenic particles are formed in the two uppermost layers of the model, which represents the euphotic zone. Particle fluxes are defined below this model euphotic zone, i.e., below 133 $\mathrm{m}$, following a function of the form

$$
f(z)=a * z^{-b}
$$

where $z$ is depth and $a$ and $b$ are constants. For the other GOSAC models, $a$ and $b$ are constants derived from empirical relations, based on sediment trap data, which are found in the literature. In the AWI model, the strength of the particle flux (equivalent to the export flux and represented by parameter $a$ ) and the depth of main remineralization (controlled by parameter $b$ ) were taken from the hydrographic, nutrient and carbon optimization runs mentioned above. Using the 
optimized parameter values for $a$ and $b$ (instead of, for instance, constant values for $b$ taken from the literature) produces a more realistic simulation of the marine nutrient fields. The slight modifications of the GOSAC procedures concerning biogenic particle production and remineralization were necessary in onder to guarantee consistency of our model.

Simulations of the historical evolution of ${ }^{14} \mathrm{C}$, influenced mainly by bomb tests, were made following the GOSAC guidelines. We used atmospheric ${ }^{14} \mathrm{C}$ values and gas exchange equations proposed by the GOSAC guidelines. The simulation of future scenarios and pulse run also closely follow the GOSAC HOWTO's.

For the injection scenarios we introduced the 7 GOSAC injection sites in the closest cells of the AWI model grid. For the simulations we used GOSAC routines provided by the coordinators group together with the HOWTO's.

For our mantle Helium simulations that were presented at the Princeton workshop before the final procedures for Helium simulations were released, we made simulations following Farley et al. [1995]. We considered essentially mantle $\mathrm{He}-$ lium as tracer and computed with a constant background concentration of ${ }^{3} \mathrm{He}$ and ${ }^{4} \mathrm{He}$ in the ocean. As sources for mantle Helium, mid-ocean ridge positions [DeMets et al., 1990] were adapted to the AWI model grid. This presented some difficulties for the exact depth of the Helium sources, but we followed the advice of Farley and Maier-Reimer, i.e., Helium plumes develop about $300 \mathrm{~m}$ above the ridges crest. From Farley and Maier-Reimer, we also adopted the idea that the mantle Helium coming out of the ridges may be proportional to the spreading rates of the ridges. Spreading rates were taken from DeMets et al. [1990]. The mantle Helium simulations were terminated when equilibrium was nearly reached, namely when almost the same quantity of mantle Helium entering the abyssal ocean leaves the ocean through sea surface.

\section{References}

DeMets, C., R. Gordon, D. F. Argus, and S. Stein, Current plate motions, Geophysical Journal International, 101, 425-478, 1990.

Farley, K. A., E. Maier-Reimer, P. Schlosser, and W. S. Broecker, Constraints on mantle ${ }^{3} \mathrm{He}$ fluxes and deep-sea circulation from an oceanic general circulation model, J. Geophys. Res., 100(B3), 3829-3839, 1995.

Schlitzer, R., Determining the mean, large-scale circulation of the atlantic with the adjoint method, J. Phys. Oceanogr., 23, 1935-1952, 1993.

Schlitzer, R., An adjoint model for the determination of the mean oceanic circulation, air-sea fluxes and mixing coefficients, Ber. zur Polarforschung 156, Alfred-Wegener-Institut, Bremerhaven, 1995.

Schlitzer, R., Inverse methods in global biogeochemical cycles, in Applying the adjoint method for global biogeochemical modeling, edited by P. Kasibhatla, 
M. Heimann, D. Hartley, N. Mahowald, R. Prinn, and P. Rayner, volume 114 of Geophys. Monograph Series, pp. 107-124, Washington D.C., AGU, 1999.

Schlitzer, R., Electronic atlas of WOCE hydrographic and tracer data now available, EOS Trans. $A G U, 81(5), 45,2000$.

Schlitzer, R., Carbon export fluxes in the Southern Ocean: results from inverse modeling and comparison with satellite based estimates, Deep-Sea Res. II, in press, 2001. 


\subsection{Partner 4: UL (LPAP and2 ASTR)}

PI: Dr. Louis Francois (LPAP, Liège)

Contributors: Ms. Anne Mouchet (LPAP, Liège),

Dr. Eric Deleersnijder and Dr. Jean-Michel Campin (ASTR, Louvain-la-Neuve)

\section{Introduction}

In investigating GOSAC themes the LPAP team (University of Liege, Belgium) works in collaboration with ASTR (University of Louvain-la-Neuve, Belgium), which is subcontractor in the project. To meet the aims of the GOSAC subprojects, several adaptations of both the ocean circulation and the carbon cycle models were necessary. The OCMIP-2 simulations for Abiotic Equilibrium, Biotic Equilibrium, Abiotic Historical, Future and Pulse with their corresponding Control were made available for common analysis. Our group is also among those who performed the Helium simulation. Evaluation of the results obtained within this framework was performed and several sensitivity analyses were also carried out. These subjects are described after an introduction to the models involved in this project.

\section{Model Description}

Fields of advection and diffusion from the OGCM developed at ASTR are used off-line to drive the OCCM built at LPAP.

\section{Ocean Circulation and Sea Ice Model:}

The CLIO (Coupled Large-scale Ice Ocean) model [Goosse, 1998] results from the coupling of a global, free-surface Ocean General Circulation Model (OGCM) [Deleersnijder and Campin, 1995; Campin, 1997; Campin and Goosse, 1999] with a comprehensive sea-ice model [Morales Maqueda, 1995; Fichefet and Maqueda, 1997]. The OGCM is a primitive-equation model resting on the usual set of assumptions, i.e., the hydrostatic equilibrium and the Boussinesq approximation.

The governing equations of the model are solved numerically by using a finitevolume technique on an Arakawa B-grid. The simple centered-in-space advection scheme is used for the momentum equation and remains stable thanks to a large horizontal eddy viscosity (common amongst low resolution OGCM's) of $10^{5} \mathrm{~m}^{2}$ $\mathrm{s}^{-1}$, which is required to represent western boundary currents. For the horizontal advection of scalar quantities, the fractional time stepping [Yanenko, 1971] combined with Lax-Wendroff advection scheme guarantees numerical stability. Furthermore, a moderate horizontal eddy diffusion $\left(150 \mathrm{~m}^{2} \mathrm{~s}^{-1}\right)$ and an hybrid upwind / Lax-Wendroff advection scheme [Campin, 1997] derived from James [1986] limit the occurrence and growth of spurious local extrema. An implicit centered scheme is used for scalar transport along the vertical. 
Different time steps are employed for the tracers and ice thermodynamic variables ( 1 day), for the ice dynamics ( 6 hours), the baroclinic dynamics ( 3 hours), and the barotropic variables ( 5 minutes).

The horizontal resolution is $3 \times 3$ degrees. In order to avoid the North Pole singularity, two spherical grids are patched together. The first one is a standard geographical latitude-longitude grid covering the whole World Ocean except for the Northem Atlantic and the Arctic which are displayed on a spherical grid having its poles on the equator. The two grids are connected in the equatorial Atlantic [ $E$. Deleersnijder and van Ypersele, J. P. and J.-M. Campin, 1993]. The flow through Bering Strait is parameterized as a linear function of the cross-strait sea-level difference [Goosse et al., 1997] in accordance with the geostrophic control theory. The so-called "z-coordinate" underlies the vertical discretization with 20 levels ranging in thickness from $10 \mathrm{~m}$ at surface to $750 \mathrm{~m}$ in the deep ocean. The bathymetry is as realistic as permitted by the grid.

The parameterization of vertical mixing [Goosse et al., 1999] is based on the Kantha and Clayson [1994] version of the Mellor and Yamada's level-2.5 model. One differential equation is solved for the square of the turbulent velocity scale. The mixing length is prescribed as an algebraic function of depth, stratification, and turbulent velocity scale. A minimum value for vertical diffusivity and viscosity is imposed following the vertical profile proposed by Bryan and Lewis [1979]. Whenever, the vertical profile is unstable, the vertical diffusivity is increased to 10 $\mathrm{m}^{2} \mathrm{~s}^{-1}$. The sea water density and the stratification are computed from a non linear equation of state [Eckart, 1958].

The parameterization of dense water flow down topographic features of [Campin and Goosse, 1999] is applied in the model. Dense water from the top of a bathymetric step flows down the slope until it encounters water of equal density.

The sea-ice model has a representation of both thermodynamic and dynamic processes. A 3-layer model [Fichefet and Gaspar, 1988], which takes into account sensible and latent heat storage in the snow-ice system, simulates the changes of snow and ice thicknesses in response to surface and bottom heat fluxes. The ice model also incorporates a simple scheme for snow-ice formation when the load of snow is large enough to depress the snow-ice interface under the water level. The variation of ice compactness due to thermal processes is a function of the energy balance of the surface layer in the region occupied by leads. For ice dynamics computations, sea ice is considered to behave as a viscous-plastic continuum [Hibler, 1979].

The model is driven by surface fluxes of heat, freshwater, and momentum determined from the empirical bulk formulae described in [Oberhuber, 1988]. Input fields consist of monthly climatological surface air temperatures [Taljaard et al., 1969; Crutcher and Meserve, 1970], cloud fractions [Berliand and Strokina, 1980], air relative humidity [Trenberth et al., 1989], precipitation rates [Xie and Arkin, 1996], and surface winds and wind stresses from Hellerman and Rosenstein [1983] between $15^{\circ} \mathrm{S}$ and $15^{\circ} \mathrm{N}$ and from Trenberth et al. [1989] out of this latitude band. The river runoff is based on the monthly mean climatology of [Grabs 
et al., 1996] for major rivers and on the annual mean climatology of Baumgartner and Reichel [1975] for smaller ones. Owing to inaccuracies in the precipitation and runoff data and in the evaporation computed by the model, the net freshwater flux at the surface exhibits a slight imbalance inducing a drift in the simulated global salinity. To remedy this problem, a weak relaxation to annual mean observed salinities [Levitus, 1982] is applied in the surface layer with a time constant of two months.

\section{Carbon cycle model:}

The comprehensive and prognostic ocean carbon model LOCH is based on an earlier version [Mouchet and Francois, 1996]. It has been developed at LPAP and is now in the application phase. State variables in the ocean include DIC, alkalinity, $\mathrm{PO}_{4}^{3-}$, organic matter, $\mathrm{O}_{2},{ }^{13} \mathrm{C},{ }^{14} \mathrm{C}$ and silica. An atmospheric layer allows the modeling of concentrations of $\mathrm{CO}_{2},{ }^{13} \mathrm{C},{ }^{14} \mathrm{C}$, and $\mathrm{O}_{2}$ for future or past scenarios. Values in that layer may also be imposed in order to force the ocean model with prescribed boundary conditions. Processes in the ocean include soft and hard tissue formation in relation with the growth of phytoplanktonic biomass. Decay of organic matter occurs through remineralization of the grazing products when sinking to deep waters. Shells consist of opal or of calcite in case of lack of silica. Dissolution of $\mathrm{CaCO}_{3}$ is chemically driven (the presence of aragonite is allowed for). Loss of alkalinity, carbon and silica to the sediments through shell deposition is compensated for by river inputs. The remineralization rate of the organic matter is driven by oxygen availability, anoxic remineralization may also occur in $\mathrm{O}_{2}$-depleted areas. Total amounts of carbon and alkalinity in the system are held constant and the pre-industrial atmospheric values of $\mathrm{CO}_{2}$ and $\delta^{13} \mathrm{C}$ are obtained by adjusting parameters of the different processes. Distributions of alkalinity and carbon among the main ocean basins satisfactorily agree with observations and computed global fluxes are consistent with values from the literature.

The model as described above was used in sensitivity studies, while in accordance with GOSAC/OCMIP guidelines the nutrient-restoring method was used for the Biotic run.

For computational efficiency, our ocean carbon-cycle model LOCH, is run offline. It uses circulation fields predicted from the on-line model (CLIO), to calculate transport of biogeochemical tracers. However the advection scheme in the off-line model is not the same as in the on-line model.

In CLIO advection of scalar is performed with a centered scheme along the vertical while a hybrid scheme is used along the horizontal. This low diffusive scheme (hereafter referred to as $L D$ ) is non-positive and leads to physically unrealistic negative concentrations for age, $\mathrm{O}_{2}$ and $\mathrm{PO}_{4}$. The simple solution of setting all negative values to zero is not satisfactory because it does not conserve mass. Furthermore, such corrections are not at all negligible, being of the same order as changes due to the seasonal cycle. We then use a different scheme in the off-line model to assure that passive tracer concentrations do not become negative. Reduc- 
ing the time step would not have been sufficient to obtain monotonicity.

The solution was found in using an upwind scheme whose high dispersive effect is reduced by lowering the explicit diffusivities by the theoretical amount of numerical diffusion. Such a scheme guarantees conservation and positive tracer concentrations. Comparison of age tracer distributions obtained with the on-line and off-line models permitted to verify the correct reproduction of the transport by the off-line model.

For the sake of consistency, simulation involving CFC carried out at ASTR makes use of the same scheme. The other simulations were performed at LPAP.

\section{Assessment of OCMIP-2 results for UL group}

\section{Sensitivity to circulation:}

A first test consisted in driving the OCCM with the fields from an earlier version of the OGCM: $O M$; this step also provided for a quality test of the codes that had to comply with the OCMIP protocols. The OM version [Campin, 1997] differs from CLIO in 3 aspects: annual rather than seasonal mean fields, different surface forcing with slight salinity restoring, and prescribed instead of prognostic sea-ice. The consequences on the circulation seem to be less open-ocean convection and less ventilated north Indian and Pacific oceans. The stabilizing effects come from the restoring term toward surface salinities together with the prescribed ice. Indeed ice formation can sustain or amplify convection through brine release.

Most of the GOSAC-OCMIP runs were performed with both fields (for this purpose seasonal ice, wind and pressure fields were carefully averaged toward their annual means) and some of the global results are presented in Table 2.1.

\begin{tabular}{|l|r|r|}
\hline Model: & LOCH-CLIO & LOCH-OM \\
\hline$\delta^{3} \mathrm{He}$ & $9.91 \%$ & $15.33 \%$ \\
\hline$\Delta^{14} \mathrm{C}$ & $-111.29 \%$ & $-138.46 \%$ \\
\hline $\mathrm{CO}_{2}$ uptake in 1990 & $2.80 \mathrm{PgC} \mathrm{yr}^{-1}$ & $2.43 \mathrm{PgC} \mathrm{yr}^{-1}$ \\
\hline Export POC $\left(b^{1}\right)$ & $15.9 \mathrm{PgC} \mathrm{yr}^{-1}$ & $13.9 \mathrm{Pg} \mathrm{C} \mathrm{yr}^{-1}$ \\
Export POC $\left(b^{2}\right)$ & & $7.5 \mathrm{Pg} \mathrm{Cyr}^{-1}$ \\
\hline
\end{tabular}

Table 2.1: Annual global averages of some tracers as obtained with the seasonal and annual version of the UL model used for GOSAC/OCMIP-2. The POC export at $75 \mathrm{~m}$ is given as obtained with the nutrient-restoring formulation $\left(b^{1}\right)$ and with the LOCH biological module $\left(b^{2}\right)$.

Figures 2.9 and 2.10 present the zonal annual mean of $\Delta^{14} \mathrm{Cfor}$ each ocean basin. With $O M$ (figure 2.9) the Indian and North Pacific Oceans exhibit too old ${ }^{14} \mathrm{C}$ ages, a problem no longer encountered with CLIO (figure 2.10). On the other hand the old ${ }^{14} \mathrm{C}$ signature of Antarctic Intermediate Waters (AIW) flowing north- 

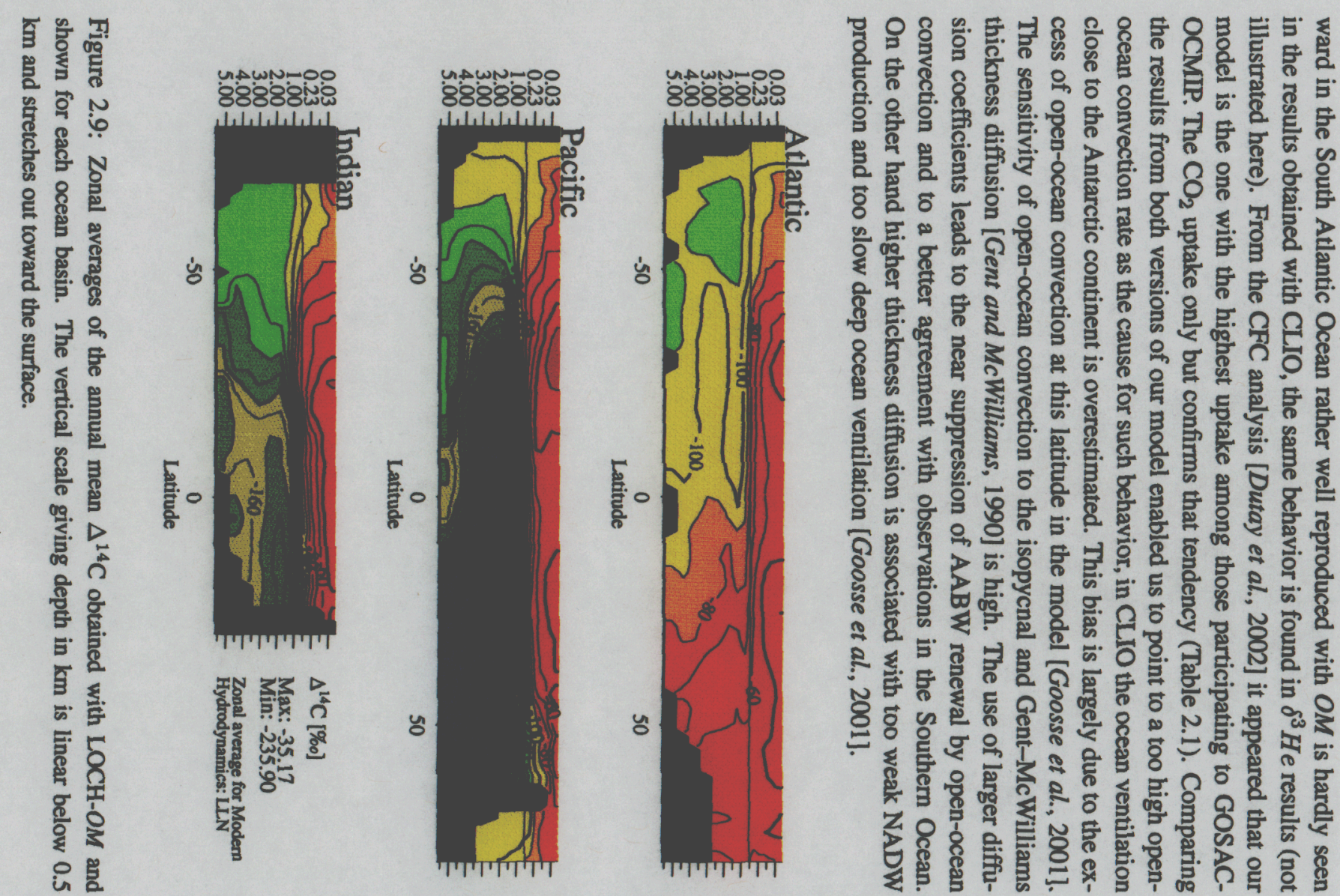

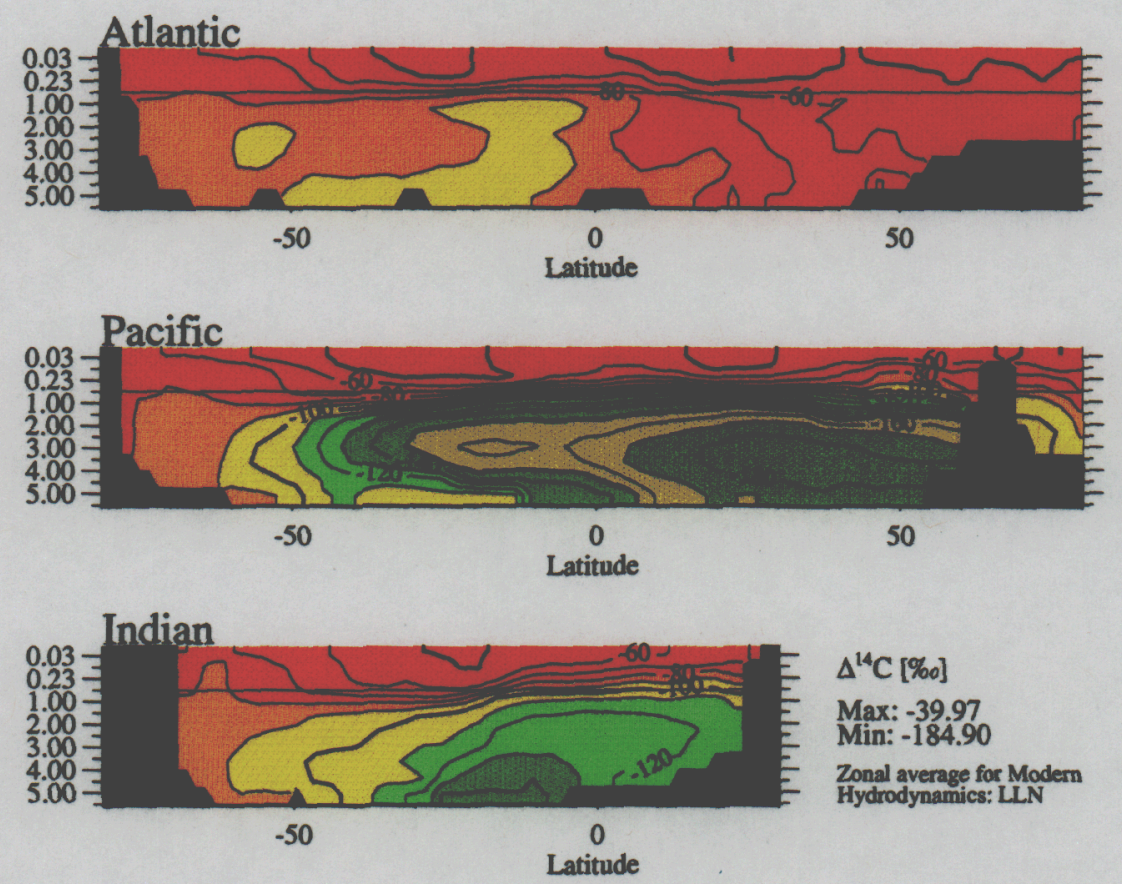

Figure 2.10: Zonal averages of the annual mean $\Delta^{14} \mathrm{C}$ obtained with LOCH-CLIO and shown for each ocean basin. The vertical scale giving depth in $\mathrm{km}$ is linear below $0.5 \mathrm{~km}$ and stretches out toward the surface.

\section{Sensitivity to biological model:}

While the dynamics may explain the higher export POC obtained with CLIO compared to $O M$, the figure in the later case is still situated in the highest range of estimated values, 5-12 $\mathrm{Pg} \mathrm{C} \mathrm{yr}^{-1}$ [Longhurst, 1991; Shaffer, 1993]. However when using the biological module of LOCH the export particulate drops from 13.9 to 7.5 $\mathrm{PgCyr}^{-1}$ with the same hydrodynamic fields (Table 2.1). The observed $\mathrm{PO}_{4}^{3-}$ field reflects the actual ocean dynamics and is not necessarily coherent with the model dynamics in terms of coincidence of low or high $\mathrm{PO}_{4}^{3-}$ surface concentrations. That is, features of the general circulation may be well reproduced in the model but, due to the coarse grid resolution, are not to be found at the same location as in the data field, introducing a bias in the estimated productivity. The main cause for differences seems however to be found in the biological model formulation. In the nutrient restoring method the export production is a first order function of a unique variable, $\mathrm{PO}_{4}^{3-}$ availability, with constant rate. In $\mathrm{LOCH}$, the export production depends in a non-linear way on $\mathrm{PO}_{4}^{3-}$. Growth limitation by light and grazing, and to a smaller extent by temperature, allows for an export rate not solely determined by $\mathrm{PO}_{4}^{3-}$ availability. Other differences between the two models exist, but seem to 
play a more negligible role. The fact that in both cases the organic matter occurs under particulate and dissolved forms explains the similarity of vertical profiles of $\mathrm{PO}_{4}^{3-}$ obtained with each model.

\section{Sensitivity to Ice cover:}

The OGCM of our group, CLIO, is able to compute ocean ice cover prognostically. Such is noteworthy, when compared to the other GOSAC models. As a sensitivity test, we used the model predicted ice field rather than the prescribed seasonally varying field (the standard for GOSAC/OCMIP) for computing CFC fields. Differences in simulated fluxes and concentrations of CFC's are negligible.

\section{Sensitivities to Advection:}

We conducted sensitivity tests in the framework of GOSAC to assess how the choice of the advection scheme affected results. For these tests we have used the annual version of our OCCM-OGCM.

For modeling the full carbon cycle we began by using a first order upwind scheme $(U)$ for transporting passive tracers. Simple tracer distributions (age, passive tracer, quick- $\Delta^{14} C$ ) were then computed in order to assess the effect of changes in the advective schemes.

All our tests lead to the conclusion that the chosen vertical advection scheme is of critical importance. Indeed, changes in the predicted fields when switching from the LD to the U scheme are completely explained by modifying in the vertical advection scheme. The influence of the horizontal advection scheme is much smaller. Furthermore differences in asynchronous time steps ( 1 day in CLIO, 7 days in $\mathrm{LOCH}$ ) and in the convection parameterization have negligible effects.

To reduce departures from the original scheme, we applied a correction to the $\mathrm{U}$ scheme. That is, we reduced the explicit diffusion coefficient when feasible by the amount of implicit numerical diffusion which is easily computed from the velocity field. This "RU" scheme is that used in LOCH and CLIO for passive tracers; active tracers (temperature, salinity) are computed with the classical LDscheme. Age-related simulations (i.e., ideal age and quick- $\Delta^{14} C$ ) revealed their general significance in two additional sensitivity experiments.

In the on-line model, the CFC distribution is sensitive to a switch from RU to LD advection scheme. This leads to a reduction of $8 \%$ of the global CFC uptake whereas concentrations appear more contrasted especially in the Southern Ocean.

Finally, a test of $\mathrm{O}_{2}$ ventilation of the deep ocean, which is critical for the fate of organic carbon in the ocean, was based on a Biotic simulation with the LOCH model. In this case the $\mathrm{PO}_{4}$ field was held constant, so that the primary production and organic matter production rates were the same in both experiments. The oxygen distribution is then only determined by air-sea exchanges and remineralization of the organic matter in the deep layers. The ocean oxygen inventory globally increases by about $2 \%$ when switching from the $U$ to the RU scheme, a change not 
evenly distributed among water masses. Higher $\mathrm{O}_{2}$ concentrations are obtained in deep waters with the RU scheme than with the U scheme, while intermediate waters are more depleted with the former scheme (Fig. 2.11).
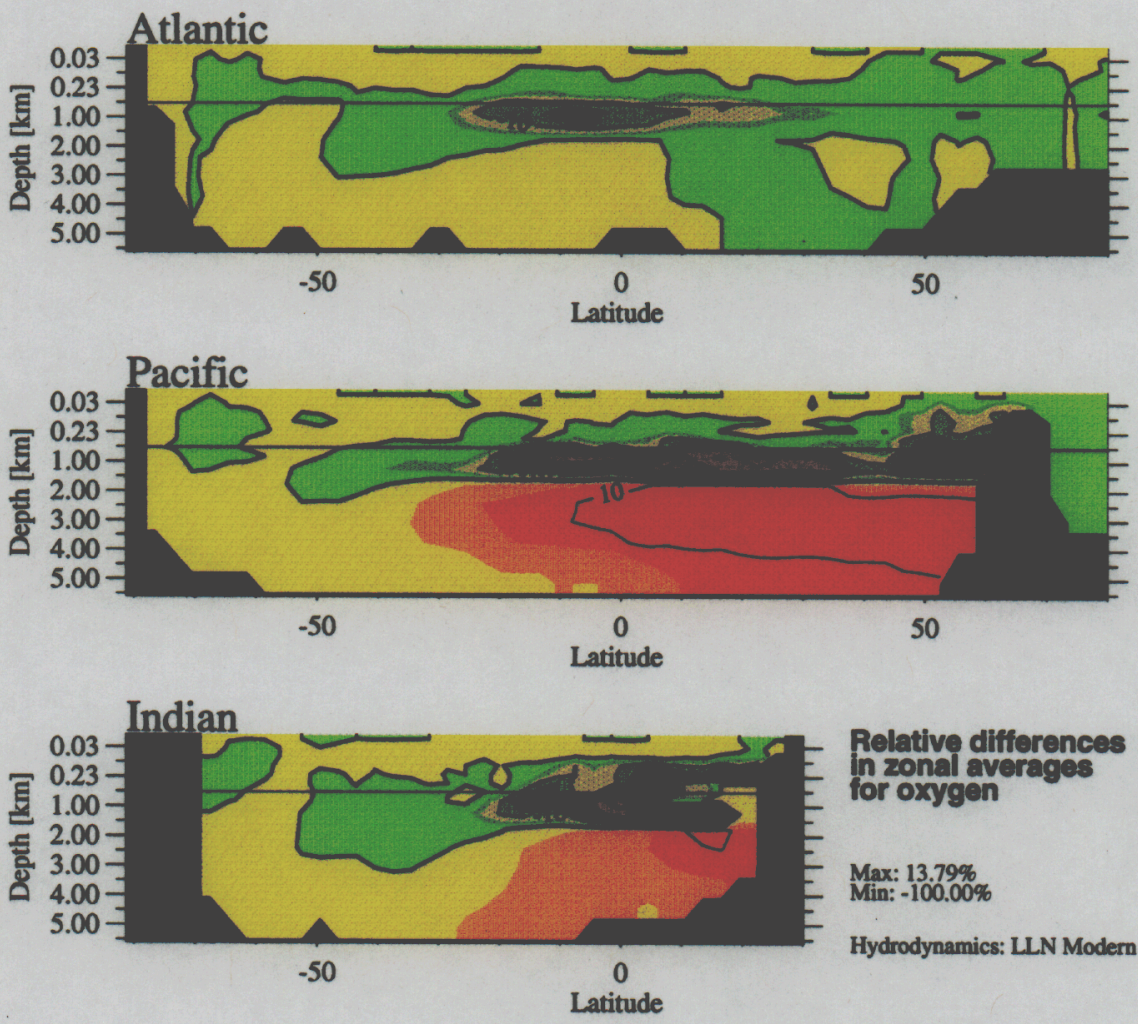

Figure 2.11: Relative differences in zonal averages of $\mathrm{O}_{2}$ concentrations obtained with the $\mathrm{RU}$ and $\mathrm{U}$ advection schemes. Positive values correspond to higher ventilation by the $\mathrm{RU}$ scheme. The $\mathrm{U}$ scheme leads to increased concentrations in intermediate waters. The maximum value in deep North Pacific corresponds to an increase of $22.3 \mu \mathrm{mol} . \mathrm{l}^{-1}$ for a background value of $162 \mu \mathrm{mol} . \mathrm{l}^{-1}$. In intermediate waters depletion can reach up to 20 $\mu \mathrm{mol} . l^{-1}$ with respect to mean values of the order of $40 \mu \mathrm{mol.l} \mathrm{l}^{-1}$. The vertical scale giving depth in $\mathrm{km}$ is linear below $0.5 \mathrm{~km}$ and stretches out toward the surface.

\section{Off-line versus on-line validation:}

We investigated how well is the distribution of an idealized passive tracer reproduced in the off-line model with respect to that predicted with the on-line model. The water age tracer has been retained since it combines the advantage of a simple implementation (zero at the surface; interior source term equal to unity) with 
a distribution that is relevant for ventilation time scale and biogeochemical processes. Under steady climatological forcing, the OGCM was integrated until equilibrium. The time averaged hydrodynamical fields were then subsequently used in the OCCM, for the off-line integration.

In order to address the sole effect of the off-line technique, the advection scheme applied to the water age is identical in both models. For the same reason, the convective adjustment scheme that consists in increasing the vertical diffusivity in unstable region is selected since diffusion is easily diagnosed and applied in the same way in both models. Therefore, any water age difference can be attributed to the OGCM short timescales internal variability which is not to be found in the off-line integration.

Although the two models produced similar water age distributions, differences of both signs appeared even in zonal mean diagnostic. Further analysis indicated that, when comparing the on-line results to those obtained off-line, older water age is associated to convection variability, whereas vertical advection variability is responsible for younger water age signal. Two types of corrective terms were expressed in terms of vertical diffusivity. Applying those corrections in the off-line model resulted in an almost perfect agreement in term of water age between the two models.

The magnitude of those corrections and relevance for other tracers or other model formulations were also examined. Additional water age comparisons addressing the effect of different advection schemes or convective adjustment formulations were performed [Campin and Mouchet, 2001].

Though the variability in the vertical velocity field remains the same, the age departures seem to be related to the numerical diffusivity of the numerical scheme used for vertical transport. Indeed, without any corrective terms, the disagreement between off-line and on-line simulations was reduced by switching in both models from a first order upwind scheme to a second order centered one. The way convection is taken into account in the OGCM, that is by permutation or by diffusion, does not bear any strong consequence on the off-line results. And this despite the fact that the longer time step used in the off-line model does not allow the permutation procedure to be reproduced as is: permutation is only partial, the remaining exchange rate being modeled through a diffusion term. Those results strengthen the crucial role of vertical processes in global ocean models.

\section{References}

Baumgartner, A. and E. Reichel, The world water balance, Elsevier, Amsterdam, $179 \mathrm{pp}, 1975$.

Berliand, M. E. and T. Strokina, Global distribution of the total amount of clouds (in Russian), Hydrometeorological Publishing House, Leningrad, Russia, 71 pp., 1980. 
Bryan, K. and L. J. Lewis, A water mass model of the world ocean, J. Geophys. Res., 84(C5), 2503-2517, 1979.

Campin, J.-M., Modelisation tridimensionnelle de la circulation générale oceanique lors du dernier maximum glaciaire, Ph.D. thesis, Universite Catholique de Louvain, Louvain-la-Neuve, Belgium, 342 pp., 1997.

Campin, J.-M. and H. Goosse, Parameterization of density driven downsloping flow for coarse resolution model in z-coordinate, Tellus, 51, 412-430, 1999.

Campin, J.-M. and A. Mouchet, Validation of off-line versus on-line simulations: water age tracer as a tool to assess internal variability effects in OGCMs, Ocean Modelling, in prep., 2001.

Crutcher, H. L. and J. M. Meserve, Selected level heights, temperatures and dew points for the northern hemisphere, NAVAIR 50-1C-52, Naval Weather Service, Washington DC, Revised, 1970.

Deleersnijder, E. and J.-M. Campin, On the computation of the barotropic mode of a free-surface world ocean model, Ann. Geophys., 13, 675-688, 1995.

Dutay, J.-C., J. Bullister, S. C. Doney, J. C. Orr, R. G. Najjar, K. Caldeira, J.-M. Campin, H. Drange, M. Follows, Y. Gao, N. Gruber, M. W. Hecht, A. Ishida, F. Joos, K. Lindsay, G. Madec, E. Maier-Reimer, J. C. Marshall, R. Matear, P. Monfray, A. Mouchet, G. K. Plattner, J. L. Sarmiento, R. Schlitzer, R. D. Slater, I. J. Totterdell, M.-F. Weirig, Y. Yamanaka, and A. Yool, Evaluation of ocean model ventilation with CFC-11: Comparison of 13 global ocean models, Ocean Modelling, 4(2), 89-120, 2002.

E. Deleersnijder and van Ypersele, J. P. and J.-M. Campin, An orthogonal curvilinear coordinate system for a world ocean model, Ocean Modell., 100, 7-10, 1993.

Eckart, C., Properties of water, part 2: The equation of state of water and sea water at low temperatures and pressures, Am. J. Sci., 256, 225-240, 1958.

Fichefet, T. and P. Gaspar, A model study of upper ocean-sea ice interactions, J. Phys. Oceanogr., 18, 181-195, 1988.

Fichefet, T. and M. M. Maqueda, Sensitivity of a global sea ice model to the treatment of ice thermodynamics and dynamics, J. Geophys. Res., 102(C6), 12609-12646, 1997.

Gent, P. R. and J. C. McWilliams, Isopycnal mixing in ocean circulation models, J. Phys. Oceanogr., 20, 150-155, 1990.

Goosse, H., Modelling the large-scale behavior of the coupled ocean-sea-ice system, Ph.D. thesis, Universite Catholique de Louvain, Louvain-la-Neuve, Belgium, 231 pp., 1998. 
Goosse, H., J.-M. Campin, T. Fichefet, and E. Deleersnijder, Sensitivity of a global ice-ocean model to the bering strait throughflow, Clim. Dyn., 13, 349-358, 1997.

Goosse, H., J.-M. Campin, and B. Tartinville, The sources of Antarctic bottom water in a global ice-ocean model, Ocean Modelling, 3, 51-65, 2001.

Goosse, H., E. Deleersnijder, T. Fichefet, and M. H. England, Sensitivity of a global coupled ocean-sea ice model to the parameterization of vertical mixing, J. Geophys. Res., 104, 13681-13695, 1999.

Grabs, W., T. D. Couet, and J. Pauler, Freshwater fluxes from continents into the world oceans based on data of the global runoff data base, Global Runoff Data Centre Report 10, Global Runoff Data Centre, Federal Institute of Hydrology, Koblenz, Germany, 1996.

Hellerman, S. and M. Rosenstein, Normal monthly wind stress over the world ocean with error estimates, J. Phys. Oceanogr., 13, 1093-1104, 1983.

Hibler, W. D., A dynamic thermodynamic sea ice model, J. Phys. Oceanogr., 9, 815-846, 1979.

James, I. D., A front-resolving sigma coordinate sea model with a simple hybrid advection scheme, Appl. Math. Modelling, 10, 87-92, 1986.

Kantha, L. H. and C. A. Clayson, An improved mixed layer model for geophysical applications, J. Geophys. Res., 98(C12), 25235-25266, 1994.

Levitus, S., Climatological atlas of the world ocean, Prof. Pap. 13, Natl. Oceanic and Atmos. Admin., US Gov Printing Office, Washington DC, 1982.

Longhurst, A. R., Role of the marine biosphere in the global carbon cycle, Limnol. Oceanogr., 36, 1507-1526, 1991.

Morales Maqueda, M. A., Un modelo acoplado del hielo de mar y del oceano superficial para estudios climaticos, Ph.D. thesis, Universidad Complutense, Madrid, Spain, 426 pp., 1995.

Mouchet, A. and L. Francois, Sensitivity of a global ocean carbon cycle model to the circulation and to the fate of organic matter: preliminary results, Phys. Chem. Earth., 21, 511-516, 1996.

Oberhuber, J. M., An atlas based on the 'COADS' data set: The budgets of heat, buoyancy and turbulent kinetic energy at the surface of the global ocean, Technical Report 15, Max-Planck-Inst. für Meteorol., Hamburg, Germany, 194 pp., 1988. 
Shaffer, G., Effects of the marine biota on global carbon cycling, in The Global Carbon Cycle, edited by M. Heimann, volume I15 of NATO ASI Series, pp. 431-455, Springer Verlag, Berlin Heidelberg, 1993.

Taljaard, J. J., H. van Loon, H. L. Crutcher, and R. L. Jenne, Climate of the upper air, Part I. Southern Hemisphere, Vol. 1, temperatures, dew points, and heights at selected pressure levels., NAVAIR 50-1C-55, U.S. Naval Weather Service, Washington DC, 135 pp., 1969.

Trenberth, K. E., J. G. Olson, and W. G. Large, A global ocean wind stress climatology based on ecmwf analyses, Report NCAR/TN-338 +STR, National Center for Atmos. Res., Boulder, Colorado, 93 pp., 1989.

Xie, P. and P. A. Arkin, Analyses of global monthly precipitation using gauge observations, satellite estimates and numerical model predictions, J. Clim., 9, 840-858, 1996.

Yanenko, N. N., The Method of Fractional Steps, Springer-Verlag, New York, 160 pp., 1971. 


\title{
2.5 Partner 5: MPIM Hamburg, Germany
}

\author{
PI: Dr. Ernst Maier-Reimer
}

\section{Model Description}

The model is based on the Hamburg LSG (Large Scale Geostrophic) model of the general circulation of the ocean. The Hamburg LSG model has been designed for long time studies. The basic philosophy was to incorporate standard oceanographic assumptions, i. e. geostrophy, into a time dependent circulation model, reducing thus the movement on the propagation of Rossby waves. During the development and parameter tuning we relied on the distribution of radiocarbon as well as standard hydrographic properties like temperature and salinity. From a series of experiments with different plausible parameterizations of thermohaline forcing, we choose that with the most realistic radiocarbon gradients to be our standard run, even though deep sea hydrographic properties were more realistic in other experiments. The motivation for this preference was the widespread experience from diagnostic models that the strong restoring to the hydrographic dataset by Levitus produces a rather unrealistic circulation.

The Hamburg LSG model formally solves the full set of primitive equations with the usual approximations (Boussinesq and hydrostatic pressure) on an E-grid in the Arakawa notation. The grid can be seen as a system of two overlapping $\mathrm{C}$-grids, each with a horizontal resolution of $5^{\circ}$. The configuration allows for representation of continuity and geostrophy by direct differences. In the present applications, the vertical variations are computed in 22 layers where the layer thickness increases from $50 \mathrm{~m}$ at the sea surface to approximately $600 \mathrm{~m}$ near the ocean floor. Topographic variations are represented in arbitrary increments; there is no restriction to the levels of computation.

The time discretization is done by a fully implicit scheme. This leads to a strong suppression of gravity waves but allows us to use a very long timestep, 1 month. Outside the equatorial belt, the system of wave equations degenerates to the geostrophic balance between velocity and pressure gradient. Tracer advection is computed with an implicit upwind scheme; this procedure is linked with an inherent diffusivity proportional to the modulus of velocity and operating in the direction of velocity. In the interior ocean the diffusion is small due to sluggish circulation. Since the grid tends to separate into two distinct solutions, an explicit diffusion of $200 \mathrm{~m}^{2} \mathrm{~s}^{-1}$ is applied between the grids in order to suppress the splitting.

The model is forced with monthly wind stress data from Hellerman and Rosenstein. Salinity is restored to annual mean values from Levitus in ice-free regions. Thermal forcing is made by restoring to atmospheric temperature from COADS. In case of temperature below freezing point of seawater $(-1.9 \mathrm{C})$ ice is formed assuming a linear profile between atmospheric temperature and freezing temperature 
at the upper and lower bounds, respectively. Ice is advected by wind stress and surface circulation with a simplified theology (resistance against convergence but not against divergence). Equation of state is according UNESCO 1983 with a linearized transformation from potential to in-situ temperature.

\section{Work completed}

The problems mentioned in the reports for the first two years of the project were settled thanks to the help of coordinators team. We submitted all required simulations, including the mantle helium runs. Due to the efficiency of the model in use, a steady state could be achieved within a few kilotons of carbon per year. Thus submission of control runs for the experiments was therefore not necessary. During the GOSAC project, MPIM contributed to two joint OCMIP-2 papers [Dutay et al., 2002; Orr et al., 2001a].

\section{Special considerations}

Some test runs were performed to investigate the effect of restoring to surface phosphate, as required in the common OCMIP/GOSAC Biotic run. This restoring, when combined with strong equatorial upwelling (a common feature amongst most coarse resolution models), results in an overestimate of equatorial production. We found that using a time constant of 2 months for production yielded a reasonable pattern of surface phosphate in our model. The inclusion of DOC represents a good compromise between HAMOCC3 [Maier-Reimer, 1993], which uses a time constant of 4 months (to avoid excessive dessertification in the subtropical gyres), and the more computer intensive HAMOCC4 [Six and Maier-Reimer, 1996], which relies on explicit plankton dynamics.

\section{References}

Dutay, J.-C., J. Bullister, S. C. Doney, J. C. Or, R. G. Najjar, K. Caldeira, J.-M. Campin, H. Drange, M. Follows, Y. Gao, N. Gruber, M. W. Hecht, A. Ishida, F. Joos, K. Lindsay, G. Madec, E. Maier-Reimer, J. C. Marshall, R. Matear, P. Monfray, A. Mouchet, G. K. Plattner, J. L. Sarmiento, R. Schlitzer, R. D. Slater, I. J. Totterdell, M.-F. Weirig, Y. Yamanaka, and A. Yool, Evaluation of ocean model ventilation with CFC-11: Comparison of 13 global ocean models, Ocean Modelling, 4(2), 89-120, 2002.

Maier-Reimer, E., Geochemical cycles in an ocean general circulation model: Preindustrial tracer distributions, Global Biogeochem. Cycles, 7(3), 645-677, 1993.

Orr, J. C., O. Aumont, A. Yool, K. Plattner, F. Joos, E. Maier-Reimer, M.-F. Weirig, R. Schlitzer, K. Caldeira, M. Wickett, and R. Matear, Ocean $\mathrm{CO}_{2}$ sequestration 
efficiency from 3-D ocean model comparison, in Proceedings of the Fifth Int. Conf. on Greenhouse Gas Control Technologies, pp. 469-474, CSIRO, 2001.

Six, K. D. and E. Maier-Reimer, Effects of plankton dynamics on seasonal carbon fluxes in an ocean general circulation model, Global Biogeochem. Cycles, 10(4), 559-583, 1996. 


\subsection{Partner 6: NERSC}

PI: Dr. Helge Drange

Contributor: Dr. Yongqi Gao

\section{Introduction}

In GOSAC, the Nansen Environmental and Remote Sensing Center (NERSC) has used a quasi-global version of the Miami Isopycnic Coordinate Ocean Model (MICOM). MICOM differs from the other models in the project in that the vertical discretization follows water masses of constant potential density. Thus vertical discretization varies in time and space. The vertical discretization is expressed in terms of potential density relative to a depth of $2000 \mathrm{~m}$ in order to minimize problems with folding of the coordinate surfaces at high southern latitudes.

\section{Model description}

The basic version of MICOM is documented in Bleck et al. [1992], whereas the quasi-global $\sigma_{2}$ version used in GOSAC follows the set-up described by Sun [1997].

The model consists of an upper mixed layer in which the potential density is free to vary spatially and temporally, and 15 interior isopycnic layers below the mixed layer. The $\sigma_{2}$ values for the isopycnic layers are 33.22, 34.26, 35.04, 35.62, $36.05,36.37,36.61,36.79,36.92,37.01,37.07,37.11,37.14,37.17$, and 37.20.

The mixed layer is in direct contact with the atmosphere, and therefore all the air-sea exchanges (momentum, heat, and fresh water fluxes) are incorporated into the mixed layer. The mixed layer physics uses the Gaspar [1988] bulk parameterization for dissipation of turbulent kinetic energy. The interior isopycnic layers are considered to behave adiabatically, except for a weak diapycnal mixing [McDougall and Dewar, 1998]. All interior layers can transfer their properties with the mixed layer by entrainment or detrainment which control the seasonal variation of the mixed layer and pass the physical signal of surface layer into the deep ocean.

Some interior layers may intersect the bottom of the mixed layer and outcrop, thus losing all mass. The flux corrected transport scheme [Zalesak, 1979; Smolarkiewicz and Clark, 1986] is used to handle these layers with no mass.

If the uppermost mixed layer becomes more dense than one or several of the underlaying isopycnic layers, the static instability is removed by increasing the mixed layer depth until the stability is removed. The water masses entrained into the mixed layer during convection is then uniformly mixed with the original mixed layer water.

The model has been configured using the Arakawa and Lamb [1977] C-grid with horizontal resolution of $2^{\circ}$-by $-2^{\circ}$ latitude by longitude, covering $65^{\circ} \mathrm{N}$ to $69^{\circ} \mathrm{S}$. Conventional bulk formulas are applied to the surface forcing. The presence of sea ice has been mimicked by setting the surface wind stirring and the heat fluxes to zero where the modeled mixed layer temperature or climatological 
Levitus sea surface temperature is below -1.8 degree $\mathrm{C}$. No ice-related physical processes(e.g., brine rejection [Anderson and Jones, 1991]) are included.

The simplified equation of state by Friedrich [1972] is used in the simulations, yielding efficient computation of the water density as function of temperature and salinity, and inversion of the equation of state.

During integration, mode splitting is used, allowing a baroclinic time step 16 times as long as the barotropic time step (4320 and $270 \mathrm{~s}$, respectively).

Topography is obtained by interpolating ETOPO5 database of $5 \mathrm{~min}$ resolution onto the model grid. The diffusion velocity for depth diffusion, momentum dissipation, and temperature and salinity mixing are $0.5 \mathrm{~cm} \mathrm{~s}^{-1}, 1.0 \mathrm{~cm} \mathrm{~s}^{-1}$, and 0.5 $\mathrm{cm} \mathrm{s}^{-1}$, respectively (a diffusion velocity of $1.0 \mathrm{~cm} \mathrm{~s}^{-1}$ corresponds to a diffusion coefficient of $10^{3} \mathrm{~m}^{2} \mathrm{~s}^{-1}$ for a $100 \mathrm{~km}$ grid cell size).

The diapycnal diffusivity depends on the vertical density stratification, and is parameterized as $2 \times 10^{-7} \mathrm{~m}^{2} \mathrm{~s}^{-2} / N$, where $N$ is the buoyancy frequency.

Atmospheric surface forcings used to drive the model include surface wind stress, atmospheric relative humidity and surface temperature are from the Comprehensive Oceanographic and Atmospheric Data Set (COADS) [Woodruffet al., 1987]), the net radiation flux is from the Oberhuber Atlas [Oberhuber, 1988], and the precipitation is from the NOAA microwave sunder [Spencer, 1993].

Tracer and biochemical routines have been implemented and tested with the physical model in order to perform the required OCMIP-2 tracer simulations. Online integration of the tracer fields are performed with a time step of 6 hours.

\section{Work completed}

During the project, NERSC completed the following OCMIP-2 simulations:

- CFC simulation

- Abiotic Equilibrium Run

- Abiotic Historical Run

- Abiotic Control Run

of which the latter three integrations have been finalized in year three. It has not been possible to finalize the other simulations in the project as a result of initial problems with the model system and national computer constraints (see Sec.2.6). All together, 2000 model years have been completed.

For common analyses, the 3-D fields of layered model have been interpolated onto fixed depths. After vertical interpolation, the fields were transformed into the required NetCDF format and delivered to the project coordinator.

In addition, the simulated 3-D temperature and salinity fields, and the diagnosed 2-D meridional overturning and the barotropic streamfunction have been interpolated onto standard grids and have been delivered to the NCAR partner for further analyses. 
NERSC has participated in the discussion of the new model guidelines, particularly in the location and depth specifications of the $\mathrm{CO}_{2}$ injection sites and in the amount of $\mathrm{CO}_{2}$ to be released in the ocean carbon storage simulations.

Our group, led by H. Drange, was represented at the Paris OCMIP-2 workshop in May, 1999, the Princeton OCMIP-2 workshop in July, 2000, and the final OCMIP-2 workshop in Amsterdam in July, 2001. The group has also contributed to discussions to prepare the Injection HOWTO protocol documents.

Members of our group are co-authors on an OCMIP paper presented at the IUGG 1999 Meeting [Dutay et al., 1999] as well as a paper published by Ocean Modelling [Dutay et al., 2002]. Both papers detail the OCMIP comparison of CFC11 and CFC-12 simulations. We also published a paper in Geophysical Research Letters, which discusses the release of $\mathrm{CO}_{2}$ in the Norwegian Sea [Drange et al., 2001].

\section{Special considerations}

During Year 1 of GOSAC, after submitting the CFC run it was found that the model tracer inventory was not conserved. Thus, in Year 2, four CFC-simulations were carried out in order to identify which process or processes that were responsible for the problem (see Tab. 2.2 and Fig. 2.12). All of the vertical processes (mixed layer

\begin{tabular}{|c|c|c|c|}
\hline Exp. & Advection & Diffusion & Conserved inventory \\
\hline 3 & yes & no & No \\
\hline 4 & no & yes & Yes \\
\hline 5 & no & no & Yes \\
\hline 6 & yes & yes & Yes \\
\hline
\end{tabular}

Table 2.2: Experiments to test model conservation properties. Advection and diffusion denote advection and diffusion along the isopycnals. Experiments 3-5 represent the default tracer module, Experiment 6 the modified (and conservative) tracer module.

entrainment and detrainment, and diapycnal and convective mixing) were found to be conservative, as is illustrated by Experiment 5, in which only these processes are included. With Experiments 3 and 4, we found that tracer mass was conserved for isopycnal diffusion, but not for isopycnal advection. We then determined that the reason was a mismatch between the change in the layer thicknesses and the mass fluxes which satisfy the continuity equation. This mismatch was corrected (Experiment 6), yielding a conservative tracer scheme.

Based on the updated version of the tracer module, the model code was further converted to a parallel version in order to speed up the integration. Despite acceleration, however, available national computational resources limited the number of integrations that could be performed within the time frame of the GOSAC project.

Furthermore, to be able to address the ocean sequestration issue with the available resources and within the project time frame, a regional version of the model was used to assess the feasibility of disposing off $\mathrm{CO}_{2}$ in the Nordic Seas. This 

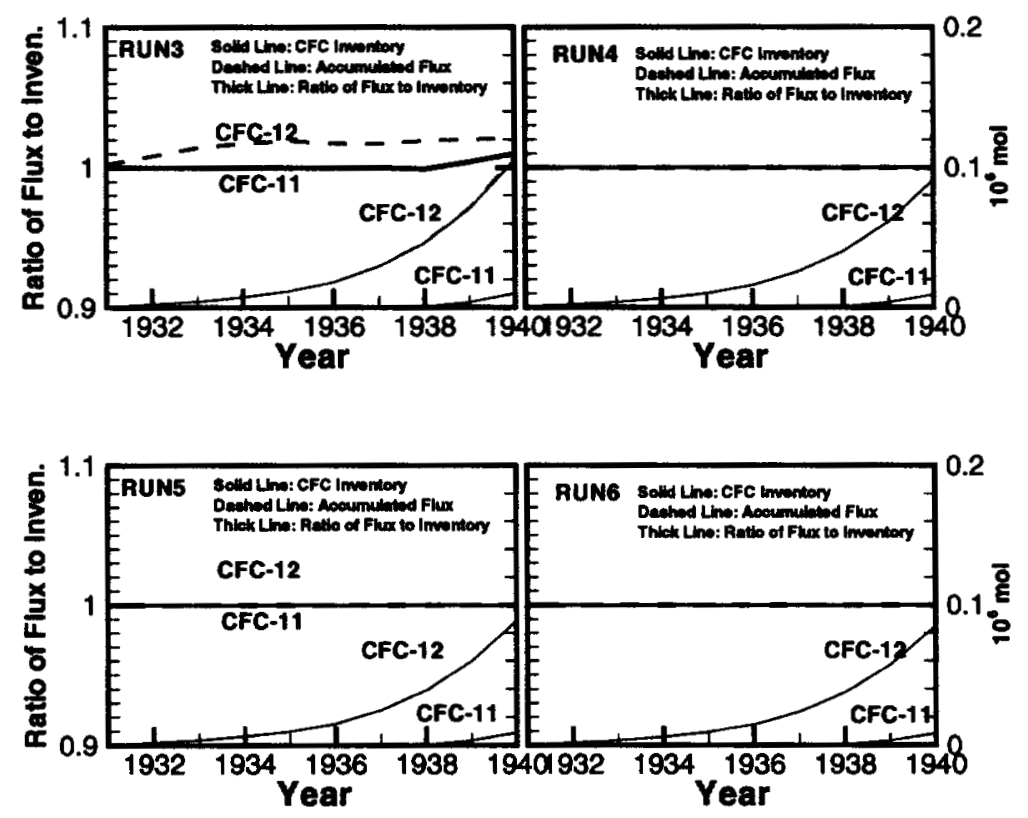

Figure 2.12: Accumulated CFC fluxes and CFC inventories in world oceans and the ratio of flux to inventory in the experiments. 


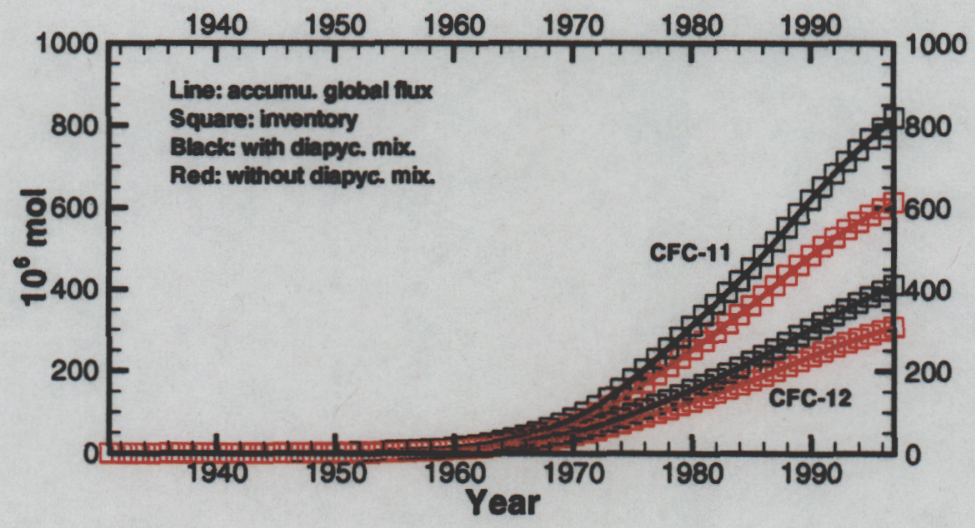

Figure 2.13: Accumulated CFC fluxes and CFC inventories in world oceans.

work was published in Geoph. Res. Letters in July 2001 [Drange et al., 2001], and was covered by several international mass media, including interviews in BBC radio (June 17 and 16 August).

In addition to the standard CFC-experiments, we tested the sensitivity of oceanic uptake of CFCs to diapycnal mixing. Figure 2.13 shows the oceanic uptake of CFCs with $\left(K_{v}=2 \times 10^{-7} / \mathrm{N} \mathrm{m}^{2} \mathrm{~s}^{-1}\right)$ and without diapycnal mixing. The overlap between the solid lines and the squares indicates that model conserves tracer mass. After the 67-year integration (1931 to 1997), oceanic uptake of CFC-11 is $25 \%$ lower for the simulation where there is no diapycnal mixing.

Since CFC uptake in the isopycnic model is quite sensitive, we also conclude that the strength of diapycnal mixing must also be important in regards to ocean uptake of other greenhouse gases, such as $\mathrm{CO}_{2}$. A manuscript is now in preparation describing these and other sensitivity tests, using variations of the OCMIP-2 CFC formulation in our model. 


\section{References}

Anderson, L. G. and E. P. Jones, The transport of $\mathrm{CO}_{2}$ into Arctic and Antarctic Seas: Similarities and differences in the driving processes, J. Mar. Systems, 2, 81-95, 1991.

Arakawa, A. and V. R. Lamb, Computational design of the UCLA general circulation model, Methods Comput. Phys., 16, 174-265, 1977.

Bleck, R., C. Rooth, D. Hu, and L. T. Smith, Salinity-driven thermocline transients in a wind- and thermohaline-forced isopycnic coordinate model of the North Atlantic, J. Phys. Oceanogr, 22, 1486-1515, 1992.

Drange, $\mathrm{H}$., G. Alendal, and O. Johannessen, Ocean release of fossil fuel $\mathrm{CO}_{2}$ : A case study, Geophys. Res. Lett., 28(13), 2637-2640, 2001.

Dutay, J.-C., J. Bullister, S. C. Doney, J. C. Orr, R. G. Najjar, K. Caldeira, J.-M. Campin, H. Drange, M. Follows, Y. Gao, N. Gruber, M. W. Hecht, A. Ishida, F. Joos, K. Lindsay, G. Madec, E. Maier-Reimer, J. C. Marshall, R. Matear, P. Monfray, A. Mouchet, G. K. Plattner, J. L. Sarmiento, R. Schlitzer, R. D. Slater, I. J. Totterdell, M.-F. Weirig, Y. Yamanaka, and A. Yool, Evaluation of ocean model ventilation with CFC-11: Comparison of 13 global ocean models, Ocean Modelling, 4(2), 89-120, 2002.

Dutay, J.-C., J. Bullister, J. C. Orr, R. G. Najjar, M. Follows, R. Matear, S. Doney, E. Maier-Reimer, Y. Yamanaka, H. Drange, A. Yool, J.-M. Campin, M.-F. Weirig, N. Gruber, and K. Caldeira, Comparisons of simulations of CFC-11 and CFC-12 during OCMIP, in IUGG Meeting, p. A253, Birmingham, UK, 1999.

Friedrich, F. L. S., An approximation to the equation of state for sea water, suitable for numerical ocean models, J. Phys. Oceanogr., 2, 514-517, 1972.

Gaspar, P., Modeling the seasonal cycle of the upper ocean, J. Phys. Oceanogr., 18, 161-180, 1988.

McDougall, T. and W. Dewar, Vertical mixing, cabbeling and thermobaricity in layered models, J. Phys. Oceanogr., 28, 1458-1480, 1998.

Oberhuber, J. M., An atlas based on the 'COADS' data set: The budgets of heat, buoyancy and turbulent kinetic energy at the surface of the global ocean, Technical Report 15, Max-Planck-Inst. für Meteorol., Hamburg, Germany, 194 pp., 1988.

Smolarkiewicz, K. P. and T. L. Clark, The multidimensional positive definite advection transport algorithm: further development and applications, $J$. of Comp. Phys., 67, 396-438, 1986. 
Spencer, R., Global Oceanic Precipitation from the MSU during 1979-91 and comparisons to other climatologies, J. Climate, 6, 1301-1326, 1993.

Sun, S., Compressibility effects in the Miami Isopycnic Coordinate Ocean Model, Ph.D. thesis, University of Miami, 138 pp., 1997.

Woodruff, S., R. Slutz, and R. Jenne, A comprehensive ocean-atmosphere data set, Bull. Amer. Meteor. Soc., 68, 1239-1250, 1987.

Zalesak, S., Fully multidimensional flux-corrected transport algorithms for fluids, J. Comp. Physics, 31, 335-362, 1979. 


\subsection{Partner 7: PIUB}

PI's: Dr. Fortunat Joos, Dr. Thomas Stocker

Contributor: Dr. Kasper Plattner

\section{Role of PIUB}

The role of the PIUB group in the GOSAC project was to

1. perform all the standard simulations as outlined in the GOSAC proposal and to submit the results to the GOSAC data facility for further analysis and interpretation,

2. carry out sensitivity experiments in addition to GOSAC standard simulations to provide guidance for the development of the standard simulation protocols to be used within the GOSAC and Ocean Carbon Cycle Model Intercomparison Projects (OCMIP), to explore uncertainties associated with the various modeling assumptions, and

3. contribute to the analysis of the GOSAC results, and specifically to analyze the results of the impulse response simulations. The PIUB group has achieved all goals associated with these tasks.

\section{Model Description}

We use a low-order physical-biogeochemical climate model that consists of a zonally averaged ocean model [Wright and Stocker, 1992; Wright and Stocker, 1998], coupled to an atmospheric energy balance model [Stocker et al., 1992]. The model includes a basic representations of the carbon cycle, both marine [Marchal et al., 1998] and terrestrial [Siegenthaler and Oeschger, 1987] components. The marine biological model is based on the classical Redfield approach and phosphate $\left(\mathrm{PO}_{4}^{3-}\right)$ is used as a limiting nutrient for biological production. Nine tracers are considered explicitly: $\mathrm{PO}_{4}^{3-}$, dissolved inorganic carbon (DIC), alkalinity, labile dissolved organic carbon (DOC), dissolved oxygen, and ${ }^{13} \mathrm{C}$ and ${ }^{14} \mathrm{C}$ in DIC and DOC. In the standard version, export of organic material out of the euphotic zone (export production) is calculated by Michaelis-Menten kinetics using the rates diagnosed at the end (19 kyr) of the model's spin up to equilibrium. During spin up, surface $\mathrm{PO}_{4}^{3-}$ values were restored to observations. $\mathrm{CaCO}_{3}$ export production is a function of the organic export production and SST. The modeled ratio of $\mathrm{CaCO}_{3}$ to organic matter export increases with increasing SST. For the land biosphere, a potential fertilization by elevated atmospheric $\mathrm{CO}_{2}$ is described by a logarithmic dependence of net primary production on $\mathrm{CO}_{2}$. The climate sensitivity of the energy balance model, $\mathrm{dT} 2 \mathrm{x}$, that is the increase in global mean surface air temperature for a doubling of atmospheric $\mathrm{CO}_{2}$, is selected according to the range found in current coupled atmosphere-ocean circulation models. 


\section{Work Performed}

1. The PIUB group performed all standard GOSAC simulations and submitted the results to the data facility at IPSLLSCE. All deadlines of the GOSAC time table were met.

2. A series of sensitivity experiments were performed explicitly directed to guide the development of the GOSAC standard experimental protocols. For example, the uncertainties in tracer concentrations and transport associated with the parameterization of net evaporation by the virtual flux approach, and different formulations for the implementation of radiocarbon in ocean models have been investigated. Additional simulations were performed to evaluate the basic assumptions of a constant ocean circulation that is implicit in all GOSAC standard simulation. Feedbacks between global warming and the marine carbon cycle were investigated in detail and results are published in the peer reviewed literature [Joos et al., 1999; Plattner et al., 2001d] Air-sea oxygen fluxes due to global warming and volcanic eruptions were found to be important when inferring the present terrestrial and oceanic carbon sinks from atmospheric measurements of $\mathrm{CO}_{2}$ and $\mathrm{O}_{2}$. A manuscript describing these results and providing a revised estimate of the present carbon budget has been submitted [Plattner et al., 2001b]. These and additional results are also described in Plattner [1997].

3. The PIUB group participated actively in the the definition of the GOSAC Abiotic standard protocols, in particular the GOSAC Abiotic HOWTO, particularly sections dealing with the pulse response simulation and the radiocarbon simulations. The PIUB group continues to contribute regarding analysis of results. Various papers have been published [Orr et al., 2001b; Dutay et al., 2002] and are in preparation. Members of the PIUB group have attended all GOSAC project meetings. We presented our results at several international conferences and workshops (AGU meeting, EGS meeting, IGBP Open Science Conference).

Below, we present selected results related to the last two items above.

\section{Selected Results}

Global warming-marine carbon cycle feedbacks and future atmospheric $\mathrm{CO}_{2}$ :

Potentially important climate feedbacks on carbon uptake are not considered in standard OCMIP/GOSAC simulations. We have investigated a potentially important positive feedback loop in the climate system that involves atmospheric $\mathrm{CO}_{2}$, global warming, the hydrological cycle, ocean circulation, and the marine carbon cycle in a world of continued carbon emissions. Rising atmospheric $\mathrm{CO}_{2}$ leads to increased radiative forcing and climate change. Consequently, an increase of sea surface temperature and a reduction in high-latitude sea surface salinity due to a 
stronger hydrological cycle may result in a breakdown of the thermohaline circulation of the North Atlantic, a reorganization of the marine carbon cycle, and a reduction in the surface-to-deep transport of anthropogenic carbon. The resulting reduction in oceanic carbon uptake may in turn accelerate the atmospheric $\mathrm{CO}_{2}$ growth.

We have carried out two types of experiments. First, we prescribe carbon emissions until year 2100 (IPCC SRES and IS92 scenarios) or year 2500 and predict atmospheric $\mathrm{CO}_{2}$ with the coupled model. Second, we prescribe atmospheric $\mathrm{CO}_{2}$ until year 2500 directly (IPCC $\mathrm{CO}_{2}$ profiles WRE350 to WRE1000) and deduce anthropogenic carbon emissions. In both cases, radiative forcing is calculated from the atmospheric $\mathrm{CO}_{2}$ concentration assuming a logarithmic dependence. Results are compared with those of 'baseline' simulations where radiative forcing is kept constant (constant climate and ocean circulation).

We find that the North Atlantic thermohaline circulation is weakening in all global warming simulations and even collapses when $\mathrm{CO}_{2}$ is stabilized at 1000 ppmv (Fig. 2.14). The projected atmospheric $\mathrm{CO}_{2}$ increase since pre-industrial time is about $4 \%$ higher at year 2100 and about $20 \%$ higher at year 2500 for simulations with global warming than for simulations without global warming. Our model results suggest that the global-warming/marine-carbon-cycle feedback has a small impact on atmospheric $\mathrm{CO}_{2}$ until year 2100 , but may modify long term oceanic uptake considerably.

Major circulation changes occur in the North Atlantic, whereas the circulation in the equatorial region and in the Southern Ocean is less affected by global warming in the PIUB model. The uptake of atmospheric $\mathrm{CO}_{2}$ by the ocean is reduced between 7 to $10 \%$ by year 2100 compared to simulations without global warming. The reduction is of similar size in the Southern Ocean and in low-latitude regions until 2100, whereas low-latitude regions dominate on longer time scales (Fig. 2.15). In the North Atlantic the $\mathrm{CO}_{2}$ uptake is enhanced, unless the Atlantic thermohaline circulation completely collapses. At high latitudes, biologically mediated changes enhance ocean $\mathrm{CO}_{2}$ uptake, whereas in low-latitude regions the situation is reversed. Different implementations of the marine biosphere yield a range of 5 to $16 \%$ for the total reduction in oceanic $\mathrm{CO}_{2}$ uptake until year 2100 .

\section{Oxygen Fluxes and the IPCC carbon budget:}

Quantitative, data-based estimates of the present oceanic and terrestrial sink are important to validate carbon cycle models. However, the comparison between the most recent carbon budgets published by the Intergovernmental Panel on Climate Change and GOSAC model results yields a discrepancy in the growth rate of the oceanic carbon sink. The data-based sink estimates suggest a lower oceanic carbon uptake during the 1990's than during the 1980's, in contrast to the process-based ocean models used in GOSAC.

Estimates of the present carbon sinks inferred from atmospheric measurements of $\mathrm{CO}_{2}$ and $\mathrm{O}_{2}$ are widely believed to be the most reliable. In this approach, the 

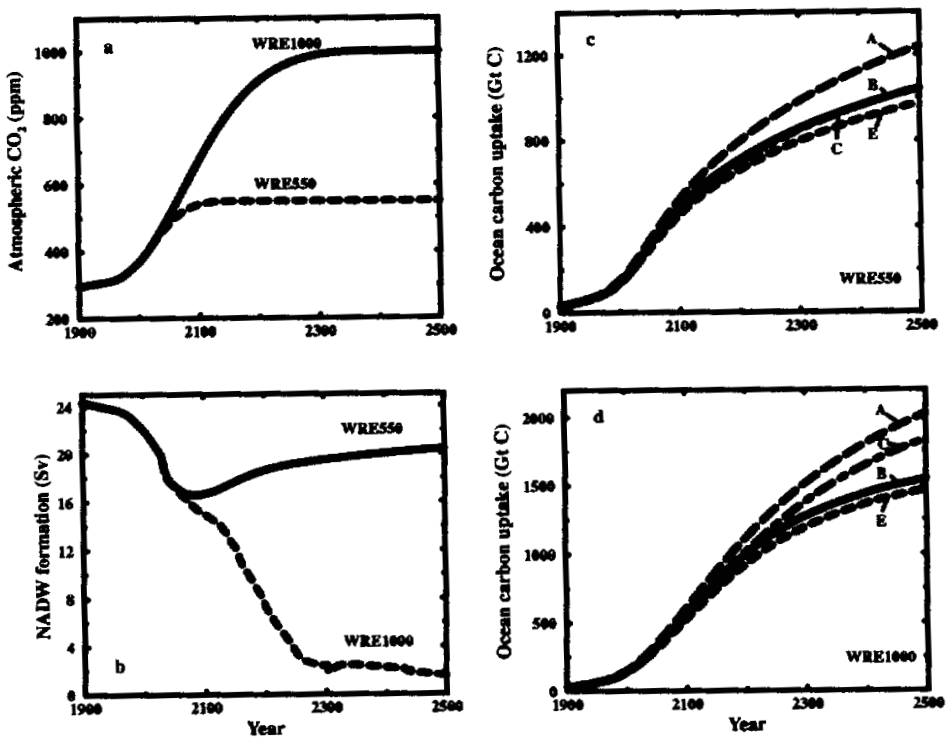

Figure 2.14: (a) Prescribed atmospheric $\mathrm{CO}_{2}$, (b) projected formation of North Atlantic Deep Water (NADW), and projected cumulative ocean carbon uptake for (c) future stabilization profiles WRES50 and (d) WRE1000. Results in (c) and (d) are shown for the standard model setup where global warming occurs (Simulation B, solid line) and for the constant-climate baseline simulation (Simulation A, long-dash). The simulations $\mathrm{C}$ (dot-dashed) and $\mathrm{E}$ (dashed) are used to identify different global warming feedback mechanisms.
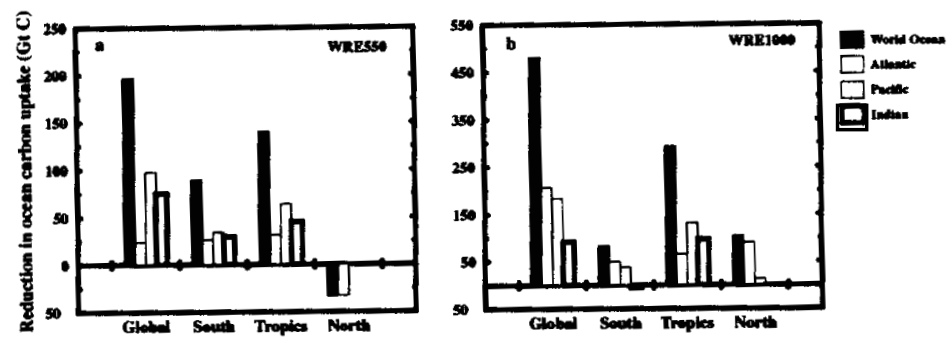

Figure 2.15: Reduction in oceanic carbon uptake in the world ocean and the three main oceanic basins due to global warming until year 2500 . The reduction is given for the standard model setup and stabilization profiles WRE550 (a) and WRE1000 (b) compared to the constant-climate baseline. Contributions from individual ocean basins and the world ocean are shown for three latitudinal regions (South: $70^{\circ} \mathrm{S}$ to $32.5^{\circ} \mathrm{S}$; Tropics: $32.5^{\circ} \mathrm{S}$ to $32.5^{\circ} \mathrm{N}$; North: $32.5^{\circ} \mathrm{N}-80^{\circ} \mathrm{N}$ ). Positive values stand for a reduction and negative values for an increase in ocean $\mathrm{CO}_{2}$ uptake. 


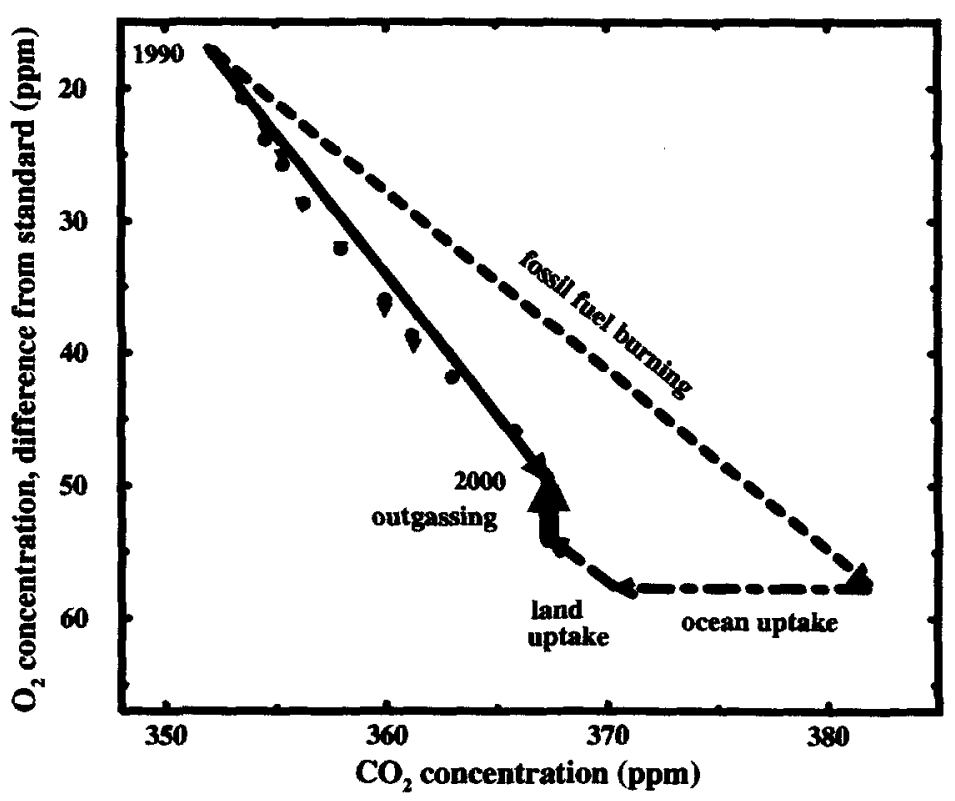

Figure 2.16: Budgets of atmospheric $\mathrm{O}_{2}$ and $\mathrm{CO}_{2}$ after IPCC. The diagram schematically illustrates the principles of the partitioning of fossil-fuel carbon using measurements of atmospheric $\mathrm{O}_{2}$ and $\mathrm{CO}_{2}$, by considering simultaneously changes in atmospheric $\mathrm{CO}_{2}$ (horizontal axis) and $\mathrm{O}_{2}$ (vertical axis). The arrow labeled "fossil fuel burning" denotes the effect of the combustion of fossil fuels assuming that $1.39 \mathrm{ppm} \mathrm{O}_{2}$ are consumed for $1 \mathrm{ppm} \mathrm{CO}_{2}$ released. The arrow labeled "outgassing" indicates $\mathrm{O}_{2}$ changes from oceanic outgassing primarily due to changes in the marine biogeochemical cycle; its size is estimated from data of ocean heat uptake and a model-derived relationship between ocean heat fluxes and atmospheric $\mathrm{O}_{2}$ changes. Carbon uptake by land and ocean is constrained by the known $\mathrm{O}_{2}: \mathrm{CO}_{2}$ stoichiometric ratios of these processes, defining the slopes of the respective arrows, and the observed changes in atmospheric $\mathrm{CO}_{2}$ and $\mathrm{O}_{2}$ (filled symbols).

terrestrial and oceanic carbon sinks are estimated by solving the atmospheric budgets of oxygen and $\mathrm{CO}_{2}$ (Fig. 2.16). The observed increase in atmospheric $\mathrm{CO}_{2}$ equals the known amount of carbon released by fossil fuel burning minus the carbon that has been taken up by the ocean and the land biosphere. For each ppm $\mathrm{CO}_{2}$ released by fossil fuel burning, about $1.4 \mathrm{ppm}_{2}$ are consumed. In turn, about 1.1 ppm $\mathrm{O}_{2}$ are released for each ppm $\mathrm{CO}_{2}$ taken up by the biosphere, whereas $\mathrm{CO}_{2}$ uptake by the ocean does not alter atmospheric $\mathrm{O}_{2}$. The basic assumption has been that air-sea oxygen fluxes are negligible on a multi-annual time scale.

We have investigated how global warming and volcanic eruptions affect seato-air oxygen fluxes and found considerable air-sea oxygen fluxes on a decadal time scale. Combining model results and observed ocean heat uptake data, we have revised earlier carbon budgets. The consideration of sea-to-air oxygen fluxes 
for the interpretation of oxygen measurements resolves the problem of an apparently decreasing oceanic carbon uptake under rising atmospheric $\mathrm{CO}_{2}$. Our revised oxygen-based estimates show an increase in oceanic $\mathrm{CO}_{2}$ uptake between the 1980s and 1990s in contrast to the decreasing trend from the uncorrected carbon budgets. The increasing trend is in qualitative agreement with estimates based on atmospheric measurements of the carbon isotope ${ }^{13} \mathrm{CO}_{2}$ and with process-based carbon cycle models. Furthermore, our results also suggest that the global net carbon uptake by the land biosphere was about a factor of two lower during the 1990s than that recently estimated by IPCC. A lower present terrestrial carbon sink, used to constrain carbon cycle models, implies that simulated future terrestrial uptake will be lower as well. A manuscript describing these results has been submitted to Global Biogeochemical Cycles (Plattner et al., 2001b).

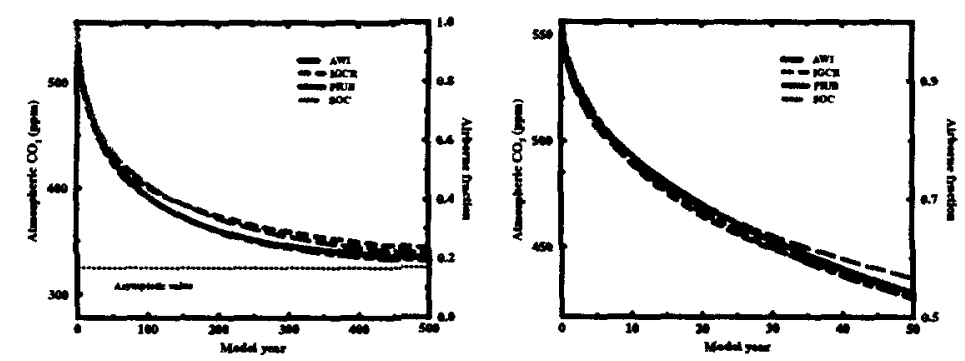

Figure 2.17: The evolution of atmospheric $\mathrm{CO}_{2}$ after a sudden doubling of the atmospheric concentration from 278 (preindustrial equilibrium) to $556 \mathrm{ppm}$ as simulated by different ocean models. The ocean models were first run to equilibrium under a constant pre-industrial $\mathrm{CO}_{2}$ concentration of $278 \mathrm{ppm}$. An impulse-like carbon input corresponding to $278 \mathrm{ppm}$ was added to the atmosphere at nominal year 0 , and the atmospheric concentration monitored for the next 1000 years. The fraction of the initial carbon input into the atmosphere that remains airborne is shown on the right hand $y$-axis; the rest has been taken up by the ocean. The thin-dot line indicates the atmospheric concentration after the ocean-atmosphere system has re-equilibrated.

\section{Impulse Response Experiments:}

The dynamics of a linear system is fully characterized by its impulse response (Green's) function. In the GOSAC framework, the models' response to a instantaneous doubling of atmospheric $\mathrm{CO}_{2}$ has been investigated. It is found that the response of the different models is fairly similar and that all ocean models sequester about 20 percent of the initial pulse when a new equilibrium is reached (Fig. 2.17). After year 50, atmospheric $\mathrm{CO}_{2}$ simulated by the IGCR and the $\mathrm{SOC}$ models is higher than that of the PIUB and AWI models. This indicates a relatively fast ventilation of the deep ocean in the PIUB and AWI models compared to the IGCR and SOC models. The implication is that the PIUB and AWI models yield a 
much higher future ocean uptake than the SOC and IGCR models under increasing atmospheric $\mathrm{CO}_{2}$, although the PIUB, AWI, and IGCR models exhibit a similar ocean uptake rate today.

\section{Virtual Flux Parameterization:}

Most models participating in GOSAC use a rigid-lid boundary condition at the surface ocean. This means that the impact of freshwater fluxes on tracer concentrations needs to be parameterized. In the standard GOSAC protocol, "a virtual flux" approach is advised, such that tracer mass is removed from the surface layer in areas of freshwater input and added to regions where freshwater is lost to the atmosphere. This non-physical virtual air-sea tracer flux has the potential to bias model results as the approach affects the column tracer burden at particular locations. The PIUB group has coded an alternative parameterization where tracer are carried as salinity (freshwater) normalized tracers. Then, the need for a virtual flux does not arise, but ocean mixing is slightly biased. Differences in modeled tracer fields between the two alternative approaches are found to be small. This suggests that the choice of a particular parameterization of the impact of freshwater fluxes on tracer concentrations is not critical.

\section{Radiocarbon:}

Often approximate equations are used to simulate the oceanic distribution of radiocarbon $\left(\Delta^{14} \mathrm{C}\right)$ for technical and CPU reasons. In principle, such a simulation requires the implementation of all three carbon isotopes $\left({ }^{12} \mathrm{C},{ }^{13} \mathrm{C},{ }^{14} \mathrm{C}\right)$ and of formulations describing the fluxes associated with the marine biota in an ocean transport model. This is a demanding task. Fortunately, approximate equations exist that allow one to carry only one tracer (the fractionation corrected $14 \mathrm{C} / 12 \mathrm{C}$ ratio) in the model and to neglect marine biotic processes.

PIUB has investigated the difference in results between simulations based on the approximate scheme now recommended in the GOSAC protocol and a simulation were all three carbon isotopes and the marine biological cycle were simulated in the model. The maximum difference in the simulated $\Delta^{14} \mathrm{C}$ values is $7 \%$ at an individual location. This is small compared to the oceanic $\Delta^{14} \mathrm{C}$ variations of around 200 per mille and is of the same order as observational uncertainties. We conclude that the scheme now proposed for GOSAC standard simulations provides an excellent approximation to the full set of equations. The GOSAC scheme is cost-efficient as model coding and analysis is considerably simplified.

\section{References}

Dutay, J.-C., J. Bullister, S. C. Doney, J. C. Orr, R. G. Najjar, K. Caldeira, J.-M. Campin, H. Drange, M. Follows, Y. Gao, N. Gruber, M. W. Hecht, A. Ishida, F. Joos, K. Lindsay, G. Madec, E. Maier-Reimer, J. C. Marshall, R. Matear, 
P. Monfray, A. Mouchet, G. K. Plattner, J. L. Sarmiento, R. Schlitzer, R. D. Slater, I. J. Totterdell, M.-F. Weirig, Y. Yamanaka, and A. Yool, Evaluation of ocean model ventilation with CFC-11: Comparison of 13 global ocean models, Ocean Modelling, 4(2), 89-120, 2002.

Joos, F., G.-K. Plattner, T. F. Stocker, O. Marchal, and A. Schmittner, The impact of global warming-marine carbon cycle feedbacks on future atmospheric $\mathrm{CO}_{2}$, Science, 284, 464-467, 1999.

Marchal, O., T. Stocker, and F. Joos, A latitude-depth, circulation-biogeochemical ocean model for paleoclimate studies: model development and sensitivities, Tellus, Ser. B, 50, 290-316, 1998.

Orr, J. C., O. Aumont, A. Yool, K. Plattner, F. Joos, E. Maier-Reimer, M.-F. Weirig, R. Schlitzer, K. Caldeira, M. Wickett, and R. Matear, Ocean $\mathrm{CO}_{2}$ sequestration efficiency from 3-D ocean model comparison, in Proceedings of the Fifth Int. Conf. on Greenhouse Gas Control Technologies, pp. 469-474, CSIRO, $2001 a$.

Orr, J. C., P. Monfray, E. Maier-Reimer, U. Mikolajewicz, J. Palmer, N. K. Taylor, J. R. Toggweiler, J. L. Sarmiento, C. L. Quéré, N. Gruber, C. L. Sabine, R. M. Key, and J. Boutin, Estimates of anthropogenic carbon uptake from four three-dimensionsal global ocean models, Global Biogeochem. Cycles, $15(1), 43-60,2001 b$.

Plattner, G.-K., Modelling the oceanic uptake of carbon dioxide and anthropogenic tracers: feedbacks and sensitivities to global warming, $\mathrm{Ph} . \mathrm{D}$. thesis, Climate and Environmental Physics, University of Bern, Switzerland, 152 pp., 1997.

Plattner, G.-K., F. Joos, T. Stocker, and O. Marchal, Feedback mechanisms and sensitivities of ocean carbon uptake under global warming, in IGBP Open Science Conference, Amsterdam, Poster in Session: Recent developments in Basin- to Global-Scale Ocean Carbon Cycle Modeling, $2001 a$.

Plattner, G.-K., F. Joos, and T. F. Stocker, Revision of the global carbon budget due to changing air-sea oxygen fluxes, Global Biogeochem. Cycles, submitted, $2001 b$.

Plattner, G.-K., F. Joos, T. F. Stocker, and O. Marchal, Global warming-marine carbon cycle feedbacks in a zonally averaged climate model, in Geophysical Research Abstracts, Abstracts of the contributions to the 26th General Assembly of the EGS, volume 3, Nice, 2001c.

Plattner, G.-K., F. Joos, T. F. Stocker, and O. Marchal, Ocean carbon uptake under global warming, Tellus, 53B, 564-592, $2001 d$. 
Plattner, G.-K., F. Joos, T. F. Stocker, O. Marchal, and A. Schmittner, Rapid ocean circulation changes and their impact on future atmospheric $\mathrm{CO}_{2}$, in AGU Fall Meeting, EOS, volume 80(46), San Francisco, November 16, 1999/Supplement, 1999.

Siegenthaler, U. and $\mathrm{H}$. Oeschger, Biospheric $\mathrm{CO}_{2}$ emissions during the past 200 years reconstructed by deconvolution of ice core data, Tellus, 39B, 140-154, 1987.

Stocker, T. F., D. G. Wright, and L. A. Mysak, A zonally averaged, coupled oceanatmosphere model for paleoclimate studies, J. Climate, 5, 773-797, 1992.

Wright, D. G. and T. F. Stocker, Sensitivities of a zonally averaged global ocean circulation model, J. Geophys. Res., 97, 12707-12730, 1992.

Wright, D. G. and T. F. Stocker, Closures used in zonally averaged ocean models, J. Phys. Oceanogr., 28, 701-804, 1998. 